\title{
USPL1, a novel SUMO isopeptidase
}

\author{
PhD Thesis \\ in partial fulfilment of the requirements \\ for the degree "Doctor of Philosophy (PhD)" \\ in the Molecular Biology Program \\ at the Georg August University Göttingen, \\ Faculty of Biology \\ submitted by \\ Lukasz Kozaczkiewicz \\ born in \\ Zakopane, Poland
}

2009 


\section{Affidavit}

I hereby declare that this doctoral thesis has been written only by the undersigned and without any assistance from third parties.

Furthermore, I confirm that no sources have been used in the preparation of this thesis other than those indicated in the thesis itself.

Göttingen, 30 $3{ }^{\text {th }}$ January 2009

Lukasz Kozaczkiewicz 
Rodzicom 


\section{List of publications:}

\section{Book chapter}

Stankovic-Valentin, N., Kozaczkiewicz, L., Curth, K., Melchior, F. An in vitro FRET-based assay for the analysis of SUMO conjugation and isopeptidase cleavage.

Methods Mol Biol. 2009, 497:241-51. 


\section{TABLE OF CONTENTS}

\section{Table of Content 1}

Acknowledgments 4

Abstract 5

Abbreviations 6

List of Figures 9

List of Tables 10

\section{Chapter 1. Introduction 11}

1.1 Protein modification with Ubl 11

1.1.1Ubiquitin-mediated protein degradation 15

1.2 SUMO 16

1.2.1 SUMO modifying enzymes 17

1.2.2 Non covalent SUMO interaction 18

1.2.3 Outcomes of SUMO modification 18

1.3 SUMO proteases 21

1.3.1 SENP/Ulp family 22

1.3.2 Structure and catalytic mechanism of SUMO proteases 24

1.3.3 Functions of Ulp1 branch proteases 27

1.3.4 Functions of Ulp2-like SUMO proteases 28

1.4 Are there more SUMO specific isopeptidases? 29

1.5 Specific Aim 30

Chapter 2. Materials and methods 31

2.1 Materials 31

2.1.1Equpiment 31

2.1.2 Commonly used reagents 32

2.1.2.1 Stock solutions 32

2.1.2.2 Commonly used buffers 32

2.1.2.3 Bacterial strains and culture media 33

2.1.2.4 Cell lines and culture medium 33

2.1.2.5 Primers 34

2.1.2.6 Antibodies 34 


\subsection{Methods 34}

2.2.1 Cloning 34

2.2.1.1 DNA isolation 35

2.2.1.2 Restriction digestion 36

2.2.1.3 DNA separation and extraction 36

2.2.1.4 Ligation 37

2.2.1.5 PCR reactions 37

2.2.1.6 Site-directed mutagenesis 38

2.2.1.7 Transformation of bacteria 41

2.2.2 Cell culture methods 41

2.2.2.1 Cultivation of mammalian cell lines 41

2.2.2.2 Transfection of HEK293T cells by calcium phosphate method 42

2.2.3 Biochemical methods 42

2.2.3.1 Preparation of HeLa cell lysate 42

2.2.3.2 Preparation of detergent extracts of HEK293T 42

2.2.3.3 Immunopurification of HA-tagged USPL1 from detergent extracts 43

2.2.3.4 Labeling of HeLa cell lysate proteins with SUMO-Vme and their enrichment by immunopurification 44

2.2.3.5 Enrichment of the paralogue specific proteases 45

2.2.3.6 Identification of labeled proteins by Mass Spectrometry 45

2.2.3.7 SDS-PAGE electrophoresis 46

2.2.3.8 Coommassie staining 47

2.2.3.9 Immunoblotting 47

2.2.4 Recombinant protein purification 48

2.2.4.1 USPL1 catalytic domain 48

2.2.4.2 Purification of YFP-SUMO and CFP-GAP 50

2.2.4.2 SUMO-VME synthesis and purification 52

2.2.4.2.1 Preparation of Strep-TEV-HA-SUMO-MESNa 53

2.2.4.2.2 Synthesis and purification of Strep-TEV-HA-SUMO-Vme 54

2.2.5 Enzymatic reactions and assays 54 
2.2.5.1 Preparation of the isopeptidase conjugate 55

2.2.5.2 Preparation of RanGAP-SUMO-2 conjugate 55

2.2.5.3 FRET-based desumoylation assay 56

2.2.5.4 Screen of bacterial expression library 56

2.2.5.5 Labeling of recombinant proteins with SUMO-Vme 57

2.2.5.6 SUMO cleavage 58

2.2.5.7 Chain cleavage 59

2.2.5.8 Binding assay 59

2.2.5.9 Ubiquitin cleavage assay 60

Chapter 3. Results 61

3.1 Search for SUMO specific isopeptidases 61

3.3.1 A high-throughput screen for SUMO isopeptidases 61

3.3.2 Biochemical purification of SUMO-isopeptidases using SUMO-Vme 66

3.2 USPL1 is a SUMO isopeptidase 76

Chapter 4. Discussion 84

4.1 USPL1 is an atypical member of the USP family. 84

4.2 Conservation of USPL1 87

4.3 Functions of USPL1 89

4.4 Open questions and further work 90

4.5 Are there more SUMO specific proteases among the USP family? 91

4.6 Further approaches to identify novel SUMO specific isopeptidases 91

References 94

Curriculum Vitae 


\section{Acknowledgments}

This thesis would have not been possible without help, intellect and inspiration of many people that help me along the way.

The first person that I would like to acknowledge is my advisor Prof. Frauke Melchior. Without her, this entire project would have never happened. She invited me to her laboratory, inspired and guided me along the way. She was a demanding, patient and helpful mentor. She has been optimistic and encouraging, not avoiding criticism. I am truly grateful for her help and support.

I would like to express my gratitude to the members of my doctoral committee Prof. Gerhard Braus and Prof. Detlef Doenecke for the inspiring discussions and support.

I am truly grateful to Dr. Steffen Burkhardt for his help and involvement.

This thesis is a result of collaboration and help of many people. l'd like to thank them all for this. Prof. Erich Wanker for providing the library, Dr. Reinert Hitt for performing the screen, Dr. Huib Ovaa for the vinylmethylester, Dr. Henning Urlaub for the MS anlysis and Dr. Kai Hoffman the for bioinformatics analysis

I am grateful to Dr. Ralp Kehlenbach for discussions and reagents.

A big part of this work is based on the labeling technology that Dr. Erik Meulmeester introduced me to. I would like to thank him for that as well as for fruitful discussion and his help during this project.

Dr. Ruth Geiss-Friedlander has been very encouraging throughout this project, but not avoiding criticism. This allowed me seeing things from a different angle, which was very important. She has also been great friend. I am very grateful to her.

The time at the laboratory would have not been the same without my labmates: Marie-Christine, Sarah, Tina, Annette, Nicolas, Andreas, Achim, Guido, Guillaume. I would like to acknowledge them for their help, discussions and sharing reagents.

This work would have not been possible without excellent technical support of Frank Rhode, Ulrike Moeller, Katja Curth, Marion Kunze, Monika Raabe and Gerlinde Grelle.

I would also like to thank the Niedersachsen Lichtenberg Program for funding.

Thank you all

LK 


\section{ABSTRACT}

Small Ubiquitin-like Modifiers (SUMO) are $10 \mathrm{kDa}$ proteins that are covalently attached to hundreds of intracellular proteins to regulate their function. In mammals, three members of the SUMO family are known to be conjugated (SUMO-1,-2,-3). Desumoylating enzymes (isopeptidases) play an essential role by ensuring reversibility of this posttranslational modification. At present, only a small number of these enzymes, members of the UIp/SENP family, are known. They share a conserved catalytic cysteine protease domain, $\mathrm{C} 48$, wile remaining quite different in other regions. Mammals express only 6 distinct SENP proteases. This number appears extremely small, if one considers the plethora of SUMO targets that are individually regulated by reversible modification. For comparison, more than 80 different Ubiquitin proteases are currently known. This let us suspect that as yet undiscovered SUMO-specific isopeptidases exist.

The goal of this work was to identify and perform initial characterization of a novel SUMO specific isopeptidase. Here I describe the approaches I undertook to find such an enzyme. The first approach used a FRET-based desumoylating assay developed in our laboratory. I adapted this assay to a high-throughput screen, and screened a partial bacterial expression library of human ORFs. While positive controls could easily be identified, this approach did not result in identification of a novel SUMO isopeptidase. This was due, at least in part, to the small size of the available library. The second approach was based on a biochemical purification strategy using HeLa cell lysates and HA-eptitope tagged SUMO-Vinylmethylester (SUMO-VME), a SUMO derivate that specifically and irreversibly reacts with desumoylating enzymes. In addition to enriching already known isopeptidases, this resulted in the identification of USPL1 (Ubiquitin Specific Protease Like 1) as a protein that reacts with SUMO-VME. USPL1 is present in all vertebrates and lower invertebrates but absent in, e.g., fungi, C. elegans and plants. It is necessary for zebra fish development. Interestingly, USPL1 is not related to SENPS, but belongs to the Ubiquitin Specific Protease (USP) family. This family has a C19 cysteine protease domain. Upon expression and purification of the catalytic domain of USPL1 I could demonstrate that it indeed is a SUMO specific isopeptidase that exhibits a high specificity for SUMO-2/3, works less efficiently on SUMO1, but does not cleave Ubiquitin. Initial experiments suggest that USPL1 is a nuclear protein and database search revealed a possibility that it may be upregulated upon heat shock. 


\section{Abbreviations}

AMC - 7-amino-4-methylcoumarin

APS - ammonium persulfate

ATP - Adenosine-5'-triphosphate

Atg12 - autophagy 12 protein

AVP1 - adenoviral protease-1

BSA - bovine serum albumine

CFP - cyan fluorescent protein

DNA - deoxyribonucleic acid

dNTP - Deoxyribonucleotide triphosphate

DEN-1 - Deneddylase-1,

DMEM - Dulbecco's Modified Eagle's Medium

DTT - dithiothreitol

EDTA - ethylenediaminetetraacetic acid

FboxWD40.5 - F-box and WD repeat domain containing 5

FRET - Fluorescence resonance energy transfer

$\mathrm{HA}$ - hemagglutinin

HBM - HCF-1 binding motif

HCF-1 Host cell factor 1

HECT - Homologous to E6- Associated Protein (E6AP) C-Terminus

HEK - Human embroyinc kidney

GMP-1 - Gap Modifying Protein 1

GST - Glutathione S-transferase

IPTG - isopropyl $\beta$-D-1-thiogalactopyranoside

ISG-15 - Interferon-stimulated gene-15

$\mathrm{kDa}$ - kiloDalton

kB - Kilobasepair

LB - Luria Bertani

MESNa - Sodium methanethiolate

mRNA - Messenger ribonucleic acid 
Nedd8 - Neural precursor cell-expressed developmentally downregulated 8 NPC - nuclear pore complex

OGT-1 O-linked GIcNAc transferase

ORF - open reading frame

OV - ovalbumine

PAA - polyacrylamide

Pc2 - Polycomb protein 2

PBS - Phosphate buffered saline

PCNA - proliferating cell nuclear antigen

PCR - polymerase chain reaction

PIAS - protein inhibitor of activated STAT

PML - Promyelocytic leukaemia

PMSF - phenylmethanesulphonylfluoride

RanBP2 - Ran binding protein 2

RanGAP1 - Ran GTPase activating protein 1

RIPA - Radioimmunoprecipitation assay

RING - Really Interesting New Gene

RNF4 - RING finger protein 4

rRNA - ribosomal ribonucleic acid

$S A B$ - sumoylation assay buffer

SBM - SUMO binding motif

SDS - sodium dodecyl sulfate

SDS-PAGE - sodium dodecyl sulfate polyacrylamide gel electrophoresis

SENP - SUMO/Sentrin- specific protease

SIM - SUMO interaction motif

Smt3 - suppressor of mif two 3

STUbl - SUMO-Targeted Ubiquitin Ligase

SUMO - Small Ubiquitin-like protein modifier

TEMED - tetramethylethylenediamine

TEV - Tobacco Etch Virus

TDG - Thymine DNA glycosylase 
TOPORS - topoisomerase I binding, arginine/serine-rich

Ub - Ubiquitin

$\mathrm{UCH}$ - Ubiquitin C-terminal hydrolase

Ulp1 - Ubl specific protease 1

Ufm - Ubiquitin-fold modifier 1 ,

USP - Ubiquitin Specific protease

USPL1 - Ubiquitin specific protease like protein 1

VME - Vinylmethylester

VS - vinylsuflon

YFP - yellow fluorescent protein

WB - Western Blot 


\section{List of figures}

Figure 1. Overlay of Ubl structures

Figure 2. A General outline of the protein modification with Ubl mechanism

Figure 3. A general outline of Ubiquitin mediated protein degradation

Figure 4. Molecular outcomes of sumoylation

Figure 5. Evolutionary relationship of the UIp/SENP family members

Figure 6. The structure of the SENP2/SUMO1 complex

Figure 7. FRET-based assay as a tool to study isopeptidases.

Figure 8. The FRET-based assay can be used to screen bacterial expression libraries.

Figure 9. Generation, purification and testing of SUMO-VMEs

Figure 10. Enrichment of SUMO-1-VME and SUMO-2-VME modified proteins.

Figure 11. Sequential application of SUMO-VMEs can be used to enrich for paralogue specific isopeptidases

Figure 12. Gel with immunoprecipitated proteins

Figure 13. USPL1 reacts with SUMO-VMEs..

Figure 14. Expression and purification of USPL1 catalytic domain

Figure 15. The reaction of USPL1 with SUMO traps depends on the catalytic cysteine C236

Figure 16. USPL1cat is a SUMO isopeptidase with preference towards SUMO-2

Figure 17. USPL1cat can cleave SUMO-2 chains

Figure 18. USPL1 binds non-covalently to SUMO but not to Ubiquitin

Figure 19. USPL1 does not exhibit specificity towards Ubiquitin-AMC

Figure 20. Catalytic domain of USPL1 has conserved Cys-box and His-box but the QQD-motif is absent from it

Figure 21. Structural elements of USP2 participating in Ubiquitin recognition.

Figure 22. Domain organization of USPL1 


\section{List of Tables}

Table 1. Some of the Ubls expressed in human and their relationship to Ubiquitin Table 2. Primary antibodies

Table 3. PCR conditions

Table 4. Constructs prepared and used during this work

Table 5. Proteins identified upon SUMO-1-VME treatment

Table 6. Proteins identified upon treatment with SUMO-2-VME. 


\section{INTRODUCTION}

\subsection{Protein modification with Ubl}

Posttranslational protein modifications allow the expansion of the cell's proteome without increasing its genome size. In some cases, this can ensure a faster cellular response to changing conditions or stimuli without the need for new/additional protein synthesis. It is well documented that target proteins can be modified by the addition of phosphate groups, sugars, fatty acids or even entire polypeptides to confer some activity that is distinct from the unmodified native protein. Polypeptides as posttranslational modifications were first described when Ubiquitin was shown to be covalently attached to histones (Goldknopf \& Bush, 1975). At that time, neither the function nor the mechanism of this attachment were known. Work pioneered by Avram Hershko and Aaron Ciechanover elucidated the role of ubiquitin in ATP-dependent protein degradation (Ciechanover et al., 1980, Hershko et al., 1980, Wilkinson et al., 1980). For their discovery they were awarded the Nobel prize. Till date, many proteins functioning in a manner similar to Ubiquitin have been discovered and are collectively known as Ubiquitin like-proteins or Ubls (Welchman et al., 2005, Kerscher et al., 2006). Among these, Ubiquitin is best characterized for its role in protein degradation, SUMO for the regulation of a variety of cellular processes, and Atg12 and Atg8 for a role in autophagy. A list of the currently known Ubls that are expressed in human cells and their relation to ubiquitin are summarized in Table 1. Although the sequence homology between the Ubls is not high, they share a conserved 3 dimensional fold, termed the Ubiquitin fold or ß-grasp (Figure 1) (Welchman et al., 2005, Kerscher et al., 2006). Another common feature of Ubls is a glycine residue at the C-terminus and often two glycins are present (Gly-Gy motif). The carboxy group of the C-terminal glycine forms an isopeptide bond with the epsilon amino group of a lysine residue of a substrate. A general outline of protein modification with Ubl is shown in Figure 2. Most Ubls 
are expressed as inactive precursors in which the glycine used for conjugation is followed by a short peptide, which renders it unavailable for conjugation with

\begin{tabular}{c|c} 
Ubl & \% identity with Ubiquitin \\
\hline \hline & \\
Ubiquitin & 100 \\
Nedd8 & 52 \\
FAT10 & $30 / 42$ \\
ISG15 & $32 / 37$ \\
SUMO-1 & 20 \\
SUMO-2 & 16 \\
SUMO-3 & 16 \\
SUMO-4 & 15
\end{tabular}

Table 1. Some of the Ubls expressed in human and their relationship to Ubiquitin. In case of FAT10 and ISG15, which have two beta-grasp domains, sequence identity is shown for each domain.

substrate. C-terminal hydrolases cleave this peptide bond, exposing the carboxy group of the glycine for conjugation to protein substrate (Amerik and Hochstrasser 2004, Love et al., 2007). Ubl processed in such way can be conjugated to target proteins via an enzymatic cascade involving at least 3 steps (reviewed in Hershko \& Ciechanover 1998). First, the C-terminus of Ubl is activated in an ATP dependent manner by E1 activating enzyme (E1), and a thioester bond is formed between $\mathrm{Ubl}$ and the catalytic cysteine of E1. The second step involves transfer of $\mathrm{Ubl}$ to the active cysteine of E2 conjugating enzyme (E2). The third step is transfer of $\mathrm{Ubl}$ to a lysine residue in substrate protein either directly from E2 or with the help of E3 ligases. For Ubiquitin two distinct classes of E3 ligases have been identified: HECT- and RING-Type. HECT E3 ligases have a catalytic cysteine to which thioester charged Ubl is transferred from E2 and subsequently put on a target. RING-type E3 ligases do not have such a catalytic activity, instead they bring the E2 enzyme and a substrate together. (Hershko \& Ciechanover 1998, Welchman et al., 2005, Kerscher et al., 2006 ). 


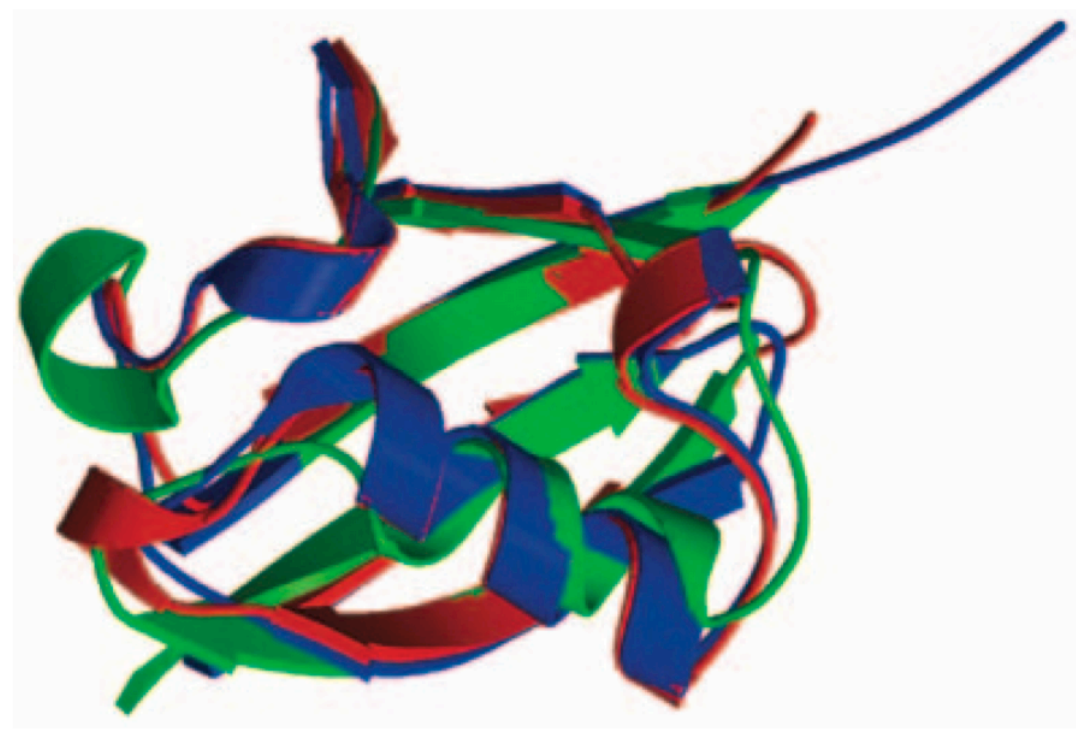

Figure 1. Overlay of Ubl structures. Ubiquitin is shown in blue, SUMO in green and Nedd8 in red. (Taken from Welchman et al 2005)

Protein modification with $\mathrm{Ubl}$ is a fully reversible process due to the action of isopeptidases. These enzymes cleave an isopeptide bond between $\mathrm{Ubl}$ and a target. Both the target and the $\mathrm{Ubl}$ can be used for a next round of conjugation (Amerik and Hochstrasser 2004, Nijman et al., 2005).

There is only one known class of E1 and E2 enzymes (Welchman et al., 2005, Kerscher et al., 2006 ) and these are related for the different Ubls. In contrast, Ubl proteases for the specific Ubls can be very different from each other. For example SUMO proteases belong to the SENP/Ulp family, Ufm-1 is processed by completely unrelated UfSP proteases and Ubiquitin proteases fall into five 
different classes, none of them related to SENP/Ulp or UfSPs (Amerik and Hochstrasser 2005, Routenberg et al., 2007).

Even though Ubl enzymes are specific for one Ubl, some of them can work on more than one Ubl (Kerscher et al., 2006). For example, E1-L2 is an activating

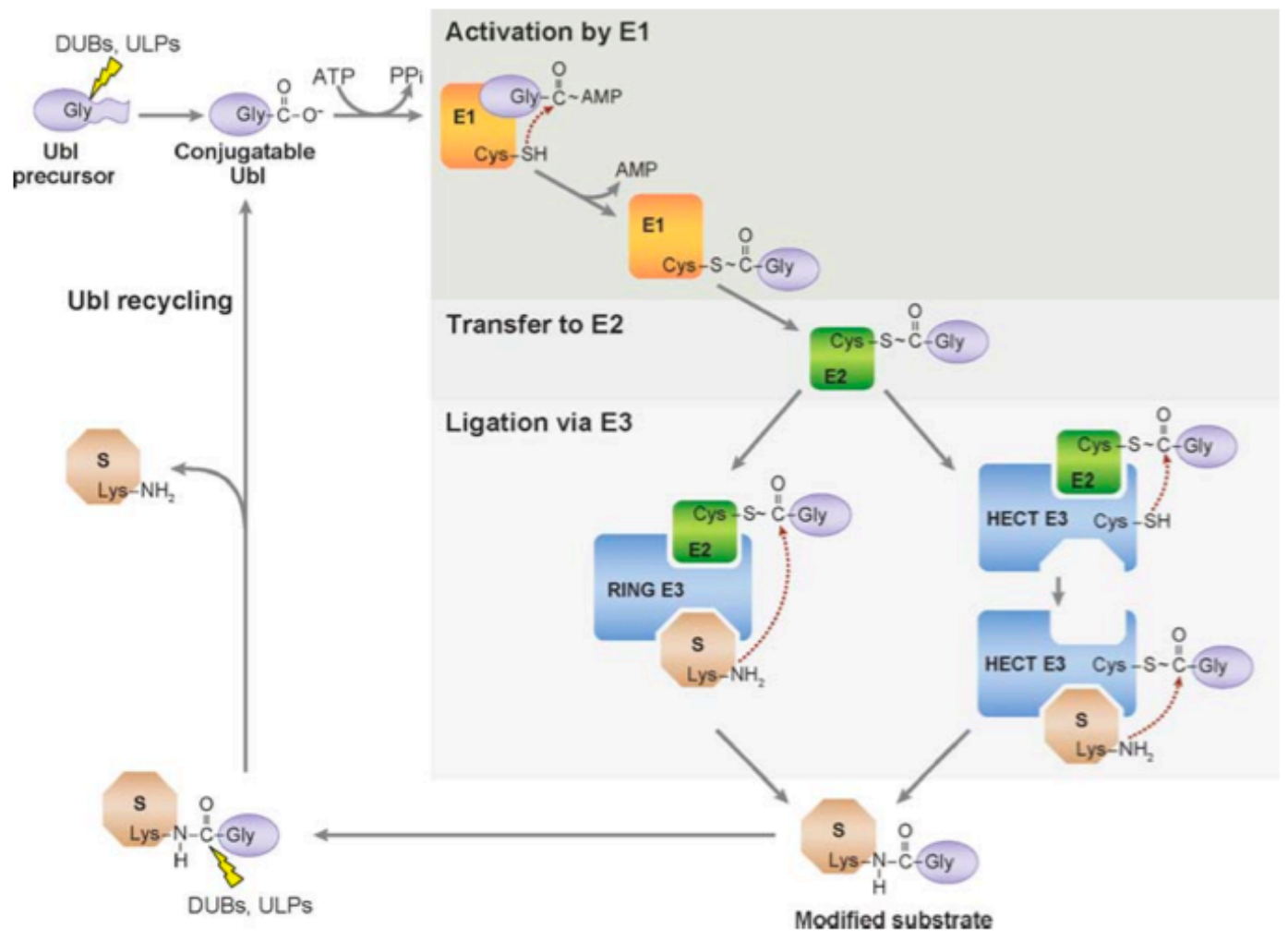

Figure 2. A General outline of the protein modification with Ubl mechanism. Newly synthesized $\mathrm{Ubl}$ is processed by a protease. The processed form can be activated in ATP dependent manner by an E1 activating enzyme, which transfers it to an E2 conjugating enzyme. The final step of modification involves formation of an isopeptide bond between the carboxy group of C-terminal glycine in Ubl and the amino group of a lysine residue in the substrate. Modification is reversed by action of isopeptidases. After deconjugation both $\mathrm{Ubl}$ and target can undergo the next round of modification (taken from Kerscher et al. 2006). 
(E1) enzyme for Ubiquitin and FAT10 (Chiu et ., 2007), while UCH-L1 and USP21 are proteases with dual specificity for Ubiquitin and Nedd-8 (Wada et al., 1998, Gong et al., 2000).

\subsubsection{Ubiquitin-mediated protein degradation}

The best known and characterized function for Ubls is ubiquitin-mediated protein degradation. Figure 3 outlines this process. Proteins destined for degradation are modified with Ubiquitin chains, in which the ubiquitin that is placed directly on a target is itself an attachment site for a second ubiquitin molecule, which becomes an attachment site for a third one and so on. The growing chain is being recognized by ubiquitin binding proteins, which direct such polyubiquitinated

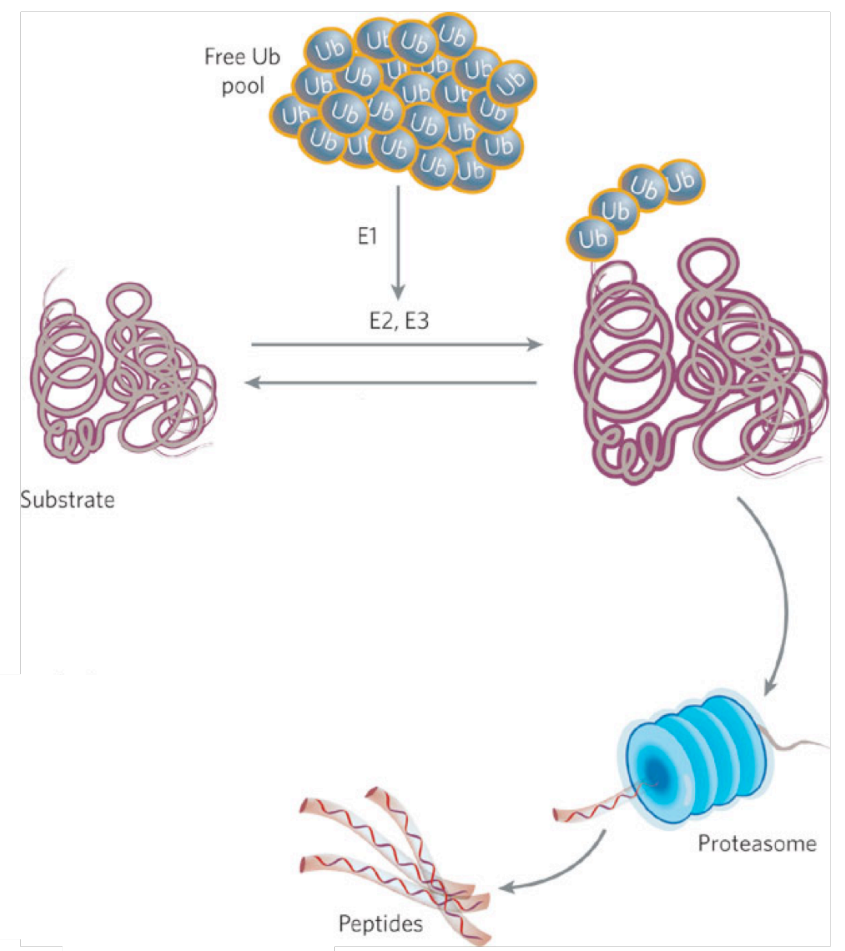

proteins for degradation by the proteasome, a large, multisubunit protease (Hochstrasser 1996, Hershko and Ciechanover 1998, Bochtler at al., 1999).

Figure 3. A general outline of Ubiquitin mediated protein degradation. (taken from Rubinsztein 2006). 


\subsection{SUMO}

SUMO (Small ubiquitin like modifier), also known as Sentrin or GMP-1, is a subfamily of Ubls (Melchior 2000, Johnson 2004). Different organisms vary in the number of SUMO proteins they express. S. cerevisiae, D. melanogaster and C. elegans have only one SUMO protein. Lower vertebrates like $D$. rerio or $X$. leavis have two and mammals have 3 SUMO proteins (SUMO-1,2,3). Primates have a fourth SUMO gene encoding protein SUMO-4, however it is unclear whether it is conjugated to protein substrates or not, owing to the presence of a proline residue, believed to inhibit its processing by SENPs (Owerbach et al., 2005). The SUMO pathway is essential in many organisms including $S$. cerevisiae, $C$. elegans or A. thaliana (Johnson et al., 1997, Fraser et al., 2000, Saracco et al., 2007). Human SUMO-1 was discovered as a protein modifying RanGAP and targeting it to nuclear pore complexes (Mahajan et al., 1997, 1998; Matunis et al., 1996, 1998). Soon after, SUMO-2 and 3 were discovered, and it became clear that sumoylation is a commonly used process. SUMO-2 and SUMO-3 are $97 \%$ identical, differing mostly within the C-terminal peptide after the Gly-Gly motif, and they both are $50 \%$ identical to SUMO-1. So far there is no evidence for functional differences between SUMO-2 and SUMO-3 and they are often referred to as SUMO-2/3. Whereas Ubiquitin is highly conserved in evolution (97\% identity between Ubiquitin from human and yeast) SUMO proteins are conserved to a much lower extent between species. All three human SUMOs share only $50 \%$ identity with the S. cerevisiae SUMO, Smt3p (Lapenta et al 1997, Kamitani et al., 1998). A unique feature of the SUMO family is the $\mathrm{N}$-terminal tail preceding the ß-grasp domain. Many targets can be modified with either SUMO-1 or SUMO-2/3, however a number of targets are specifically modified with one isoform only even in vitro (Johnson 2004, Meulmeester et al,. 2008, Zhu et al., 2008). SUMO-1 is present in the cell predominantly in form of conjugates. SUMO-2/3 under non-stress conditions are present mainly in the unconjugated form. When stress conditions are applied, SUMO-2/3 are rapidly conjugated to their targets (Saitoh et al., 2000). Another feature differing between SUMO-1 and 
SUMO-2/3 is chain formation in vivo. The $\mathrm{N}$-terminal tail of SUMO-2/3 has a Sumoylation consensus site that is absent from SUMO-1 (Tatham et al., 2001) and this may be the reason that only SUMO-2/3 can form chains in vivo. It is not currently known whether modification of a given protein with SUMO-1 has the same or different outcome than modification with SUMO-2, and vice versa.

\subsubsection{SUMO modifying enzymes}

In contrast to other Ubl activating enzymes, which are single polypeptide chains, the SUMO E1 is composed of two subunits, Aos1 and Uba2. Aos1 corresponds to the $\mathrm{N}$-terminal part of the ubiquitin $\mathrm{E} 1$ and Uba2 to its $\mathrm{C}$-terminal part. Both subunits associate together to form a stable enzymatically active complex (Johnson et al 1997). After ATP dependent activation, SUMO is transferred to the E2 conjugating enzyme, Ubc9 (Desterro et al., 1997). In contrast to ubiquitination, sumoylation can occur efficiently without E3 and can take place at a specific lysine residue within the SUMO consensus motif. This motif was identified by aligning SUMO-1 modification sites in different targets, and consists of $\Psi \mathrm{KxE}$, where $\Psi$ is a bulky hydrophobic residue and $\mathrm{x}$ is any residues. Ubc9 interacts directly with this motif, which explains both lysine residue specificity and conjugation without E3 (Bernier-Villamor et al. 2002). However, the affinity of Ubc9 for the consensus site is very low and therefore in most cases additional factors are necessary for efficient sumoylation. The first discovered SUMO E3 ligases were Siz1 and Siz2 in S. cerevisiae. Siz1 is required for SUMO attachment to the $S$. cerevisiae septins in vivo and strongly stimulates septin sumoylation in vitro (Johnson and Gupta 2001). Its homologues in animals belong to the PIAS (protein inhibitor of activated STAT) family. PIAS/Siz proteins have an SP-RING domain, which is similar to the RING domain of Ubiquitin E3 ligases and believed to have an analogous function (Hochstrasser 2001). PIAS

proteins are expressed in all eukaryotes and are implicated in a number of processes including cytokine signaling, hormone signaling and DNA repair (Palvimo 2007). A special type of E3 ligase so far unique to the SUMO pathway 
is RanBP2, a nucleoporin localized to the cytoplasmic side of nuclear pore complexes (Pichler et al.2002). It does not belong to either the HECT or RING class of E3 ligases, however it enhances sumoylation by placing SUMO-charged Ubc9 in an optimal position for SUMO transfer (Pichler et al.,2004, Reverter and Lima 2005). RanBP2 in vitro enhances sumoylation of many targets, however in vivo only topisomerase II and borealin have been identified as targets (Dawlaty et al., 2008, Klein et al., 2008). Additional proteins e.g. polycomb protein 2 and TOPORS have also been reported to have a SUMO E3 ligase activity, but these findings still need to be confirmed (Kagey et al., 2003, Weger et al., 2005).

\subsubsection{Non covalent SUMO interaction}

In contrast to the Ubiquitin pathway, for which more than 20 Ubiquitin-binding domains have been identified (reviewed in Hicke et al., 2005), a single SUMO binding motif called SBM (SUMO Binding Motif) or SIM (SUMO interaction motif) is known (Song et al., 2004 and 2005, Hecker et at., 2006). This motif consists of hydrophobic residues flanked $\mathrm{N}$ - or C-terminally by acidic residues or serins and interacts with beta2-strand of SUMO (Song et al., 2004 and 2005, Hecker et at., 2006). It has been identified in a number of SUMO enzymes and targets (Song et al., 2004, Sehn et al., 2006, Knipscheer et al., 2007, Meulmeester et al., 2008)

\subsubsection{Outcomes of SUMO modification}

Similar to other Ubls, conjugation of SUMO changes the interaction partners or the conformational state of the substrate protein, therefore the outcomes can be different for different targets and hard to predict. SUMO attachment to a target can provide a new surface for protein-protein interaction, thereby allowing for new binding partners. Alternatively, SUMO can mask existing interaction sites, therefore excluding interaction with proteins binding to the unmodified target. A third mode in which sumoylation influences the protein function is by inducing conformational changes in target. This is mediated via non-covalent interaction 
between SUMO and target's SIM (Geiss-Friedlander and Melchior 2007) (Figure $4)$.

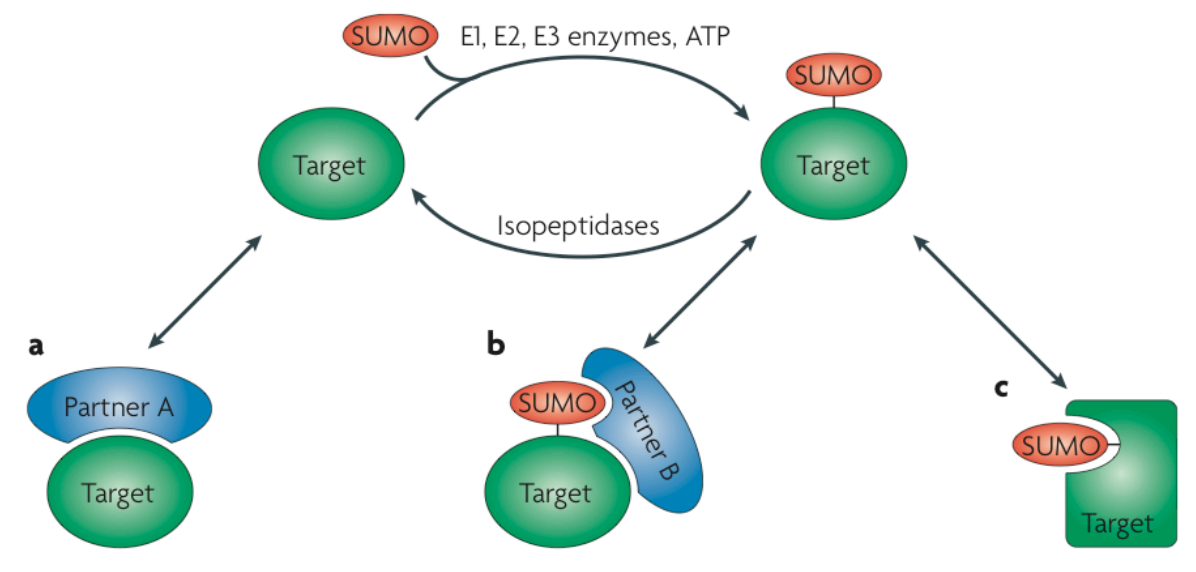

Figure 4. Molecular outcomes of sumoylation. a) Sumoylation interferes with proteinprotein interaction by masking of the binding surface in the target. b) Sumoylation induces new interaction by providing additional surface for binding partners. c) Sumoylation induces a conformational change in the target (taken from GeissFriedlander and Melchior 2007).

Selected examples for physiological outcomes of sumoylation are given below:

\section{Localization}

Sumoylation targets vertebrate RanGAP1 to nuclear pore complexes (NPC) by allowing interaction with RanBP2 - a nucleoporin localized at the cytoplasmic side of NPC (Mahajan et al., 1997, 1998; Matunis et al., 1996, 1998). Another example of SUMO regulated localization is targeting of sumoylated proteins to PML-nuclear bodies via SIM mediated interactions between SUMO and PML protein (Shen at el., 2006). 


\section{Transcriptional repression}

Many transcription factors have been identified as targets for sumoylation. In most cases the modification represses the transcription. According to a current model, sumoylation of a transcription factor results in recruitment of transcriptional repressors or chromatin modifying enzymes that inhibit transcription by histone modifications (Geiss-Friedlander and Melchior., 2007). A recent siRNA screen in D. melanogaster identified MEP-1, Mi-2, and Sfmbt as SUMO-dependent repressors of Sp3 transcription (Stielow et al., 2008).

\section{DNA metabolism and repair}

PCNA (proliferating cell nuclear antigen) functions as a sliding clamp during DNA replication. Sumoylation of PCNA prevents unwanted homologous recombination during DNA replication by recruiting antirecombinogenic helicase Srs2 (Pfander et a.l, 2005). Thymine DNA glycosylase (TDG) is an enzyme involved in DNA mismatch repair and undergoes sumoylation as part of its catalytic cycle. A current model suggests that sumoylation induces a conformational change in enzyme bound to DNA, which results in dissociation from DNA (Hardeland et al., 2002, Baba et al., 2005).

\section{Signaling}

SUMOylation has also been reported for a number of proteins involved in signaling. For example, a recent study demonstrates that TGF- $\beta$ receptor is modified by SUMO upon TGF- $\beta$ stimulation. This enhances signaling by facilitating the recruitment and phosphorylation of Smad3 (Kang et al., 2008). 


\section{Protein stabilization/degradation}

It has been reported for I kappa B that sumoylation and ubiquitination are mutually exclusive since the same lysine residue is target for both SUMO and Ubiquitin modification (Desterro et al., 1998). This observation led to the suggestion that SUMO can act as a repressor of protein degradation. Interestingly, recent findings have revealed that SUMO can also stimulate protein degradation by recruitment of the RNF4/STUbl ubiquitin E3 ligases (Prudden et al., 2007, Sun et al., 2007, Uzunova et al., 2007, Xie et al.,2007, LallemandBreitenbach V et al., 2008, Tatham et al., 2008).

\subsection{SUMO proteases}

SUMO proteases catalyze hydrolysis of a peptide (peptidase/C-terminal hydrolase activity) or isopeptide bond (isopeptidase activity). In spite of their biochemical similarity, the outcomes and functions of these two reactions are very different. Like most Ubls SUMO proteins are synthesized as inactive precursors in which the C-terminal Gly-Gly motif is followed by a short peptide. Hydrolysis of the peptide bond between the last glycine and the following residue exposes the carboxy group of the glycine and makes SUMO available for conjugation. The isopeptidase activity of SUMO proteases results in their ability to remove SUMO from targets, thereby reversing modification (Melchior et al., 2003, Hay 2007, Yeh 2008). So far all known eukaryotic SUMO proteases belong to the UIp/SENP family (Dasso 2007, Yeh 2008). The first SUMO protease was identified in yeast, employing a biochemical screen (Li and Hochstrasser 1999). Pools of bacterial transformants expressing yeast proteins were assayed for their ability to cleave a model substrate - His-Ubiquitin-Smt3c-HA. This screen led to the identification of a previously uncharacterized protein that cleaved SUMO but not ubiquitin. It had no strong similarity to ubiquitin or any other Ubl protease and was named Ubl specific protease 1 (Ulp1). Database searches revealed a number of proteins in different organisms that shared similarity within a single 
domain of around 200 amino acids. Inhibitor studies, mutational analysis and sequence alignments resulted in characterization of this domain as the catalytic core of Ulp1. Biochemically, Ulp1 is a cysteine protease with a conserved catalytic triad composed of cysteine, aspartate and histidine in a domain referred to as the "C48 protease domain" This will be henceforth referred to as "catalytic domain" for clarity. Database searches for proteins that have the same conserved catalytic triad led to discovery of a weak similarity between the catalytic domain of Ulp1 and processing proteases of several adenoviruses. Interestingly these proteases cleave a consensus motif similar to glycine-glycine$X$ of SMT3 and SUMO (Lopez-Otin et al., 1999). Human proteins that have C48 domains were named SENP - for Sentrin/SUMO specific protease (Yeh et al., 2000).

\subsubsection{SENP/Ulp family}

Members of the UIp/SENP family are present in all eukaryotes. S. cerevisiae has two proteins (Ulp1 and Ulp2) while humans have 7 proteins with a C48 domain SENP1,2,3,5,6,7,8. The family has three main branches: Ulp1-like, Ulp2-like and DEN-1 like (Figure 5). The DEN-1 like branch diverged from the other two branches quite early in evolution (Dasso 2007) and these enzymes are not SUMO specific proteases in spite of having C48 domains. Rather, they act on another Ubl, Nedd8 (Gan-Erdene et al., 2003, Wu. et al., 2003). Members of Ulp1-like and Ulp2-like branches are specific for SUMO. The generic member of the UIp/SENP family has a C-terminal catalytic domain and a N-terminal domain that contains sequences responsible for the localization. The catalytic domain of the Ulp2-like branch has conserved insertions within the catalytic domain that are absent from Ulp1-like enzymes (Dasso 2007, Reverter and Lima 2008). 


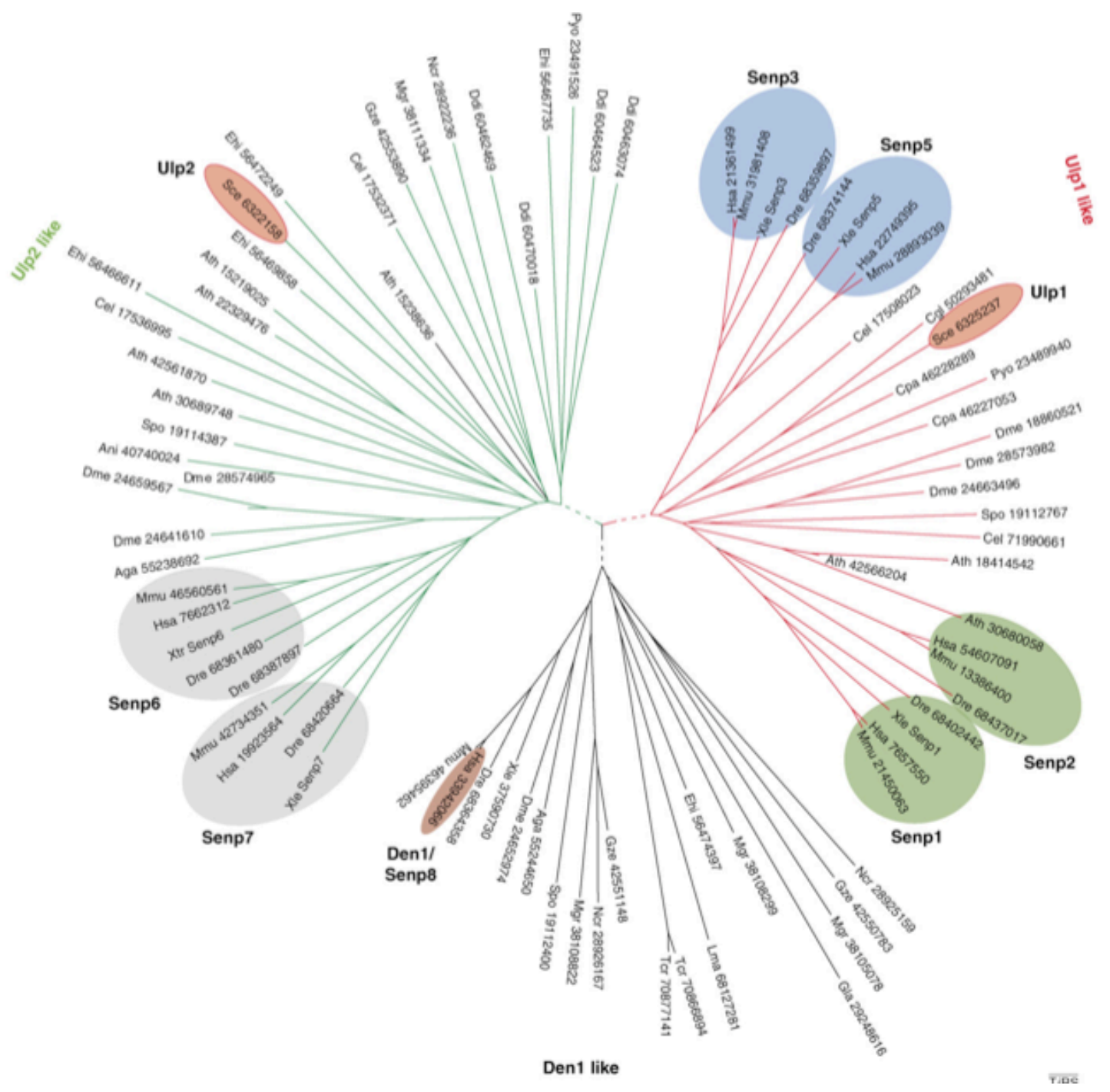

Figure 5. Evolutionary relationship of the UIp/SENP family members. The Ulp1 like branch including human SENP1,2,3 and 5 is shown in red, the Ulp2 like branch including human SENP6 and 7 is shown in green. The Den1 like branch of enzymes specific for Nedd8, which includes human SENP8 is shown in black (taken from Dasso 2007). 


\subsubsection{Structure and catalytic mechanism of SUMO proteases}

The crystal structure of the C48 domain has been solved for several members of the Ulp1-like branch and for one member of the Ulp-2 like branch, SENP7. The structures provide insights into the mode of SUMO recognition by the catalytic domain and suggest a model for catalysis.

The C48 domain can be divided into two parts: an N-terminal subdomain rich in alpha helices that contains the catalytic cysteine and a C-terminal part composed of five anti-parallel beta strands surrounded by 2 alpha helices, that contains the remaining two residues of the triad (Reverter and Lima 2004). The catalytic domain of SENP shows the highest degree of structural similarity with adenoviral protease-1 fragment (AVP1), representing a prototype of this family of cysteine proteases. AVP1 was reported to exhibit a deubiquitinating activity, however it appears that its physiological function is restricted to processing of viral proteins (Balakirev et al., 2002, Mangel et al.,1993).

In case of ubiquitin specific proteases, residues forming the active site are often misaligned in the structure prior to ubiquitin binding. Ubiquitin binding induces structural rearrangements resulting in formation of the active site. In contrast, the C48 active site is already preformed in the absence of SUMO. The active site is localized to a cavity on the enzyme's surface (Reverter and Lima 2004). Structures of catalytic mutants of SENP1 and SENP2 catalytic domains in complex with sumoylated RanGAP show no specific interaction between RanGAP and the C48 domain, indicating lack of specificity towards specific targets (Reverter and Lima 2006, Shen et al., 2006). Specificity observed in vivo must therefore come either from specific interaction of targets with the $\mathrm{N}$-terminal part of the protease or from limiting the localization of the protease to distinct cellular compartments (Reverter and Lima 2006, Dasso 2007).

The structure of a covalent thiohemiacetal transition-state complex of SENP2's catalytic domain with SUMO-1 showed that SUMO is recognized at two different sites, the surface of the globular core and the C-terminal tail (Figure 6). Surface recognition depends on salt bridges between side chains of arginin in SUMO 
(R63) and a conserved aspartic acid (D413) in the catalytic domain as well as a conserved phenylalanine residue (F441) of the catalytic domain, which is inserted into a hydrophobic pocket on the SUMO surface. Of note, the mutation of the corresponding residues in Ulp1 results in conditional lethality in yeast, indicating the importance of this interaction. The second site of recognition is localized to the C-terminus of SUMO, which adopts the structure of an elongated beta strand and inserts into a hydrophobic tunnel leading to the active site, in which the Gly-Gly motif is capped by conserved tryptophan residues (W410 and W479) (Reverter and Lima 2004). Biochemical analysis revealed that SENPs exhibit specificity towards the type of reaction (deconjugation vs. processing) and SUMO paralogues. Structures of catalytic mutants of either SENP1 or SENP2 catalytic domain in complex with unprocessed SUMO or sumoylated RanGAP led to a model for the mechanism of catalysis and provided a structural basis for SENP specificity (Reverter and Lima 2006, Shen et al., 2006). SENP binds SUMO non-covalently and binding induces cis-trans isomerization of the scissile bond. As a result the amide bond is in a favorable position for the attack by the catalytic cysteine. SENP specificity is determined by two factors: binding affinity to the SUMO paralogue, and SENP's ability to isomerize the scissile bond (Reverter and Lima 2006, Shen et al., 2006). The latter depends on how well the enzyme accommodates the C-terminal side of the scissile bond and how rigid are the residues that are found there. SENP1 binds SUMO-1 and SUMO-2 equally well and deconjugates it from targets with similar efficiencies, however it processes efficiently only full-length SUMO-1. This discrepancy is due to the fact that in the conjugated form SUMO-1 and SUMO-2 have the same C-terminal side of the isopeptide bond, the lysine side chain, but the full length forms differ significantly. In SUMO-2 a rigid proline residue in position P2 to the scissile bond interferes with isomerization, whereas in SUMO-1 a histidine residue in position P1 stabilizes the cis conformation of the scissile peptide bond (Shen et al., 2006). SENP2 binds SUMO-2 better than SUMO-1, which explains its preference for SUMO-2-modified substrates. It also seems to be less efficient at isomerizing 
scissile bonds in full length SUMO, which explains why it is less active in processing (Shen et al., 2006).

A

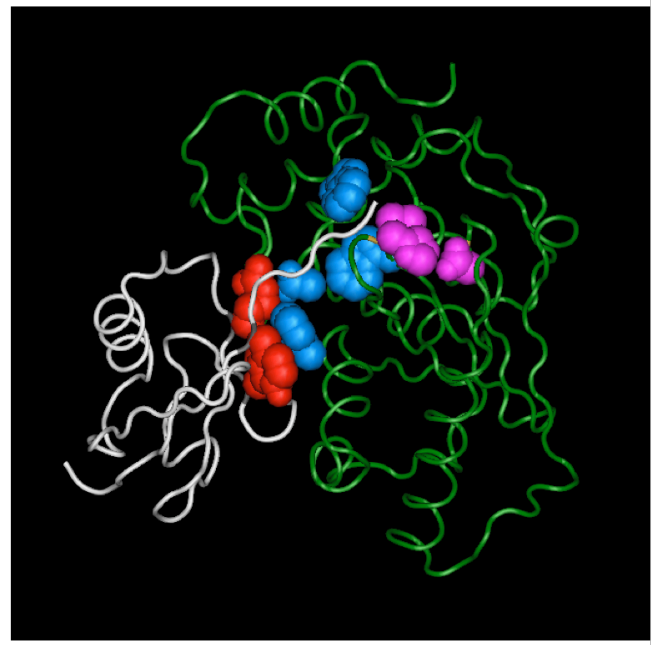

B

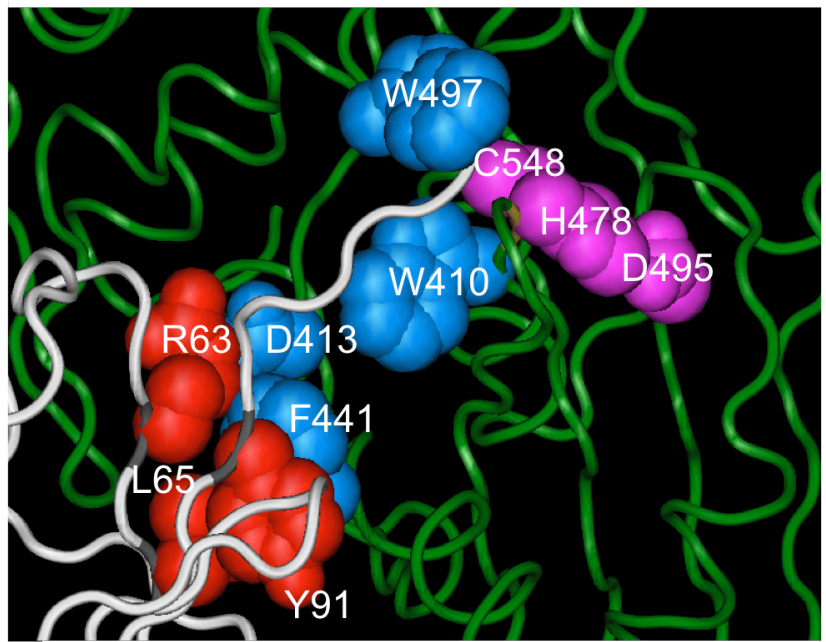

Figure 6. The structure of the SENP2/SUMO1 complex. A) General arrangement of the SENP2/SUMO-1 complex. SENP2 and SUMO-1 backbones are shown in green and white respectively. SENP2 residues participating in SUMO-1 binding are schown in blue and the residues of the catalytic triad in magenta. SUMO-1 residues mediating binding to SENP2 are shown in red. B) SUMO-1 and SENP2 residues participating in binding and catalysis. Color scheme same as in panel A. (Prepared using Cn3D application and PBD file 2HD5)

A recently solved structure of SENP7, which exhibits specificity for SUMO2 chains, revealed that Ulp2-like proteases differ from Ulp1 not only in sequence but also in structure (Reverter and Lima 2008). Although the structures are similar, they do not align well. SENP7 lacks some elements present in Ulp1 and contains several additional loops. These loops correspond to the insertions observed in the sequence of Ulp2 like proteases. So far there is no structure of SENP7 with SUMO-2 chains and therefore the exact elements determining the preference of Ulp2 like proteases towards SUMO chain cleavage remain to be determined. 


\subsubsection{Functions of Ulp1 branch proteases}

Deletion of Ulp1 in S. cerevisiae results in lethality, and the level of Ulp1 activity correlates with its ability to support cell growth. Ulp1 depleted cells experience problems with vegetative growth and arrest at the G2/M phase of the cell cycle. The $\Delta$ Ulp1 strain can be partially rescued by the expression of processed form of Smt3, which indicates an important role of Ulp1 in pre-Smt3 processing (Li and Hochstrasser 1999). Ulp1 is localized to the nuclear periphery, where it associates with nuclear pore complexes via interaction with Psp1 and the nuclear import receptors importin $\alpha / \beta$ (Panse et al., 2003). This localization may regulate its substrate specificity. An expression of the deletion mutant that contains only the catalytic domain of Ulp1 is lethal for the cells, suggesting that Ulp1 anchoring to the NPC may be a way to regulate its activity. Mutants that are not localized to the NPC show much more activity than wild-type (Li and Hochstrasser 2003). In addition to cell division, Ulp1 plays a role in RNA processing and ribosome biogenesis (Dasso 2007).

Humans have four members of the Ulp1-like branch, which fall into two subgroups. The first one consists of SENP1 and SENP2. SENP1 is active both in processing and in deconjugation. For processing it favors SUMO-1 as a substrate. It can also process SUMO-2, but shows a very limited activity towards SUMO-3. SENP1 can deconjugate SUMO-1 and SUMO-2 from substrates with equal efficiencies (Shen et al., 2006). SENP2 on the other hand prefers SUMO-2 to SUMO-1 for deconjugation and is a poor processing enzyme (Reverter and Lima 2006). SENP1 is localized to the nucleoplasm and nuclear speckles, whereas SENP2 localizes to the nucleoplasmic side of the NPC (Bailey and O'Hare 2004, Hang and Dasso 2002). Localization to the NPC is similar to that of Ulp1, however the mechanism may be different. SENP2 interacts with Nup153, but it is not known whether this interaction is direct or if it requires importin $\alpha / \beta$ (Hang and Dasso 2002, Zhang et al., 2002). The role of the NPC localization has not been directly addressed in human cells. Analogous to Ulp1 NPC 
localization, it may be a way to restrict enzymatic activity only to a certain localization. Overexpression of a SENP2 mutant, which can no longer localize to the NPC, results in a stronger reduction of SUMO conjugates than overexpression of a wild-type protein (Hang and Dasso 2002). SENP2 has also been implicated in transcriptional regulation (Best et al 2002). Considering the localization of other SUMO enzymes to the NPC (Ubc9,RanBP2) it is possible that SENP2 has a role in nuclear transport. SENP1 is essential for embryonic development (Cheng et al., 2007). It has been implicated in regulation of transcription, keratinocyte differentiation and prostate cancer development (Cheng et al., 2006, Deyrieux et al., 2007).

The second subgroup of the Ulp1 branch consists of SENP3 and SENP5. Both of these enzymes localize to the nucleolus, and are specific for SUMO2/3 in deconjugation reaction, having almost no processing activity (Gong and Yeh 2006, Di Bacco et al., 2006). SUMO-2/3 conjugates are absent from the nucleolus. Localization of SENP3/5 to the nucleolus may be a way to exclude SUMO2/3 conjugates from this compartment. Upon depletion of SENP5 strong enrichment of SUMO2/3 conjugates is nucleoli can be observed (Di Bacco et al., 2006). Multiple functions have been associated with SENP3/5, including cell cycle control, rRNA processing and regulation of mitochondrial morphology (Di Bacco et al., 2006, Zunino et al., 2007, Kuo et al., 2008, Haindl et al., 2008, Klein et al., 2008).

\subsubsection{Functions of Ulp2-like SUMO proteases}

Ulp-2 like proteins appear to be specialized for SUMO chain cleavage. They are more proficient in chain disassembly than in deconjugation, but have no activity in processing (Dasso 2007, Reverter and Lima 2008).

Contrary to Ulp1, Ulp2 is not essential for vegetative growth of S. cerevisiae. Deletion of Ulp2 results in increased sensitivity to hydroxyurea and DNA damaging agents like UV or gamma radiation. Ulp2 is also required for normal 
recovery from spindle check point arrest. The delta Ulp2 strain exhibits higher rates of chromosome loss and cells exhibit problems with rDNA condensation and shows premature loss of chromosomal cohesion during mitosis. Although not essential for normal growth, Ulp2 is needed for sporulation. In early meiosis the mRNA levels of ULP2 increase 10 fold. The deletion mutant arrests in meiotic prophase (Li and Hochstrasser 2000). Ulp2 was implicated in remodeling of synaptonemal complexes - protein complexes involved in chromosomal pairing and crossing over (Cheng et al., 2006).

Ulp2 has a different substrate specificity than Ulp1, as judged from the accumulation of SUMO conjugates in delta strains. Ulp2 depletion leads to accumulation of high molecular weight sumoylated species. The defects can be rescued by overexpression of a SUMO mutant that does not form chains, indicating than Ulp2 is responsible for chain disassembly (Bylebyl et al., 2003).

Humans have two members of the Ulp2 like branch - SENP6 and SENP7. Recent characterization revealed that similar to UIp2 SENP6 and SENP7 are very efficient in disassembling SUMO chains (Mukhopadhyay et al., 2006, Reverter and Lima 2008). In deconjugation reactions both enzymes prefer SUMO-2/3 over SUMO1, but have no processing activities. Both enzymes are nuclear proteins. Depletion of SENP6 leads to the accumulation of SUMO-2/3 species within PML nuclear bodies (Mukhopadhyay et al., 2006).

\subsection{Are there more SUMO specific isopeptidases?}

The small number of SUMO proteases is in clear contrast to the ubiquitin pathway, in which the number of proteases is close to one hundred. Ubiquitin proteases fall into five different families, none of which are related to SUMO proteases. The biggest group is the Ubiquitin Specific Proteases family (USP), a family of cysteine proteases with more than fifty members in humans (Nijman et al 2005). Three out of the remaining four families are also cysteine proteases, whereas enzymes belonging to the last family are metallo proteases (Amerik and Hochstrasse 2004, Nijman et al., 2005). The plethora of ubiquitin proteases 
allows us to suspect that yet undiscovered SUMO proteases exist. In agreement with this, unpublished data from our laboratory as well as from studies conducted by Suzuki et al. in 1999 suggest the presence of a SUMO isopeptidase activity that correlates with a protein of $\sim 30 \mathrm{kDa}$. The smallest known member of the SUMO proteases (SENP5) is $65 \mathrm{kDa}$ in size therefore it is reasonable to suspect that the activity observed by us is distinct. This supports the hypothesis that a novel yet unidentified protease exists.

\subsection{Specific Aim}

A specific aim of my work was to identify a new SUMO specific isopeptidase and to perform its initial characterization. Two approaches were used: an in vitro FRET based desumoylation assay was applied to screen a bacterial expression library of human ORFs, and chemically modified SUMO was used to purify desumoylating enzymes from HeLa cell lysates. As a result Ubiquitin specific protease like protein 1 (USPL1) was identified as a protease specific for SUMO but not Ubiquitin. 


\section{Materials and methods}

\subsection{Materials}

\subsubsection{Equpiment}

Automated robotic station BioMek2000 (Beckman Coulter)

Bacterial incubator (Kelvitron t Heraeus, Hanau)

Cell culture incubator (Hera cell Heraeus, Hanau)

Centrifuge J6MI (Beckman Coulter, München)

Centrifuge Avanti J30I (Beckman Coulter, München)

Centrifuge Allegra X-15R (Beckman Coulter, München)

Chromatography system Äkta Purifier (GE Healthcare, München)

Chromatography system Äkta Prime (GE Healthcare, München)

Documentation system Gel Jet Imager Intas, Göttingen

Documentation system LAS 3000 Fujifilm, Tokyo (Japan)

Elektrophoresis and blotting chambers (Workshop MPI for Biochemistry, Martinsried )

Film developing machine Curix 60 (Agfa, Köln )

high pressure homogenizer EmulsiFlex-C3 (Avestin)

Microplate reader, Fluoroskan Ascent (Labsystems)

Photometer SmartSpec (Plus Bio-Rad, München)

Power supply Variomag Biomodul 40B H+P (Labortechnik, München)

Rotors JS 4.2, JA 30.50Ti, SX4750, TLA 100.3 (Beckman Coulter, München)

Rotors Type45, Type60Ti, Type70.1Ti (Beckman Coulter, München)

Scanner 4990 (Photo Epson, Meerbusch)

Shaking incubator Innova 4230 (New Brunswick Scientific, Edison, NJ,USA)

Sterile cell culture hood Hera safe (Heraeus, Hanau)

Table centrifuge 5415C, 5424 (Eppendorf, Hamburg)

Thermomixer compact (Eppendorf, Hamburg )

Ultracentrifuge OptimaMax (Beckman Coulter, München)

Ultracentrifuge Optima L-80 XP (Beckman Coulter, München)

Vacuum pump LABOPORT N480.3FTP (KNF Neuberger, Freiburg) 
Water purification system Ultra Clear (SG, Barsbüttel)

\subsubsection{Commonly used reagents}

Unless indicated otherwise Millipore water was used for preparation of all buffers and and stock solutions.

\subsubsection{Stock solutions:}

Ampicillin $100 \mathrm{mg} / \mathrm{ml}$

Aprotinin, $1000 \times 1 \mathrm{mg} / \mathrm{ml}$

ATP 20 mM HEPES pH 7.4, 100 mM ATP, 100 mM magnesium acetate

Chloramphenicol $30 \mathrm{mg} / \mathrm{ml}$

Dithiothreitol (DTT) $1 \mathrm{M}$

Kanamycin $50 \mathrm{mg} / \mathrm{ml}$

Leupeptin/Pepstatin, $1000 \times 1 \mathrm{mg} / \mathrm{ml}$ each, in DMSO

PMSF 100 mM in 2-propanol

Puromycin $1 \mathrm{mg} / \mathrm{ml}$ in PBS

\subsubsection{Commonly used buffers Buffers}

Phosphate buffered saline (PBS) PBS (140 NaCl, $2.7 \mathrm{mM} \mathrm{KCl}, 1.5 \mathrm{mM}$

$\mathrm{KH}_{2} \mathrm{PO}_{4}, \mathrm{pH} 7.5$ )

PBST PBS supplemented with $0.2 \%(\mathrm{v} / \mathrm{v})$ Tween 20

Transport buffer $20 \mathrm{mM}$ HEPES, $110 \mathrm{mM} \mathrm{KOAc}, 2 \mathrm{mM} \mathrm{Mg}(\mathrm{OAc})_{2}, 1 \mathrm{mM}$ EGTA $\mathrm{pH} 7.3$ )

Sumoylation assay buffer (SAB) transport buffer supplemented with $0.2 \mathrm{mg} / \mathrm{ml}$ ovalbumine, $0.05 \%(\mathrm{v} / \mathrm{v})$ Tween 20, $1 \mathrm{mM}$ DTT, $1 \mu \mathrm{M}$ PMSF and $1 \mu \mathrm{g} / \mathrm{ml}$ each of aprotinin, leupeptin, pepstatin

DNA loading dye (stock 6x) $10 \mathrm{mM}$ Tris-HCl, $50 \mathrm{mM}$ EDTA, $1 \%$ (w/v) SDS, 30 $\%(\mathrm{w} / \mathrm{v})$ glycerol, $0.1 \%(\mathrm{w} / \mathrm{v})$ bromophenol blue, $0.1 \%(\mathrm{w} / \mathrm{v})$ xylencyanol, $\mathrm{pH} 8$ TE buffer (10mM Tris, 1mM EDTA, pH 7.5) 


\subsubsection{Bacterial strains and culture media}

\section{LB (Luria-Bertani)}

$1 \%(\mathrm{w} / \mathrm{v})$ bacto-tryptone, $0.5 \%(\mathrm{w} / \mathrm{v})$ yeast extract, $1 \%(\mathrm{w} / \mathrm{v})$ sodium chloride, $\mathrm{pH} 7$ ) sterilized by aoutoclaving

\section{LB plates}

LB medium with addition of $1.5 \%(\mathrm{w} / \mathrm{v})$ bacto-agar

In case when antibiotics were used LB medium and plates was supplemented with either $100 \mu \mathrm{g} / \mathrm{ml}$ ampicillin or $50 \mu \mathrm{g} / \mathrm{ml}$ of kanamycin or $30 \mu \mathrm{g} / \mathrm{ml}$ chloramphenicol.

\section{Bacterial strains}

E.coli DH5 $\alpha \mathrm{F}^{-}$endA1 glnV44 thi-1 recA1 relA1 gyrA96 deoR nupG Ф80dlacZLM15 $\Delta\left(\right.$ lacZYA-argF)U169, hsdR17 $\left(\mathrm{r}_{\mathrm{K}}{ }^{-} \mathrm{m}_{\mathrm{K}}{ }^{+}\right), \lambda_{-}$

E.coli BL21 (DE3) $\mathrm{F}^{-}$ompT gal dcm lon hsdS ${ }_{\mathrm{B}}\left(\mathrm{r}_{\mathrm{B}}^{-} \mathrm{m}_{\mathrm{B}}^{-}\right) \lambda($ DE3 [lacl lacUV5-T7 gene 1 ind1 sam7 nin5])

E.coli (DE3) pLysS F- ompT, hsdS(rñ, mñ), dcm, gal, $\lambda(D E 3)$, pLysS, Cmr E.coli pLysE F- ompT, hsdS(rñ, mñ), dcm, gal, $\lambda(\mathrm{DE} 3)$, pLysE, Cmr E.coli Rosetta F- ompT hsdS(r- m-) gal dcm (DE3) pRARE (Cm ) E.coli Rosetts2 F- ompT hsdS(r- m-) gal dcm (DE3) pRARE2 (Cm )

\subsubsection{Cell lines and culture medium}

DMEM (Gibco) supplemented with $10 \%$ (v/v) FBS,

\section{Cell lines}

HEK293T - HEK293 human embryonic kidney cells immortalized by transformation with adenovirus 5 DNA (Graham et al., 1977), and containing SV40 large antigen allowing episomal propagation of SV40 promoter containing plasmid (Lebkowski et al., 1985)

HeLa - human cervix carcinoma cell line 


\subsubsection{Primers}

All primers were custom orders from Operon

$\begin{array}{ll}\# 1209 & \text { GGAAAGGAAGGATCCATGATGGATTCTCCGAAGAT } \\ \# 1210 & \text { CCAAACCAACTCGAGTCAATAATTCTCAAACAGATA } \\ \# 1211 & \text { GGAAAGGAACCATGGGGATGATGGATTCTCCGAAGATTGGA } \\ \# 1212 & \text { CCAAACCAACTCGAGTCATTCCAGTTTAGATGTACATCCTTC } \\ \# 1213 & \text { GGAAAGGACCATGGGGATGCCACTGGAGAGCAAATGTACA } \\ \# 1214 & \text { CCAAACCAACTCGAGTCATATTTTTCTTTCCCAAAAACAAT } \\ \# 1231 & \text { GAAAAATGCTTATGCTCTCAGCTGGTTAGACTGTATCCTGTC } \\ \# 1232 & \text { GACAGGATACAGTCTAACCAGCTGAGAGCATAAGCATTTTTC } \\ \# 1234 & \text { CCAAACCAACTCGAGTCAAGCAGGAACTTCAAATTTCTT } \\ \# 1251 & \text { CCAAACCAACTCGAGTCAAAGTGGAAGGCAGGCAGCTTC } \\ \# 1331 & \text { CCAAACCAACTCGAGTTCCAGTTTAGATGTACATCCTTC } \\ \# 1332 & \text { GGAAAGGAACTCGAGGAATGATGGATTCTCCGAAGTT } \\ \# 1355 & \text { CCAAACCAAGGATCCCCATAATTCTCAAACAGATA }\end{array}$

\subsubsection{Antibodies}

\begin{tabular}{|c|c|c|c|c|}
\hline epitope & type & $\begin{array}{c}\text { dilution } \\
\text { for WB }\end{array}$ & source & $\begin{array}{c}\text { Concentration } \\
{[\mathrm{mg} / \mathrm{ml}]}\end{array}$ \\
\hline $\begin{array}{c}\text { HA } \\
\text { peptide }\end{array}$ & mouse monoclonal & $1: 1000$ & Covance & $2.5-3.5$ \\
\hline $\begin{array}{c}\text { HA } \\
\text { peptide }\end{array}$ & mouse monoclonal & $1: 1000$ & $\begin{array}{c}\text { Niman et al. } \\
1983\end{array}$ & 0.4 \\
\hline GFP & rabbit polyclonal & $1: 1000$ & Santa Cruz & 0.2 \\
\hline & $\begin{array}{c}\text { kindly } \\
\text { provided by } \\
\text { Prof. Ludger } \\
\text { Hengst }\end{array}$ & \\
GST & $\begin{array}{c}\text { rabbit polyclonal } \\
\text { (serum) }\end{array}$ & $1: 10000$ & \begin{tabular}{c} 
Hengst \\
\hline
\end{tabular}
\end{tabular}

\section{Table 2. Primary antibodies}

Horseradish peroxidase-conjugated secondary antibodies anti-mouse ant antirabbit for western blot analysis were obtained from Dianova and were used at a dilution of $1: 10.000$

\subsection{Methods}

\subsubsection{Cloning}

\section{Bacterial strain}

E.coli DH5 $\alpha$

\section{Media}

LB (Lysogeny broth) 


\section{LB plates}

For DNA isolation bacteria were cultured in LB medium supplied with appropriate antibiotic(s) for overnight (12-18 hours) at $37^{\circ} \mathrm{C}$ with vigorous shaking (120-180 rpm).

After DNA transformation bacteria were plated on an LB plate with appropriate antibiotic(s) and incubated overnight (12-18 hours) at $37^{\circ} \mathrm{C}$.

\subsubsection{DNA isolation}

DNA isolation was based on alkaline lysis method (Birnboim and Doly 1979). SDS breaks the cell membrane, while sodium hydroxide denatures proteins and genomic DNA. Plasmid DNA stays in solution and can be recovered.

\section{Small scale DNA isolation (mini prep)}

Materials

Solutions of:

P1 (50 mM Tris-HCl, 10 mM EDTA, $100 \mu \mathrm{g} / \mathrm{ml}$ RNase A, pH 8)

P2 (200 mM NaOH, 1\% (v/v) SDS)

P3 (3 M KOH pH 5.5)

2-propanol

$70 \%$ ethanol

TE buffer

LB medium supplied with appropriate antibiotic

A single bacterial colony was used to inoculate $3 \mathrm{ml}$ of LB medium with appropriate antibiotic. After overnight growth (16-20 hours) the cells were pelleted by centrifugation, suspended in $300 \mu \mathrm{l}$ of $\mathrm{P} 1$ solution, lysed by addition of $300 \mu \mathrm{l}$ of P2 solution and incubated for $5 \mathrm{~min}$ at room temperature. Adding 300 $\mu l$ of P3 solution precipitated proteins and genomic DNA. After 30 minutes on ice soluble fraction was obtained by centrifugation, from which DNA was precipitated by adding 0.8 volumes of 2-propanol and centrifugation. Precipitated DNA was 
washed with $70 \%$ ethanol and dried. Obtained DNA pellet was solubilized in $50 \mu \mathrm{l}$ of TE buffer.

\section{Medium scale plasmid DNA isolation (midi prep)}

\section{Materials}

LB medium supplemented with appropriate antibiotic

Macherey\&Nagel Midi Prep Kit

TE

A single bacterial colony was used to inoculate $50 \mathrm{ml}$ of LB medium with appropriate antibiotic. After overnight growth (16-20 hours) the cells were pelleted by centrifugation. DNA was purified using a Macherey \& Nagel kit following the manufacturers' instructions. Concentration and purity were determined by measuring absorbance at 280 and $260 \mathrm{~nm}$.

\subsubsection{Restriction digestion}

\section{Materials}

Restriction enzymes supplied with reaction buffer (Fermentas)

For control restriction $10 \mu \mathrm{l}$ (approximately $0.5-3 \mu \mathrm{g}$ ) of mini prep DNA was digested using $2 \mathrm{U}$ of an enzyme for 1 hour at appropriate temperature (generally $37^{\circ} \mathrm{C}$ ) in total reaction volume of $50 \mu \mathrm{l}$.

For preparative digestion $2 \mu \mathrm{g}$ of DNA was digested using $10 \mathrm{U}$ of an enzyme for 2 hours at appropriate temperature (generally $37^{\circ} \mathrm{C}$ ).

\subsubsection{DNA separation and extraction}

Materials

TAE buffer (40 mM Tris acetate, $1 \mathrm{mM}$ EDTA, $\mathrm{pH} 7.7$ )

TE buffer 
DNA was resolved by electrophoresis on agarose gel $(1-2 \%(\mathrm{w} / \mathrm{v})$ agarose in TAE buffer at $80 \mathrm{~V}$. DNA was visualized by staining in an ethidium bromide bath and exposure to UV light (365nm). Gel slices containing desired DNA were excised and DNA was extracted using a Macherey \& Nagel kit following the manufacturers' instructions. DNA was eluted in $30 \mu \mathrm{l}$ of TE buffer.

\subsubsection{Ligation}

The ligation procedure is based on T4 phage DNA ligase's ability to catalyze formation of phosphodiester bond between juxtaposed 5'-phosphate and 3'hydroxyl termini in duplex DNA (Weiss et al., 1968)

\section{Materials}

ATP stock solution

T4 DNA ligase supplied with reaction buffer (Fermentas)

Ligations were performed using 50-100 ng of vector with triple molar excess of insert. Reactions were performed in presence of $5 \mathrm{nM}$ ATP and 2 Weiss Units of T4 DNA ligase in a total volume of $20 \mu \mathrm{l}$ for one 1 hour at room temperature. To inactivate the ligase, reactions were incubated at $65^{\circ} \mathrm{C}$ for 15 minutes. Usually, $10 \mu \mathrm{l}$ of reaction was used for bacterial transformation.

\subsubsection{PCR reactions}

Polymerase chain reaction (PCR) is based on a logarithmic amplification of desired DNA fragment using primers flanking it on 5' and 3' (Kleppe and Khorana 1971). The sequential cycles and the logarithmic amplification are possible due to application of thermostable polymerase that is not deactivated during denaturing process (Mullis et al., 1986)

\section{Materials}

Phusion polymerase supplied with reaction buffer (Finnzymes) 
Mix of four dNTPs (Fermentas)

Primers (custom order, Operon)

To amplify DNA fragment 100ng of template DNA was mixed with forward and reverse primers (final concentration of $500 \mathrm{~nm}$ each), each of four dNTPs (final concentration of each $250 \mu \mathrm{M}), 1 \mathrm{U}$ of polymerase in a final volume of $50 \mu \mathrm{l}$. Reaction was subjected to $30 \mathrm{sec}$ of initial denaturation at $98^{\circ} \mathrm{C}$, followed by 30 cycles of: 10 seconds of denaturation at $98^{\circ} \mathrm{C}, 30$ seconds of annealing at appropriate temperature, 25 seconds $/ 1 \mathrm{kB}$ of amplified fragment of extension at $72^{\circ} \mathrm{C}$. The final step involved 10 minutes of extension at $72^{\circ} \mathrm{C}$.

Annealing temperature was determined using an online tool priveded by manufacturer (www.finnzymes.fi/tm determination.htm). The exact PCR conditions are summarized in Table 3.

\begin{tabular}{|c|c|c|}
\hline $\begin{array}{c}\text { primers } \\
\# 1209 / \# 1210\end{array}$ & $\begin{array}{c}\mathrm{T} \\
\text { annealing } \\
{\left[{ }^{\circ} \mathrm{C}\right]}\end{array}$ & $\begin{array}{c}\text { time of } \\
\text { extension } \\
{[\mathrm{sec}]}\end{array}$ \\
\hline$\# 1213 / \# 1251$ & 55 & 75 \\
\hline$\# 1213 / \# 1234$ & 71 & 20 \\
\hline$\# 1213 / \# 1214$ & 71 & 20 \\
\hline$\# 1231 / 1232$ & 71 & 20 \\
\hline$\# 1211 / \# 1212$ & 72 & 180 \\
\hline$\# 1211 / \# 1331$ & 67 & 20 \\
\hline$\# 1332 / 1355$ & 67 & 20 \\
\hline & 69 & 75 \\
\hline
\end{tabular}

Table 3. PCR conditions.

\subsubsection{Site-directed mutagenesis}

The approach described here is adopted from stratagen site-directed mutagenesis kit. Using of primers complementary to each other and partially complementary to template DNA allows for introduction of desired mutation. Contrary to PCR the newly synthesized DNA is not a template for the further 
synthesis. Restriction digestion with $D p n$ l removes template (if methylated) DNA but not newly synthesized.

\section{Materials}

Same as for PCR reaction

Dpnl (Fermentas)

Primers (custom order, Operon)

The reaction was set up as for the PCR using increasing amount of DNA, from 5 to $50 \mathrm{ng}$ of template DNA. Extension time was modified to 30 seconds $/ 1 \mathrm{kB}$ of the template. Primers were designed using the online the onlinetool, PrimerX. (www.bioinformatics.org/primerx/). Annealing temperature was calculated using an online tool (www.finnzymes.fi/tm determination.htm). $25 \mu \mathrm{l}$ of the reaction product was digested with $1 \mathrm{U}$ of Dpnl enzyme for 1 hour at $37^{\circ} \mathrm{C}$ and transformed into E. coli. Conditions for site directed mutagenesis of USPL1 are given in Table 3. 


\begin{tabular}{|c|c|c|c|c|c|c|}
\hline \# & construct & $\begin{array}{l}\text { primers/source } \\
\text { of the insert }\end{array}$ & template & restrictio site & purpose & remarks \\
\hline 1 & $\begin{array}{l}\text { pcDNA3.1-HA- } \\
\text { USPL1 }\end{array}$ & \#1209/\#1210 & $\begin{array}{l}\text { HeLa cDNA } \\
\text { (kindly } \\
\text { provided by } \\
\text { Dr. Ruth } \\
\text { Geiss- } \\
\text { Friedlander) }\end{array}$ & BamHI/Xho1 & $\begin{array}{l}\text { mammalian } \\
\text { expression }\end{array}$ & $\begin{array}{l}\text { N-term } \\
\text { HA tag }\end{array}$ \\
\hline 2 & $\begin{array}{l}\text { pcDNA3.1- } \\
\text { FLAG-USPL1 }\end{array}$ & contruct 1 & & BamHI/Xho1 & $\begin{array}{l}\text { mammalian } \\
\text { expression }\end{array}$ & $\begin{array}{l}\text { N-term } \\
\text { FLAG- } \\
\text { tag }\end{array}$ \\
\hline 3 & $\begin{array}{l}\text { pETM30- } \\
\text { USPL1cat(212- } \\
514)\end{array}$ & \#1213/\#1251 & contruct 1 & Ncol/Xhol & $\begin{array}{l}\text { bacterial } \\
\text { expression }\end{array}$ & $\begin{array}{l}\text { N-term } \\
\text { HIS- } \\
\text { GST- } \\
\text { TEV }\end{array}$ \\
\hline 4 & $\begin{array}{l}\text { pETM30- } \\
\text { USPL1cat(212- } \\
\text { 498) }\end{array}$ & $\# 1213 / \# 1234$ & contruct 1 & Ncol/Xhol & $\begin{array}{l}\text { bacterial } \\
\text { expression }\end{array}$ & $\begin{array}{l}\text { N-term } \\
\text { HIS- } \\
\text { GST- } \\
\text { TEV } \\
\end{array}$ \\
\hline 5 & $\begin{array}{l}\text { pETM30- } \\
\text { USPL1cat(212- } \\
502)\end{array}$ & $\# 1213 / \# 1214$ & contruct 1 & $\mathrm{Ncol} / \mathrm{Xhol}$ & $\begin{array}{l}\text { bacterial } \\
\text { expression }\end{array}$ & $\begin{array}{l}\text { N-term } \\
\text { HIS- } \\
\text { GST- } \\
\text { TEV }\end{array}$ \\
\hline 6 & $\begin{array}{l}\text { pcDNA3.1-HA- } \\
\text { USPL1 C236S }\end{array}$ & $\# 1231 / 1232$ & contruct 1 & BamHI/Xho1 & $\begin{array}{l}\text { mammalian } \\
\text { expression }\end{array}$ & $\begin{array}{l}\text { N-term } \\
\text { HA tag } \\
\text { catalytic } \\
\text { mutant }\end{array}$ \\
\hline 7 & $\begin{array}{l}\text { pETM30- } \\
\text { USPL1cat(212- } \\
\text { 514)C236S }\end{array}$ & $\# 1231 / 1232$ & contruct 3 & BamHI/Xho1 & $\begin{array}{l}\text { bacterial } \\
\text { expression }\end{array}$ & $\begin{array}{l}\text { N-term } \\
\text { HIS- } \\
\text { GST- } \\
\text { TEV } \\
\text { catalytic } \\
\text { mutant }\end{array}$ \\
\hline 8 & $\begin{array}{l}\text { pETM30- } \\
\text { USPL1(1-212) }\end{array}$ & \#1211/\#1212 & contruct 1 & Ncol/Xhol & $\begin{array}{l}\text { bacterial } \\
\text { expression }\end{array}$ & $\begin{array}{l}\text { N-term } \\
\text { HIS- } \\
\text { GST- } \\
\text { TEV }\end{array}$ \\
\hline 9 & pET28b-USPL1 & contruct 1 & & BamHI/Xho1 & $\begin{array}{l}\text { bacterial } \\
\text { expression }\end{array}$ & $\begin{array}{l}\text { N-term } \\
\text { His }\end{array}$ \\
\hline 10 & $\begin{array}{l}\text { pET28b- } \\
\text { USPL1-1-212 }\end{array}$ & $\# 1211 / \# 1331$ & contruct 1 & $\mathrm{Ncol} / \mathrm{Xhol}$ & $\begin{array}{l}\text { bacterial } \\
\text { expression }\end{array}$ & $\begin{array}{l}\text { C-term } \\
\text { His }\end{array}$ \\
\hline 11 & pEYFP-USPL1 & \#1332/1355 & contruct 1 & Xhol/BamHI & $\begin{array}{l}\text { mammalian } \\
\text { expression }\end{array}$ & $\begin{array}{l}\text { N-term } \\
\text { YFP }\end{array}$ \\
\hline 12 & pECFP-USPL1 & $\# 1332 / 1355$ & contruct 1 & Xhol/BamHI & $\begin{array}{l}\text { mammalian } \\
\text { expression }\end{array}$ & $\begin{array}{l}\text { N-term } \\
\text { CFP }\end{array}$ \\
\hline
\end{tabular}

Table 4. Constructs prepared and used during this work 


\subsubsection{Transformation of bacteria}

Materials:

Aliquot of competent E.coli (aviable as a general lab stock)

LB medium (without antibiotics)

LB plate supplemented with required antibiotic

Bacteria were transformed using the heat shock method (Hanahan 1983): an aliquot of competent bacteria was thawed and incubated on ice with DNA for 15 minutes. Cells were subjected to a heat shock $\left(42^{\circ} \mathrm{C} 45 \mathrm{sec}\right)$ and incubated on ice for 2 minutes. $900 \mu \mathrm{l}$ of LB medium without antibiotics was added and cells were grown for 1 hour at $37^{\circ} \mathrm{C}$ before plating them on LB-agar containing appropriate antibiotic.

\subsubsection{Cell culture methods}

\subsubsection{Cultivation of mammalian cell lines}

Materials

DMEM (PAA)

Trypsine (Gibco)

EDTA (PAA)

Human embryonic kidney (HEK293T) cell line

penicillin and streptomycin

glutamine (cell culture grade) Gibco

PBS

HEK293T were grown in DMEM medium supplemented with $10 \%$ fetal bovine serum, glutamine and antibiotics (penicillin and streptomycin) at $37^{\circ} \mathrm{C}$ with $5 \%$ $\mathrm{CO}_{2}$. After reaching confluence they were split in 1 to 10 ration. To do so, cells were washed twice with sterile PBS (warmed up to $37^{\circ} \mathrm{C}$ ) and incubated with trypsine/EDTA. After they detached fresh medium was added to stop the trypsinization reaction and to dilute the cells to desired density before placing 
them on a fresh dish.

\subsubsection{Transfection of HEK293T cells by calcium phosphate method.}

\section{Materials}

1/10 TE buffer ( $1 \mathrm{mM}$ Tris, $0.1 \mathrm{mM}$ EDTA $\mathrm{pH}$ 7.5)

$500 \mathrm{mM} \mathrm{CaCl}_{2}$

2 x HBS (50mM HEPES, $\left.280 \mathrm{mM} \mathrm{NaCl}, 15 \mathrm{mM} \mathrm{NaPO}_{4} \mathrm{pH}^{7.1}\right)$

$10^{6}$ HEK 293 T cells were plated on the $10 \mathrm{~cm}$ dish 24 hours before transfection.

$2 \mu \mathrm{g}$ of plasmid DNA was mixed with 1/10 TE so that the final volume was $250 \mu \mathrm{l}$ and $250 \mu \mathrm{l}$ of $500 \mathrm{mM} \mathrm{CaCl}_{2}$ was added. To the DNA/ $\mathrm{CaCl}_{2}$ solution $500 \mu \mathrm{l}$ of $2 \mathrm{x}$ HBS was added in a dropwise manner with vigorous shaking. The mixture was incubated until visible precipitate was formed (usually 10-20 minutes) and added to the cells. The medium was exchanged 6 hours after transfection.

\subsubsection{Biochemical methods}

\subsubsection{Preparation of HeLa cell lysate}

Materials

Frozen HeLa cell pellet (RELIATech, Wolfenbüttel)

Transport buffer (TB) supplemented with $1 \mathrm{mM}$ DTT, $1 \mu \mathrm{M}$ PMSF and $1 \mu \mathrm{g} / \mathrm{ml}$ each of aprotinin, leupeptin, pepstatin

HeLa cell pellet was thawed in 2 volumes of TB, centrifuged at $1500 \mathrm{~g}$ for 10 minutes to remove cell nuclei and debris. Supernatant was centrifuged first at $15.000 \mathrm{~g}$ for 25 minuets, and than at $100.000 \mathrm{~g}$ for 60 minutes. The supernatant from the last step is referred to as a HeLa cell lysate. It was aliquoted, flash frozen in liquid nitrogen and stored at $-80^{\circ} \mathrm{C}$. 


\subsubsection{Preparation of detergent extracts of HEK293T}

\section{Materials}

PBS

Lysis buffer (100 mM Tris, $150 \mathrm{mM} \mathrm{NaCl}, 5 \%$ Glycerol, $1 \%$ Triton X-100, pH 7.5) supplemented with $1 \mathrm{mM}$ DTT, $1 \mu \mathrm{M}$ PMSF and $1 \mu \mathrm{g} / \mathrm{ml}$ each of aprotinin, leupeptin, pepstatin)

All steps were performed at $4^{\circ} \mathrm{C}$. $1 \mathrm{ml}$ of lysis buffer was used for one $10 \mathrm{~cm}$ dish of HEK293T cells at $60-70 \%$ confluence $\left(\sim 7 \times 10^{6}\right.$ cells). The medium was aspirated, cells were washed carefully twice with ice cold PBS and lysed in $1 \mathrm{ml}$ of lysis buffer for 30 minutes on the rocking platform. Lysate was collected and centrifuged for 10 minutes at $14.000 \mathrm{rpm}$ in a table-top centrifuge. The supernatant containing extracted proteins was transferred to a new tube and, if not used immediately, it was flesh-frozen in liquid nitrogen.

\subsubsection{Immunopurification of HA-tagged USPL1 from detergent extracts Materials}

Anti-HA-agarose (Sigma)

HA peptide (Biomol)

All steps were performed at $4^{\circ} \mathrm{C}$ and samples were centrifuged in a tabletop centrifuge at $2000 \mathrm{rpm}$ for 20 seconds unless indicated otherwise. The first step was omitted in case of a freshly prepared extract. $1 \mathrm{ml}$ of detergent extract was centrifuged in a tabletop centrifuge at $14.000 \mathrm{rpm}$ for 10 minutes. $950 \mu \mathrm{l}$ were transferred to a fresh tube and incubated with $15 \mu \mathrm{l}$ of anti-HA agarose for 2 hours. After centrifugation, beads were extensively washed with a lysis buffer and transferred to a fresh tube. Bound proteins were eluted twice with $30 \mu \mathrm{l}$ of an HA-peptide $\left(0.2 \mathrm{mg} / \mathrm{ml}\right.$ in lysis buffer) at $30^{\circ} \mathrm{C}$ for 15 minutes. Eluates were combined. 


\subsubsection{Labeling of HeLa cell lysate proteins with SUMO-Vme and their enrichment by immunopurification.}

\section{Materials}

SUMO -Vinymmelthylester ,SUMO-VME (see later part of this chapter)

HeLa cell lysate

Protein-A-agarose (Roche)

Anti-HA-agarose (Sigma)

HA peptide (Biomol)

$1 \mathrm{ml}$ of Transport buffer $+1 \%$ Triton X-100

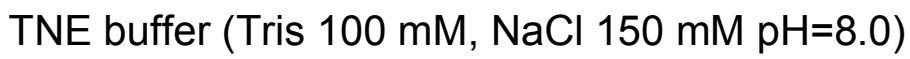

RIPA buffer $(50 \mathrm{mM}$ Tris-HCl $150 \mathrm{mM} \mathrm{NaCl}, 1 \%$ (v/v) nonidet P-40, 0.5

$\%(\mathrm{w} / \mathrm{v})$ Na-desoxycholate, $0.1 \%$ (w/v) SDS, , pH 8 )

All buffers supplemented $1 \mathrm{mM}$ DTT, $1 \mu \mathrm{M}$ PMSF and $1 \mu \mathrm{g} / \mathrm{ml}$ each of aprotinin, leupeptin, pepstatin

The amounts of used reagents are optimal to label and enrich proteins using 1.5 $\mathrm{ml}$ of HeLa cell lysate at $\sim 10 \mathrm{mg} / \mathrm{ml}$ protein concentration.

The HeLa cell lysate was centrifuged at $100.000 \mathrm{~g}$ for 20 minutes at $4^{\circ} \mathrm{C}$, and incubated for 30 minutes at $37^{\circ} \mathrm{C}$ with $600 \mathrm{ng}$ of SUMO-1-VME or $450 \mathrm{ng}$ of SUMO-2-VME. From now on all steps were carried out at $4^{\circ} \mathrm{C}$. To remove aggregated or precipitated proteins, lysates were centrifuged for 20 minutes at $100.000 \mathrm{~g}$. Supernatants were incubated with $20 \mu \mathrm{l}$ of Protein-A agarose for 1 hour for preclearing. After pelleting Protein-A agarose (2000 rpm, 20 seconds) supernatant was incubated with $20 \mu \mathrm{l}$ of Anti-HA-agarose for 2 hours. Beads were collected by centrifugation and subjected to the following washes:

1) $1 \mathrm{ml}$ of TNE buffer

2) $1 \mathrm{ml}$ of the TNE buffer with $\mathrm{NaCl}$ concentration adjusted to $500 \mathrm{mM}$

3) $1 \mathrm{ml}$ of RIPA buffer 
4) $1 \mathrm{ml}$ of TB $+1 \%$ Triton $\mathrm{X}-100$

Subsequently beads were transferred to a fresh tube, washed with $1 \mathrm{ml} 1 \mathrm{ml}$ of TB $+1 \%$ Triton $\mathrm{X}-100$, and the bound proteins were eluted twice with $30 \mu \mathrm{l}$ of an HA-peptide $\left(0.2 \mathrm{mg} / \mathrm{ml}\right.$ in TB $+1 \%$ Triton X-100) for 15 minutes at $30^{\circ} \mathrm{C}$. Eluates were combined and flash frozen.

\subsubsection{Enrichment of the paralogue specific proteases.}

The general scheme of the purification is shown in Figure 11.

The first step involved labeling of proteins of HeLa cell lysates by treatment with SUMO-1-VME. The procedure was carried out as described above, however the amount of used SUMO-1-Vme was $1000 \mathrm{ng}$ per $1.5 \mathrm{ml}$ of lysate. The elution amount of used protein-A-agarose or anti-HA-agarose and elution volume remained unchanged. The supernatant after immunoprecipitation was kept.

The second step involved the labeling of proteins with SUMO-2-Vme using HeLa lysate depleted of SUMO-1-Vme reactive proteins (supernatant from the first step). For labeling, $600 \mathrm{ng}$ SUMO-2-VME was used and the immunopurification was carried out as in the first step omitting incubation with protein-A-agarose.

\subsubsection{Identification of labeled proteins by Mass Spectrometry}

For Mass Spectrometry analysis the enrichment of paralogue specific proteases was carried out using $25 \mathrm{ml}$ of HeLa cell extract, $10 \mu \mathrm{g}$ of SUMO-1-VME and 10 $\mu \mathrm{g}$ of SUMO-2-VME. The amount of used Protein-A-agarose and anti-HAagarose was $120 \mu \mathrm{l}$. The Elution volume was $250 \mu \mathrm{l}$.

Mass Spec identification of immunoprecipitated proteins was carried out in collaboration with Dr. Henning Urlaub (Department of Mass Spectrometry, MaxPlanck Institute for Biophysical Chemistry, Göttingen). Sample preparation and MS analysis was performed by Monika Raabe. I carried out peptide identification using MASCOT software. 


\subsubsection{SDS-PAGE electrophoresis}

SDS polyacrylamide gel electrophoresis was performed according to the system described by Laemmli (Laemmli, 1970 )

Materials

Acrylamide solution, $30 \%$, 37.5:1 AA:bisAA (Applichem)

ammonium persulfate (APS) $10 \%(\mathrm{w} / \mathrm{v})$ stock solution

TEMED

Resolving gel solution (0.4 M Tris- $\mathrm{HCl} \mathrm{pH} 8.8,0.1 \%$ (w.v) SDS, acrylamide at desired concentration)

Stacking gel solution $(50 \mathrm{mM}$ Tris- $\mathrm{HCl} \mathrm{pH}$ 6,8, $0.1 \%(\mathrm{w} / \mathrm{v})$ SDS, $4 \%(\mathrm{w} / \mathrm{v})$ acrylamide)

Laemlli buffer (25 mM Tris, $192 \mathrm{mM}$ glycine, $0.05 \%$ (w/v) SDS, $\mathrm{pH}=8.3$ )

2x sample buffer (100 mM Tris, 4\% (w/v) SDS, $0.2 \%(w / v)$ bromophenol blue, $20 \%$ (v/v) glycerol, $200 \mathrm{mM} \mathrm{DTT}, \mathrm{pH}=6.8$ )

4x sample buffer $(200 \mathrm{mM}$ Tris, $8 \%$ (w/v) SDS, $0.4 \%(\mathrm{w} / \mathrm{v})$ bromophenol blue, $40 \%(\mathrm{v} / \mathrm{v})$ glycerol, $400 \mathrm{mM}$ DTT, $\mathrm{pH}=6.8$ )

Unstained $10 \mathrm{kDa}$ protein marker (Fermentas)

Gel casting chamber

\section{Polyacrylamide gel preparation}

Gels were prepared in batch by putting polyacrylamide solutions between glass plates in a casting chamber that accommodated eight gels.

$\sim 70 \mathrm{ml}$ of desired PAA concentration resolving gel solution was prepared. Polymerization was initiated by addition of APS $(0.06 \%(\mathrm{w} / \mathrm{v})$ final concentration) and TEMED $(0.06 \%(\mathrm{v} / \mathrm{v})$ final concentration), the solution was poured into the chamber and overlaid with 2-propanol to prevent oxygen access. After the gel polymerized, 2-propanol was removed and stacking gel solution in which polymerization was initiated by addition of APS $(0.1 \%(\mathrm{w} / \mathrm{v})$ final concentration) and TEMED $(0.1 \%(v / v)$ final concentration) was put on the top of resolving gel. 
If not used immediately after polymerization gels were stored at $4^{\circ} \mathrm{C}$ up to one week.

$5-20 \%$ resolving gradient gels were prepared by placing equal volumes of $5 \%$ and $20 \%$ gel solutions in a cylindrical gradient mixer connected to the casting chamber.

Polypeptides in sample were denatured by adding sample buffer to final concentration of $1 \mathrm{x}$ and incubation at $95^{\circ} \mathrm{C}$ for 5 minutes. After loading sample on the gel electrophoresis was performed in Laemlli buffer at $22 \mathrm{~mA}$ per gel until the dye run out from the gel.

\subsubsection{Coommassie staining}

\section{Materials}

Commassie blue stain solution $(0.025 \%$ Commassie R-250, $10 \%(\mathrm{v} / \mathrm{v})$ Acetic Acid, $40 \%(\mathrm{v} / \mathrm{v})$ methanol)

Destaining solution (10\% (v/v) Acetic Acid, 40\% (v/v) methanol)

After the electrophoresis the gels were incubated in Coommassie blue stain solution until completely stained (usually between 60 minutes to overnight). To destain, gels were incubated for several hours at room temperature on the rocking platform with frequent solution changes.

\subsubsection{Immunoblotting}

\section{Materials}

Nitrocellulose membrane (Schleicher \& Schuell)

Primary and secondary antibodies

Transfer buffer (25 mM Tris, $193 \mathrm{mM}$ glycine, $20 \%(\mathrm{v} / \mathrm{v})$ methanol, $0.036 \%(\mathrm{w} / \mathrm{v})$ SDS)

PBST solution

Blocking solution (5\% skim milt in PBST) 
Primary and secondary antibodies

X-ray film (GE Healthcare)

ECL kit (Millipore)

PonceauS solution $(0.5 \%(\mathrm{w} / \mathrm{v})$ PonceauS in $1 \%(\mathrm{v} / \mathrm{v})$ acetic acid )

Whatman paper stacks were soaked in transfer buffer. The membrane was soaked first with water and than with transfer buffer. The electrophoresis sandwich was built up as following: from the bottom: 3 stacks of the Whatman paper, membrane, gel, 3 stacks of the Whatman paper. The proteins were transferred at $200 \mathrm{~mA}$ for 1 hour at room temperature in a semi-dry western blotting chamber. After transfer, the membrane was stained with PonceauS solution and incubated in a blocking solution for at least 1 hour at room temperature. The primary antibody was applied for 1 hour at room temperature in blocking buffer solution. The secondary antibody was applied for 1 hour at room temperature in blocking solution. After each antibody incubation the membrane was washed 4 times with PBST solution for 15 minutes at room temperature. Proteins were visualized using ECL kit and exposed on a X-ray film. An exposure time of 2 minutes was usually sufficient. Film was developed using automated developer.

\subsubsection{Recombinant protein purification}

\subsubsection{USPL1 catalytic domain}

Materials

pET30M-USPL1cat(212-514) expression plasmid

E.coli (DE3) Rosetta2 strain

$5 \mathrm{~L}$ baffled Erlenmeyer flask

LB medium supplemented with kanamycine $50 \mu \mathrm{g} / \mathrm{ml}$ and chloramphenicole 34 $\mu \mathrm{g} / \mathrm{ml}$

IPTG 
Lysis buffer (50 mM Tris, $100 \mathrm{mM} \mathrm{NaCl}, \mathrm{pH}$ 8.0) supplemented with $1 \mu \mathrm{g} / \mathrm{ml}$ each of aprotinin, pepstatin, leupeptin and 1mM PMSF and DTT

High pressure homogenizer (Avestin)

Elution buffer (10 mM reduced glutathione in lysis buffer)

Glutathione Sepharose 4B (GE Healthcare)

Reduced glutathione

Ni-NTA Agarose (QIAGEN)

TEV protease (our laboratory common stock)

HiLoad 26/60 Superdex 75 pg, GE Healthcare

AKTA purifier (GE Healthcare)

Transport buffer supplemented with $1 \mu \mathrm{g} / \mathrm{ml}$ each of aprotinin, pepstatin, leupeptin and $1 \mathrm{mM}$ PMSF and $1 \mathrm{mM}$ DTT

Protein concentrator with 10kDa cut off, VIVASPIN, (Sartorius)

Low protein binding filters $-0.2 \mu \mathrm{m}$ (Acrodisc LC25, PALL Life Sciences)

The construct, which expression resulted in soluble catalytic domain contained amino acid residues 212-514 of USPL1 (see results section for further details).

One aliquot of competent bacteria was transformed by heat shock method with pET30M-USPL1cat plasmid. After recovery the whole aliquot was transferred directly into $20 \mathrm{ml}$ of LB medium containing antibiotics, and grown overnight (1418 hours) at $37^{\circ} \mathrm{C}, 150 \mathrm{rpm}$ shaking. The following day the culture was diluted to $\mathrm{OD}_{600}$ between 0.05 and 0.1 in a final volume of 1 liter, and grown until $\mathrm{OD}_{600}$ reached 0.6-0.7. Bacteria were induced by adding IPTG to final concentration of $0.5 \mathrm{mM}$ and grown for $16-20$ hours at $15^{\circ} \mathrm{C}, 150 \mathrm{rpm}$ shaking. The bacteria were collected by a centrifugation and suspended in $50 \mathrm{ml}$ of ice cold lysis buffer. From now all steps were carried out at $4^{\circ} \mathrm{C}$. Bacteria were lysed using high pressure homogenizer, and obtained lysate was cleared by centrifugation (100.000 g, 60 minutes). Supernatant was incubated for 2 hours at a rocking platform with $5 \mathrm{ml}$ of glutathione-agarose equilibrated with lysis buffer. Agarose was collected by passage through a plastic column and washed with $25 \mathrm{ml}$ of lysis buffer. Bound protein was eluted twice with $10 \mathrm{ml}$ of lysis buffer 
supplemented with $50 \mathrm{mM}$ glutathione. Eluted HIS-GST-TEV-USPL1cat fusion protein was digested for at least 12 hours with TEV protease. $10 \mu \mathrm{g}$ of HIS-TEV protease was sufficient to digest $1 \mathrm{mg}$ of the fusion protein. To remove uncleaved protein, free HIS-GST and HIS-TEV, $2 \mathrm{ml}$ of NiT-Agarose was added. After 2 hours of incubation the supernatant was collected. At this point DTT was added to $5 \mathrm{mM}$ final concentration and supernatant was concentrated to $2 \mathrm{ml}$ using protein concentrator. Aggregated proteins were removed by centrifugation and subsequent passage through a $0.2 \mu \mathrm{m}$ filter. Sample was applied to a preparative S-75 column equilibrated in Transport buffer, mounted on an Akta Purifier. Protein containing fractions were analyzed by $12 \%$ SDS-PAGE followed by coomassie staining. The cleanest fractions containing USPL1cat were polled, concentrated down to $1 \mathrm{ml}$, aliquoted and flash frozen. Aliquots were stored at $80^{\circ} \mathrm{C}$.

\subsubsection{Purification of YFP-SUMO and CFP-GAP}

Purification was performed according to published protocols (Bossis et al., 2005, Stankovic-Valentin et al., 2009)

\section{Materials}

E.coli (DE3) Rosetta strain

LB medium supplemented with ampicilline $100 \mu \mathrm{g} / \mathrm{ml}$

LB agar plate supplemented with ampicilline $100 \mu \mathrm{g} / \mathrm{ml}$ IPTG

YFP-SUMO Lysis buffer ( $50 \mathrm{mM}$ Tris, $50 \mathrm{mM} \mathrm{NaCl}, 1 \mathrm{mM}$ EDTA pH=8.0)

CFP-SUMO Lysis buffer (50 mM Tris, $20 \mathrm{mM} \mathrm{NaCl}, 1 \mathrm{mM}$ EDTA pH=8.0)

DTT, aprotinin, pepstatin, leupeptin, PMSF, DTT

Buffer A ( $50 \mathrm{mM}$ Tris $\mathrm{pH}=8.0$ ) with $1 \mu \mathrm{g} / \mathrm{ml}$ each of aprotinin, pepstatin, leupeptin and $1 \mathrm{mM}$ PMSF and $1 \mathrm{mM}$ DTT

Buffer B (50 mM Tris $\mathrm{pH}=8.0)$ with $1 \mu \mathrm{g} / \mathrm{ml}$ each of aprotinin, pepstatin, leupeptin and $1 \mathrm{mM}$ PMSF and $1 \mathrm{mM}$ DTT

HiLoad 26/60 Superdex 75 pg (preparative S-75 column), GE Healthcare 
HiTrap Q FF 5 ml (Q sepharose column), GE Healthcare

AKTA prime (GE Healthcare)

AKTA purifier (GE Healthcare)

Lysozyme stock solution $(25 \mathrm{mg} / \mathrm{ml})$

Transport buffer supplemented with $1 \mu \mathrm{g} / \mathrm{ml}$ each of aprotinin, pepstatin, leupeptin and $1 \mathrm{mM}$ PMSF and $1 \mathrm{mM}$ DTT

Protein concentrator with 10kDa cut off, VIVASPIN, (Sartorius)

Low protein binding filters $-0.2 \mu \mathrm{m}$ (Acrodisc LC25, PALL Life Sciences)

The procedure is the same for YFP-SUMO-1 and YFP-SUMO-2.

E. coli Rosetta (DE3) were transformed with appropriate plasmids, plated on LB agar and incubated overnight at $37^{\circ} \mathrm{C}$. A single colony was used to inoculate 500 $\mathrm{ml}$ of LB medium. The culture was grown overnight at $37^{\circ} \mathrm{C}$ with $150 \mathrm{rpm}$ shaking. The following day bacteria were collected by centrifugation and resuspended in fresh 2 I of LB medium. Protein expression was induced by adding IPTG to final concentration of $1 \mathrm{mM}$ and the culture was grown for 6 hours. Bacteria were collected by centrifugation, the pellet was resuspended in $50 \mathrm{ml}$ of appropriate lysis buffer and subjected to a freeze thaw cycle. At this point protein inhibitors were added were added to final concentration of $1 \mu \mathrm{g} / \mathrm{ml}$ each, DTT to $1 \mathrm{mM}$ and lysozyme to $1 \mathrm{mg} / \mathrm{ml}$. From now on all procedures were carried out at $4^{\circ} \mathrm{C}$. The mixture was incubated for 60 minutes on ice with frequent shaking, and clarified by centrifugation (100.000 g 60 minutes). After passage through $0.2 \mu \mathrm{m}$ filter $25 \mathrm{ml}$ of supernatant was loaded on a Q-sehparose column (equilibrated with $95 \%$ buffer A, $5 \%$ buffer B for YPF-SUMO purification, or $98 \%$ buffer $A, 2 \%$ buffer B for CFP-GAPtail purification) mounted to the AKTA prime. The column was washed with $20 \mathrm{mls}$ of appropriate lysis buffer and proteins were eluted with linear gradient of $\mathrm{NaCl}$ up to $500 \mathrm{mM}$, with $200 \mathrm{ml}$ length of the gradient. Fractions of $5 \mathrm{ml}$ were collected and the ones with yellow color were analyzed by $12 \%$ SDS-PAGE followed by coomassie staining. The same procedure was applied to the remaining $25 \mathrm{ml}$ of supernatant. Fractions containing the fusion 
protein were concentrated using a protein concentrator, precipitated protein was removed by centrifugation and the supernatant was applied to a S-75 preparative column equilibrated with transport buffer. Yellow fractions were analyzed by $12 \%$ SDS-PAGE followed by coomassie staining. The cleanest fractions were concentrated down to $1 \mathrm{mg} / \mathrm{ml}$, aliquoted, flesh frozen and stored at $-80^{\circ} \mathrm{C}$. The yield was $10 \mathrm{mg}$ of YFP-SUMO and $2 \mathrm{mg}$ of CFPGaptail per 1 liter of culture

\subsubsection{SUMO-VME synthesis and purification}

SUMO-Vinylmethylester (SUMO-VME) is a recombinant SUMO modified the C-teminus with vinylmethylester, which resembles peptide bond, and can covalently bind SUMO proteases. The synthesis of SUMO-VME is based on a intein-based chemical ligation method (Chong et al., 1997, Cotton and Muir 1999).(See results section for further details).

The procedure can be divided into two steps: 1) preparation Strep-TEV-HASUMO-MESNa 2) Synthesis and purification of Strep-TEV-HA-SUMO-VMe. The procedure is identical for SUMO-1 and SUMO-2

\section{Materials}

E.coli (DE3) BL21 strain

LB medium supplemented with ampicilline $100 \mu \mathrm{g} / \mathrm{ml}$

LB agar plate supplemented with ampicilline $100 \mu \mathrm{g} / \mathrm{ml}$

pTXB3-Strep-TEV-HA-SUMO-1 and pTXB3-Strep-TEV-HA-SUMO-2 expression plasmids (Provided by Dr. E. Meulmeester)

MESNa (sodium 2-sulfanylethanesulfonate)

glycinevinylmethylesther-tosyl (stock solution $250 \mu \mathrm{M}$ ) (Provided by Dr. Huib Ovaa, NKI, Amsterdam)

$\mathrm{N}$-hydroxysuccinimide (stock solution $1 \mathrm{M}$ )

$\mathrm{NaOH}(0.5 \mathrm{M})$

$\mathrm{HCl}(0.5 \mathrm{M})$ 
IPTG

Lysis buffer (20 mM Hepes, $50 \mathrm{mM} \mathrm{NaCl}, \mathrm{pH}=6.5$ ) supplemented with $1 \mu \mathrm{g} / \mathrm{ml}$ each of aprotinin, pepstatin, leupeptin and $1 \mathrm{mM}$ PMSF

Elution buffer (20 mM Hepes, $50 \mathrm{mM} \mathrm{NaCl}, 50 \mathrm{mM}$ MESNa, pH=6.5) supplemented with $1 \mathrm{mg} / \mathrm{ml}$ each of aprotinin, pepstatin, leupeptin and $1 \mathrm{mM}$ PMSF

Buffer A (20 mM Hepes, pH=6.5) supplemented with $1 \mathrm{mM} \mathrm{DTT,} 1 \mathrm{mg} / \mathrm{ml}$ each of aprotinin, pepstatin, leupeptin and 1mM PMSF

Buffer B (20 mM Hepes, $1 \mathrm{M} \mathrm{NaCl} \mathrm{pH=6.5)} \mathrm{supplemented} \mathrm{with} 1 \mathrm{mM}$ DTT, 1 $\mathrm{mg} / \mathrm{ml}$ each of aprotinin, pepstatin, leupeptin and $1 \mathrm{mM}$ PMSF

chitin beads (NEB)

MonoQ HR 5/5 (GE Healthcare)

HiLoad 26/60 Superdex 75 pg (preparative S-75 column), GE Healthcare

AKTA purifier (GE Healthcare)

Protein concentrator with $10 \mathrm{kDa}$ cut off, VIVASPIN, (Saturious)

Low protein binding filters $-0.2 \mathrm{~mm}$ (Acrodisc LC25, PALL Life Sciences)

High pressure homogenizer (Avestin)

PD-10 desalting column (GE Healthcare)

\subsection{Preparation of Strep-TEV-HA-SUMO-MESNa}

An aliquot of the competent E.coli (DE3) BL21 bacteria was transformed either with pTXB3-Strep-TEV-HA-SUMO-1 or pTXB3-Strep-TEV-HA-SUMO-2 by the heat shock method and plated on LB agar with ampicillin. The following day a single colony was used to inoculate $20 \mathrm{ml}$ of LB, which was grown overninght at $37^{\circ} \mathrm{C}$ with $150 \mathrm{rpm}$ shaking. The following day the bacteria were collected by centrifugation and the pellet was suspended in 2 liters of LB medium with ampicillin, grown until an O. $D_{600}$ between 0.6-0.7 was reached and induced with $1 \mathrm{mM}$ IPTG. After 4 hours the bacteria were pelleted by centrifugation, suspended in $60 \mathrm{ml}$ of ice cold lysis buffer and lysed using high pressure homogenizer. The lysate was clarified by centrifugation $(100.000 \mathrm{~g}$ for 60 
minutes at $4^{\circ} \mathrm{C}$ ) and the supernatant was loaded on $5 \mathrm{ml}$ of chitin beads packed in a plastic column, previously equilibrated with the lysis buffer at room temperature. After loading, beads material was washed with $50 \mathrm{ml}$ of lysis buffer and $15 \mathrm{ml}$ of elution buffer. At this point the flow of the column was stopped and the beads material was incubated overnight at room temperature in $15 \mathrm{ml}$ of elution buffer to cleave column bound fusion protein. The eluate was collected and the column was washed with additional $15 \mathrm{ml}$ of elution buffer to elute the rest of the protein. Both eluates were concentrated down to $1 \mathrm{ml}$ using a protein concentrator and loaded onto a preparative S-75 column equilibrated with $20 \mathrm{mM}$ Hepes $\mathrm{pH}=7.5$, Fractions were analyzed by SDS-PAGE. Fractions containing clean Strep-TEV-HA-SUMO-MESNa were concentrated down to $2 \mathrm{mg} / \mathrm{ml}$ protein concentration.

\subsection{Synthesis and purification of Strep-TEV-HA-SUMO-Vme}

To obtain Strep-TEV-HA-SUMO-Vme, to $1 \mathrm{ml}$ of Strep-TEV-HA-SUMO-MESNa $250 \mu \mathrm{l}$ of glycinevinylmethylesther-tosyl stock solution and $150 \mu \mathrm{l}$ of $\mathrm{N}$ hydroxysuccinimide stock solution were added, $\mathrm{pH}$ was adjusted to 8.0 with $\mathrm{NaOH}$ and the mixture was incubated for 2 hours at $37^{\circ} \mathrm{C}$ with gentle shaking. The reaction was stopped by addition of $50 \mu \mathrm{l}$ of $\mathrm{HCl}$ solution. Using a PD-10 column buffer was exchanged to buffer $A$. The mixture was loaded on a MONO$Q$ column mounted on an AKTA purifier and washed with $5 \mathrm{ml}$ of buffer A. StrepTEV-HA-SUMO-Vme was separated from Strep-TEV-HA-SUMO-MESNa by applying a linear gradient of $\mathrm{NaCl}$ up to $400 \mathrm{mM}$ in total volume of $20 \mathrm{ml}$ using buffer $A$ and buffer $B$ and collecting $0.5 \mathrm{ml}$ fractions. Protein containing fractions were analyzed by $15 \%$ SDS-PAGE followed by commasie staining. Strep-TEVHA-SUMO-Vme was eluted at $290 \mathrm{mM} \mathrm{NaCl}$. The fractions were aliquoted, flesh frozen and stored at $-80^{\circ} \mathrm{C}$.

\subsubsection{Enzymatic reactions and assays}

All reactions were pipetted on ice 


\subsubsection{Preparation of the isopeptidase conjugate}

Materials

CFP-GAP

YFP-SUMO

E1 SUMO enzyme (our laboratory's common stock, purification described in Bossis et al., 2005, Werner et al., 2009)

E2 SUMO enzyme (our laboratory's common stock purification described in Bossis et al., 2005, Werner et al., 2009)

Sumoylation assay (SAB)

Apyrase (sigma)

To prepare $50 \mathrm{ml}$ of $1.25 \mu \mathrm{M}$ CFP-GAPtail ${ }^{*} Y F P-S U M O$ conjugate $(100 \mu \mathrm{g} / \mathrm{ml})$ $2.5 \mathrm{mg}$ of CFP-GAPtail, $2.5 \mathrm{mg}$ of YFP-SUMO, $60 \mu \mathrm{g} \mathrm{E} 1$ and $60 \mu \mathrm{g}$ E2 were pipetted together. $500 \mu \mathrm{l}$ of $100 \mathrm{mM}$ ATP solution was added and final volume of $50 \mathrm{ml}$ was achived by adding $\mathrm{SAB}$ buffer. The mixture was incubated at $37^{\circ} \mathrm{C}$ for 40 minutes. ATP was depleted by addition of $100 \mathrm{U}$ of apyraze. The conjugate was divided into aliquots, which after flash freezing in liquid nitrogen were stored at $\quad-80^{\circ} \mathrm{C}$.

\subsubsection{Preparation of RanGAP-SUMO-2 conjugate}

Materials

RanGAP and SUMO-2 (provided by Dr. Andreas Werner)

E1 SUMO enzyme (our laboratory's common stock purification described in Bossis et al., 2005, Werner et al., 2009)

E2 SUMO enzyme (our laboratory's common stock purification described in Bossis et al., 2005, Werner et al., 2009

Sumoylation assay (SAB)

To prepare $500 \mu \mathrm{g}$ of RanGAP-SUMO-2 conjugate $450 \mu \mathrm{g}$ of RanGAP and 200 $\mu \mathrm{g}$ of SUMO-2 was incubated with $1 \mu \mathrm{g}$ of E1, $2 \mu \mathrm{g}$ of E2 in the presence of 1 $\mathrm{mM}$ ATP. The final volume of $1 \mathrm{ml}$ was achieved by addition of SAB buffer. The 
mixture was incubated for 60 minutes at $37^{\circ} \mathrm{C}$, and loaded on an S-75 analytical column to remove unconjugated SUMO and remaining ATP. Fractions were analyzed by SDS-PAGE, and concentrated down to $0.5 \mathrm{ml}$. The final concentration was $1 \mathrm{mg} / \mathrm{ml}(14 \mu \mathrm{M})$.

\subsubsection{FRET-based desumoylation assay}

\section{Materials}

CFP-GAPtail-YFP-SUMO conjugate

Black micro titer 386-well plates (Greiner)

Microplate reader, Fluoroskan Ascent (Labsystems)

The conjugated CFP-Gaptail-YFP-SUMO exerts FRET (Fluorescence Resonana Energy Transfer) signal, due to a radiation free excitation of the YFP component. Cleavage of the isopeptide bond results in loss of FRET. This is a basis for the enzymatic assay developed in our laboratory (Bossis et al., 2005, StankovicValentin et al., 2009)

To follow desumoylation $20 \mu \mathrm{l}$ of the $1.25 \mu \mathrm{M}$ conjugate are mixed with $5 \mu \mathrm{l}$ of analyzed sample.To follow the reaction two values were measured: florescence emission at $485 \mathrm{~nm}$ after excitation at $430 \mathrm{~nm}$, and fluorescence emission at 527 $\mathrm{nm}$ after exciting at $430 \mathrm{~nm}$. The ratio of emission at 527 to emission at 485 is proportional to the amount of conjugated components and decreases during deconjugation reaction. Plotting this ratio values as a function of time allows to monitor kinetics of desumoylation reaction.

All measurements were taken in a microplate reader. For enzymatic assays measurements were taken every 1 minute for 30-60 minutes with the integration time of 100 milliseconds.

\subsubsection{Screen of bacterial expression library} Materials 
Lysates of bacterial expression library of human ORFs, in 384 well plates 10 plates, 3840 clones (provided by Dr. Erich Wanker, Max-Delbrück Center, Berlin), (Grelle et al., 2006)

CFP-GAPtail-YFP-SUMO-1 conjugate

Automated robotic station - BioMek2000 (Transcriptome analysis laboratory, University of Göttingen)

SAB buffer

Black micro titer 386-well plates (Greiner)

Microplate reader, Fluoroskan Ascent (Labsystems)

The screen was performed in collaboration with Dr. Reinert Hitt (Transcriptome analysis laboratory, University of Göttingen), who programmed and operated the robotic station. In the first step the following plates were prepared:

1) for dilution of the bacterial library $95 \mu \mathrm{l}$ of $S A B$ buffer was pipetted into each well of an empty plate.

2) For deconjugation assay $20 \mu \mathrm{l}$ of $1.25 \mu \mathrm{M}$ substrate was pipetted into each well

In a second step the library was diluted. $5 \mu$ l of each lysate was transferred from the library plate into the corresponding well of the SAB buffer filled plate.

In a third step $5 \mu$ l of each diluted extract was transferred into the corresponding well of the substrate filled plate. After 30 minutes of incubation at $37^{\circ} \mathrm{C}$ fluorescence values for 430/485 excitation/emission and 430/527 excitation/emission were measured 3 times for each well. The average values were used to determine the $527 / 485$ fluorescence ratio.

\subsubsection{Labeling of recombinant proteins with SUMO-VME} Materials

SENP1 catalytic domain (N-terminal GST-tag) (our laboratory's common stock) USPL1cat domain USPL1cat domain C236S HA-USPL1 (immuprecipitated from mammalian cells) 
SUMO-1-Vme

SUMO-2-Vme

1-2 $\mu \mathrm{g}$ of recombinant catalytic domains were incubated in the presence of $1 \mu \mathrm{g}$ of SUMO-Vme for 30 minutes at $37^{\circ} \mathrm{C}$. TB buffer was used as a negative control. Reactions were stopped by adding sample buffer to a final concentration of $1 \mathrm{x}$. Samples were analyzed by 12 or $14 \%$ SDS-PAGE followed by Coomassie staining.

For HA-USPL1 overexpressed in HEK293T cells, the concentration of immunopurified USPL1 was not known. Transfection and immunopurifiaction are described in sections 2.2.2.2 and 2.2.3.3. Total volume of eluate was $60 \mu \mathrm{l}$ and was divided into 3 parts, and incubated with either $100 \mathrm{ng}$ of SUMO-1-Vme, 100 ng of SUMO-2-Vme or elution buffer. The eluate of the immunoprecipitation from cells transfected with an empty vector was used as a control. Samples were analyzed by $5 \%$ SDS-PAGE followed by anti-HA western blotting.

\subsubsection{SUMO cleavage}

Materials

RanGAP modified with SUMO-1 (provided by Dr. Andreas Werner)

RanGAP modified with SUMO-2

USPL1cat

TB buffer supplemented with $5 \mathrm{mM}$ DTT and $1 \mu \mathrm{g} / \mathrm{ml}$ each of aprotinin, leupeptin, pepstatin

Sumoylated RanGAP at a concentration of $2 \mu \mathrm{M}$ was incubated with $4 \mu \mathrm{M}$ USPL1cat for 0-120 minutes. The reaction was stopped by addition of the sample buffer to the final concentration of $1 \mathrm{x}$ and analyzed by $8 \%$ SDS-PAGE followed by Coomassie staining. 


\subsubsection{Chain cleavage}

Materials

SUMO-2 chains (provided by Sarah Schulz, PhD student in our laboratory)

USPL1cat

SENP1cat (common stock of our laboratory)

USP5 (provided by Sarah Schulz, PhD student in our laboratory)

TB buffer supplemented with $5 \mathrm{mM}$ DTT and $1 \mu \mathrm{g} / \mathrm{ml}$ each of aprotinin, leupeptin, pepstatin

$5 \mu \mathrm{l}$ of SUM0-2 chains and were incubated with $5 \mu \mathrm{M}$ USPL1cat or $150 \mathrm{~nm}$ USP5 for 0-60 minutes at $37^{\circ} \mathrm{C}$. The reaction was terminated at different time point and samples were analyzed by $5-20 \%$ gradient SDS-PAGE followed by Coomassie staining.

\subsubsection{Binding assay}

\section{Material}

SUMO-1-Sepharose, SUMO-2-Sepharose, Ovalbumin-Sepharose, UbiquitinSepharose, protein concentration $1 \mathrm{mg} / \mathrm{ml}$ (provided by Sarah Schulz, PhD student in our laboratory)

SAB buffer

Washing buffer (TB buffer supplemented $0.05 \%$ (v/v) Tween-20)

To $20 \mathrm{ug}$ of USPL1cat $20 \mu \mathrm{l}$ of either SUMO-1-Sepharose, SUMO-2-Sepharose, Ubiquitin-Sepharose or Ovalbumin-Sepharose, and SAB was added to the final volume of $200 \mu \mathrm{l}$. Samples were incubated for 2 hours on a rocking platform at $4^{\circ} \mathrm{C}$. Beads material was collected by centrifugation (tabletop centrifuge 2000 rpm, $20 \mathrm{sec}$ ) and washed 3 times with the washing buffer. Beads bound protein was eluted by adding $40 \mu \mathrm{l}$ of $1 \mathrm{x}$ Sample buffer and incubating at $95^{\circ} \mathrm{C}$ for 5 minutes. Eluates were analyzed by $15 \%$ SDS-PAGE followed by coomassie staining. 


\subsubsection{Ubiquitin cleavage assay}

Materials

Ubiquitin AMC (Biomol)

USP1cat

USP5 (Sarah Shulz)

TB buffer

Black micro titer 386-well plates (Greiner)

Microplate reader, Fluoroskan Ascent (Labsystems)

The reaction was pipetted into a black microtiter plate. $5 \mu \mathrm{M}$ Ubiquitin-AMC was used as a substrate, $50 \mathrm{~nm}$ USPL1cat and $5 \mathrm{~nm}$ USP5 were used in a total volume of $25 \mu \mathrm{l}$. AMC flurescence was measured at $360 \mathrm{~nm}$ excitation $465 \mathrm{~nm}$ emission filter pair every 6 seconds for 25 minutes with integration time of 100 ms. AMC fluorescence values were plotted against time. 


\section{RESULTS}

\subsection{Search for SUMO specific isopeptidases}

The aim of this work was to identify a novel SUMO specific isopeptidase. To do this we used two different approaches:

a) A screen of a bacterial expression library of human ORFs using a FRETbased desumoylation assay.

b) Biochemical purification of SUMO specific proteases from HeLa cells lysates using SUMO-Vinylmethylester (VME).

\subsubsection{A high-throughput screen for a SUMO isopeptidases}

To identify novel SUMO specific proteases we screened a bacterial expression library of human ORFs for desumoylating activity. This library was developed by Dr. Erich Wanker (Max-Delbrück Center, Berlin) (Grelle et al., 2006), who provided us with lysates in 384-well format (see materials and methods chapter for a detailed description of the library). The library consists of E.coli clones, transformed with human ORFs in a prokaryotic expression vector. Each clone is transformed with a different ORF. Bacterial clones are grown, induced and lysed in 384-well plate format. Lysates can be screened in highthroughput manner for activity of interest if the appropriate assay is available.

To screen the library for desumoylating activity I used a FRET-based desumoylation assay developed in our laboratory (Bossis et al. 2005, StankovicValentin et al., 2009) (see materials and methods section for a detailed description of the assay). When CFP-Gaptail and YFP-SUMO are unconjugated, excitation at $435 \mathrm{~nm}$ (excitement maximum for CFP) results in a strong emission by CFP-Gaptail at $485 \mathrm{~nm}$, but only in minimal YFP-SUMO excitement and emisson at $527 \mathrm{~nm}$. After excitation of CFP-Gaptail conjugated with YFP-SUMO, part of the energy of excited CFP-Gaptail is transferred to YFP-SUMO due to Fluorescence resonance energy transfer (FRET) between these components. As 
a result the emission of CFP-Gaptail decreases and the emission of YFP increases. Direct read out of the assay are fluorescence values for excitation at $435 \mathrm{~nm}$ with emission at $485 \mathrm{~nm}$ (CFP-Gaptail excitation and emission) and excitation at $435 \mathrm{~nm}$ with emission at $527 \mathrm{~nm}$ (CFP-Gaptail excitation, YFPSUMO emission). Changes in the ratio between fluorescence emission of CFP and YFP (485/527 $\mathrm{nm}$ ratio) are proportional to changes in the amount of the conjugated components and can be used to monitor the progress of sumoylation/desumoylation reaction. Fluorescence measurements can be performed in multi well plates, which allows adaptation of the assay to a highthroughput screen.

The buffer in which measurements are done may influence the fluorescence. The buffer used for the preparation of the bacterial lysates differs significantly from the sumoylation assay buffer in which the assay was originally developed. Therefore I tested whether this lysis buffer is compatible with the assay. When undiluted lysate is added into reaction in a standard amount $(5 \mu \mathrm{l}$ of lysates to $20 \mu \mathrm{l}$ of $1 \mu \mathrm{M}$ substrate) the signal to noise ratio becomes too low to interpret accurately obtained results (data not shown). To overcome this problem the lysates were diluted with sumoylation assay buffer. 20 fold dilution of the lysates allowed for undisturbed measurement. 


\section{A}
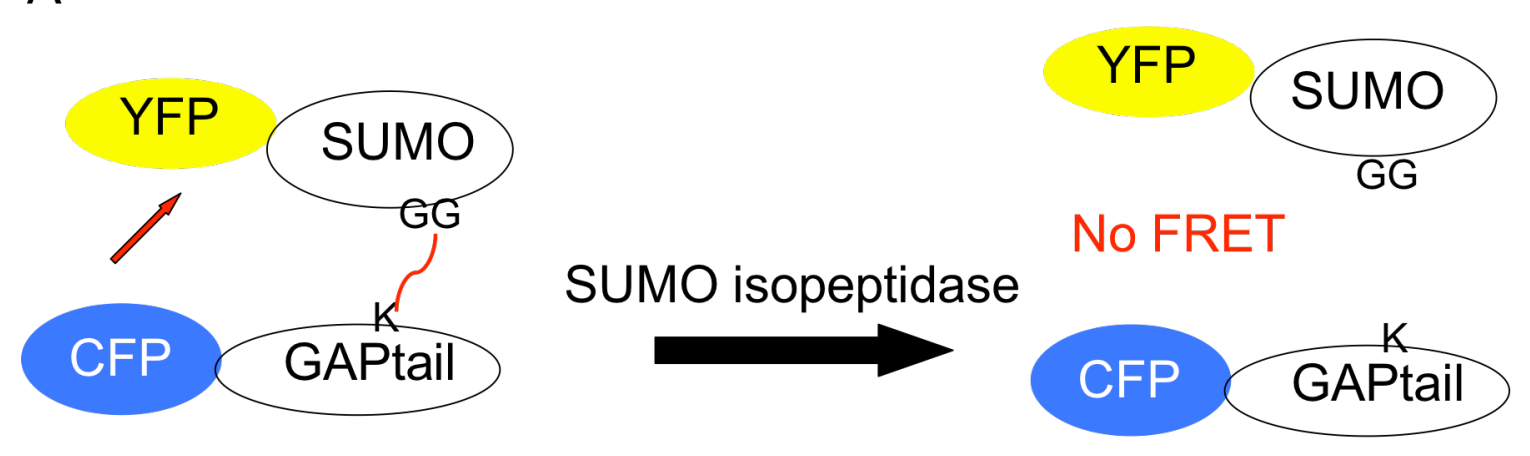

B

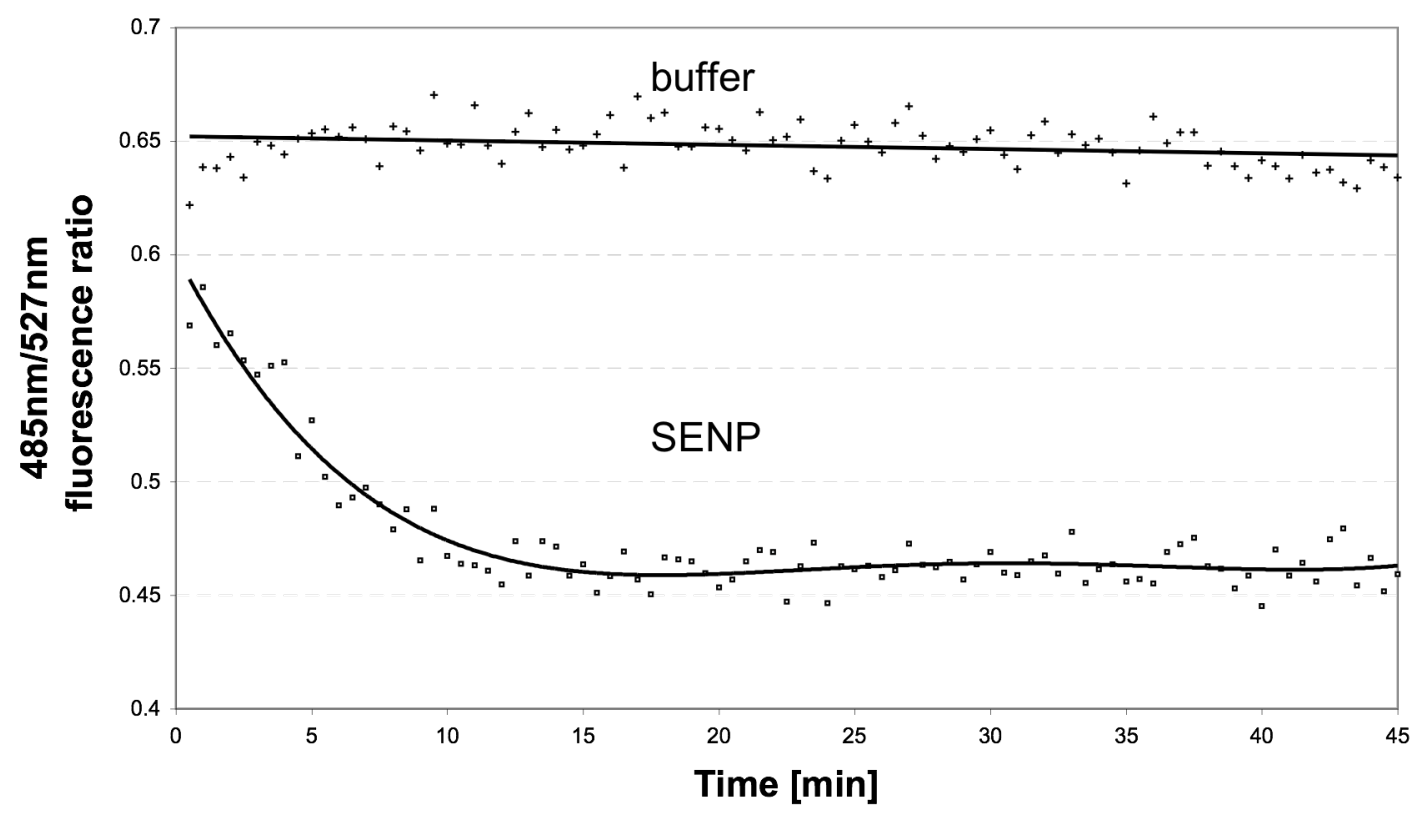

Figure 7. FRET-based assay as a tool to study isopeptidases. A. The principle of the assay. Desumoylation leads to the loss of FRET between CFP and YFP. B. CFP-GAP conjugated with YFP-SUMO-1 $(1 \mu \mathrm{M})$ was incubated with either GST-SENP1cat $(1 \mu \mathrm{M})$ or SAB buffer at $30^{\circ} \mathrm{C}$, in a 384 -well microtiter plate in total volume of $25 \mu \mathrm{l}$. The kinetics of reaction was followed by exciting CFP and measuring YFP and CFP fluorescence emission. 
Next I tested whether the assay can be applied to a high-throughput screen. For this, our collaborators included 6 colonies of E.coli the expressing catalytic domain of SENP1 (SENP1cat) in 6 unspecified wells of a 384 well plate. None of the clones present in the rest of the wells contained known SUMO isopeptidase. My goal was to identify the wells containing SENP1cat. Together with Dr. Reiner Hitt (Transcriptome analysis laboratory, the University of Göttingen) we screened the plate using an automated robotic station as shown in Figure 8A. The lysates were diluted with $S A B$ into a fresh plate and subsequently pipetted into a plate containing CFP-GapTail conjugated with YFP-SUMO-1. After incubation, I measured the fluorescence in each well. The results are summarized in Figure 8B and C. Six wells (shown in red) had a 485/527nm emission ratio corresponding to complete deconjugation, indicating presence of SENP1cat. Six wells, adjacent to SENP1cat containing wells, had the fluorescence ratio significantly lower than fully conjugated substrate (shown in blue), however the deconjugation was not complete. Our collaborators confirmed that SENP1cat was indeed present in the wells with ratios corresponding to fully deconjugated substrate. The wells with significant signal loss did not contain proteins of which it was known to posses SUMO specific isopeptidase activity or any other protease activity. However it turns out that these wells were contaminated with SENP1cat from adjacent wells: lysates of these clones grown separately showed no desumoylating activity. This confirmed that the activity observed during the screen was a result of a spill over. The fact that all six wells containing SENP1cat were easily identified and that a spill over could be detected indicated that the FRET assay is sensitive enough to use for high-throughput screening.

I screened the whole library containing 3860 different clones (Figure 8D). As a positive control I used a plate containing SENP1cat. Unfortunately no desumoylating activity was detected in any of the wells except for SENP1cat. Later I discuss the possible reasons for not detecting desumoylating activity and propose alterations in the screen. 
A
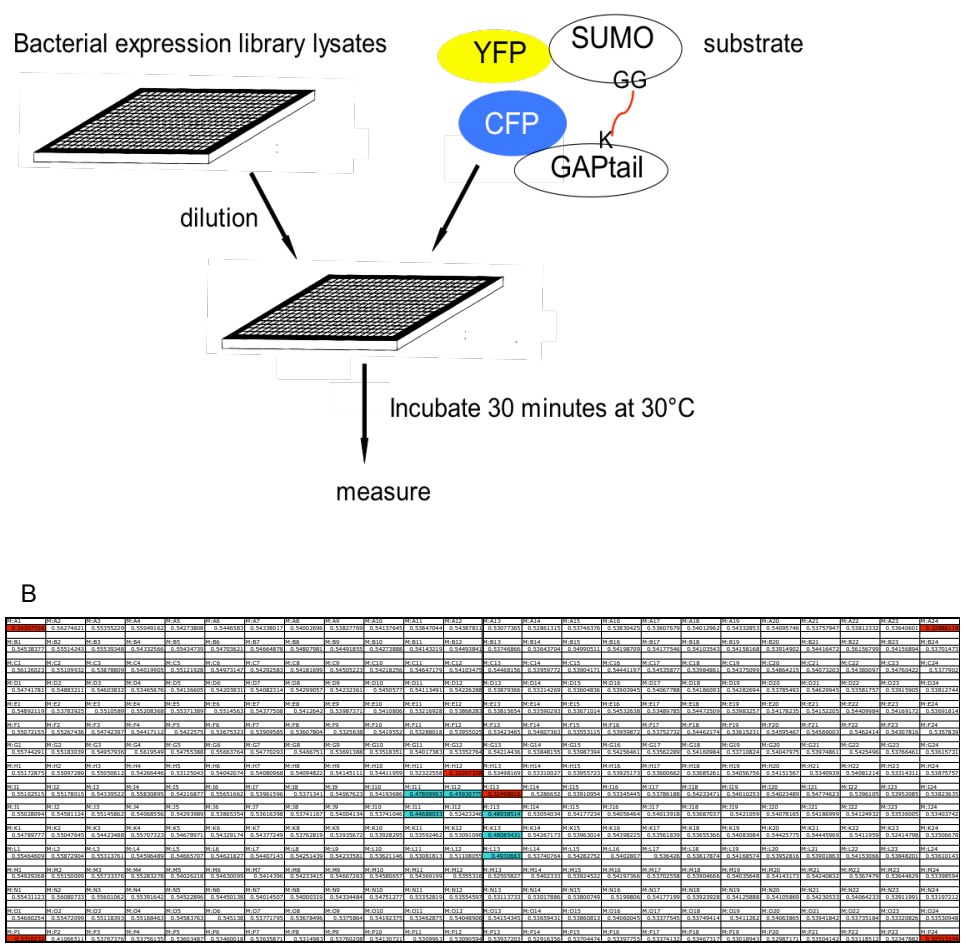

C

\begin{tabular}{|c|c|c|}
\hline well & E527/E485 ratio & content \\
\hline $\mathrm{A} 1$ & $\begin{array}{r}0.34 \\
\end{array}$ & \multirow{6}{*}{ SENP } \\
\hline $\mathrm{P} 1$ & 0.33 & \\
\hline A24 & 0.33 & \\
\hline P24 & 0.33 & \\
\hline $\mathrm{H} 12$ & 0.32 & \\
\hline I13 & 0.33 & \\
\hline I11 & 0.48 & \multirow{6}{*}{$\begin{array}{l}\text { directly adjecent } \\
\text { to SENP - spill over }\end{array}$} \\
\hline $\mathrm{J11}$ & 0.45 & \\
\hline I12 & 0.46 & \\
\hline נ13 & 0.49 & \\
\hline K13 & 0.48 & \\
\hline L13 & 0.49 & \\
\hline $\mathrm{H} 15$ & 0.54 & \multirow{5}{*}{ no SENP } \\
\hline D16 & 0.54 & \\
\hline L20 & 0.54 & \\
\hline $\mathrm{I3}$ & 0.53 & \\
\hline P11 & 0.54 & \\
\hline
\end{tabular}

\begin{tabular}{|r|r|r|r|}
\hline plates & \# of clones & fluorescence ratio $>0.5$ & fluorescence ratio $<0.5$ \\
\hline 10 & 3840 & 3840 & 0 \\
\hline
\end{tabular}

Figure 8. The FRET-based assay can be used to screen bacterial expression libraries.

A. Schematic representation of the screen. Bacterial lysates are diluted with SAB, incubated with substrate and the fluorescence is measured. B. Testplate with positive control. Bacterial clones expressing SENP1cat were placed on the plate in 6 unspecified wells. The plate was screened as shown in panel A. Wells in which FRET was completely lost are shown in red. Wells with significant loss of FRET are shown in blue. C. Testplate screen summary. D. Summary of the whole library screen. 


\subsubsection{Biochemical purification of SUMO-isopeptidases using SUMO-VME}

As our screen did not result in identification of a novel SUMO protease we decided to take an alternative approach based on biochemical purification. To do this we used SUMO-VME, which is a recombinant mature SUMO modified chemically on the C-terminus with vinylmethylester. Vinylmethylester resembles peptide bond and once attacked by a protease it forms a stable covalent bond with the catalytic residue of an enzyme.

Chemical probes used to study the Ubiquitin system were developed several years ago (Borodovsky et al., 2001 and 2002). They were successfully used to identify new Ubiquitin and other Ubl like proteases. They can also be used to study enzymatic activity of proteases. For ubiquitin proteases, the chemical with the broadest spectrum of specificity is vinylmethylester. The protocol for synthesis of Ubiquitin-VME was developed by Dr. Huib Ovaa (NKI, Amsterdam) and adopted to SUMO technology by Erik Meulmeester, a postdoc in our laboratory. He generated a construct for bacterial expression of HASUMO-intein-chitin binding domain protein. The N-terminal HA epitope allows for immunopurification of SUMO-VME-modified proteins using anti-HA antibodies. Recombinant SUMO fusion protein and the outline of the procedure generating the reactive SUMO-VME species are shown in Figure 9.

\section{Expression, purification and synthesis of SUMO electrophilic traps}

SUMO-VME were obtained by chemical ligation method (Chong et al., 1997, Cotton and Muir 1999). SUMO-1 or SUMO-2 lacking the last glycine residue were expressed recombinantly in E.coli as a fusion with intein and chitin binding domains. To obtain reactive thioester (Strp-HA-TEV-SUMO-MESNa), proteins were bound to chitin-beads followed by subsequent transthioesterification witth MESNa. Strep-HA-TEV-SUMO-MESNa was purified using size-exclusion chromatography, and used for chemical ligation with 
Glycine-vinyl-Methyl-ester. The last step of the procedure involved anion exchange chromatography to obtain pure HA-TEV-SUMO-Vinyl-Methyl-ester, referred to as SUMO-VME (Figure 9B,C). SUMO-1 and SUMO-2-VME were tested for their ability to react with desumoylating enzymes by incubating them with GST-SENP1cat. Both SUMO-1 and SUMO-2-VME were able to modify the active site of GST-SENP1 (Figure 9D) confirming their ability to covalently modify SUMO proteases.

A

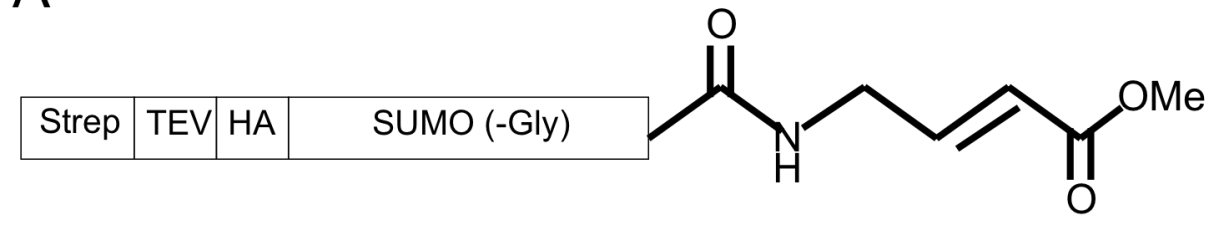

$\mathrm{B}$
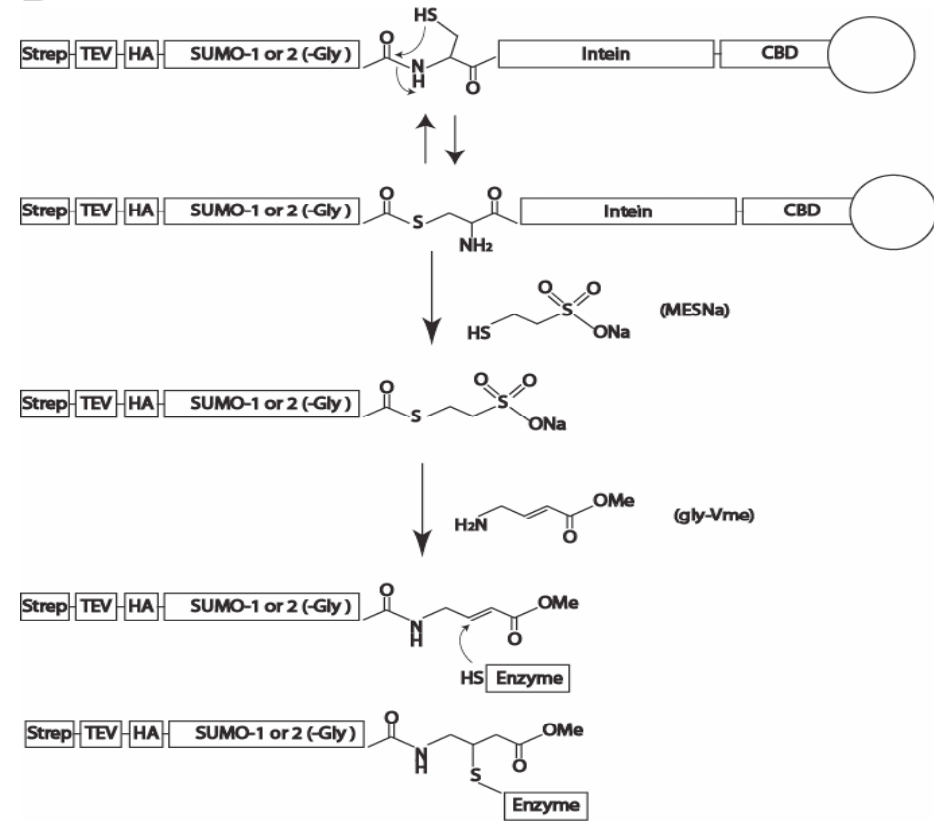


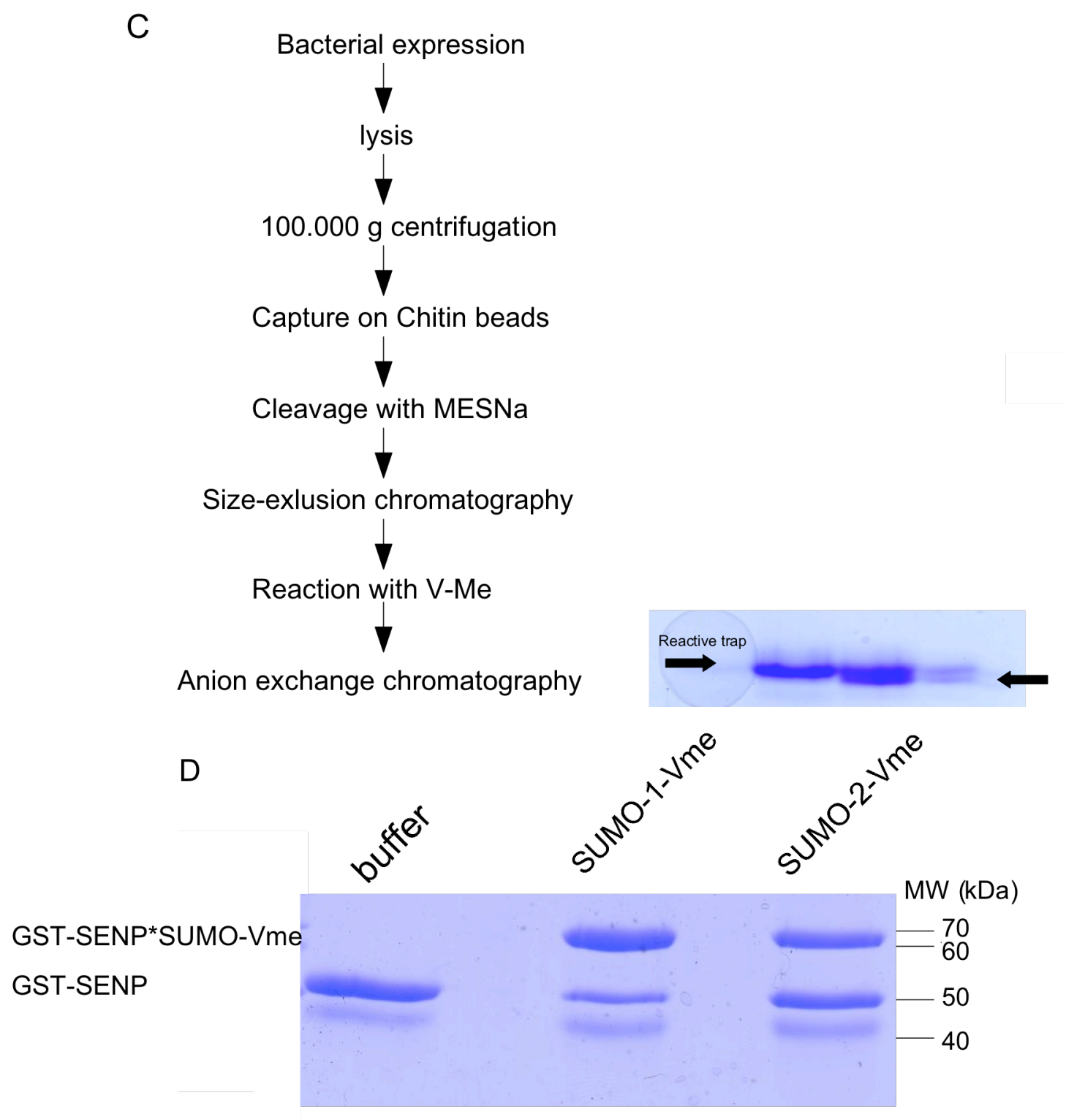

Fig 9. Generation, purification and testing of SUMO-VMEs.

A.Schematic representation of SUMO electrophilic traps - HA tag, Strep tag and TEV cleveage site are indicated. B. The scheme of electrophilic trap synthesis. C. Left - The flowchart of SUMO-VME generation (synthesis and purification), right - fractions of MONO-Q containing reactive SUMO-Vme D . SUMO electrophilic traps react with desumoylating enzymes. $2 \mu \mathrm{g}$ of recombinant GST-SENP1cat was incubated for 30 minutes at $37^{\circ} \mathrm{C}$ in the presence of $1 \mu \mathrm{g}$ SUMO-1-VME, $1 \mu \mathrm{g}$ SUMO-2-VME or buffer. Samples were analyzed by SDS-PAGE followed by coomassie staining. 


\section{SUMO-VME can modify endogenous proteins present in HeLa cell lysate.}

To identify putative novel SUMO protease I tested whether SUMO-VME can modify endogenous human proteins. The HeLa cell lysate was incubated with increasing amounts of either SUMO-1-VME or SUMO-2-VME, centrifuged to remove precipitated or aggregated proteins, precleared by incubation with protein $A$ beads and subjected to an anti-HA immunoprecipitation. Proteins bound specifically to an anti-HA antibody via an HA epitope were eluted by competition with HA-peptide. Eluates were resolved by SDS-PAGE and analyzed by immunoblotting with an $\alpha-\mathrm{HA}$ antibody (Figure $10 \mathrm{~A}$ and $\mathrm{B}$ ). Multiple bands were observed both in case of SUMO-1-VME and SUMO-2-VME samples, whereas the control, in which no SUMO-VME was present in the extract remained empty, suggesting that each of detected bands was a protein that specifically reacted with a trap. Overall patterns of proteins immunoprecipitated with SUMO-1 and SUMO-2-VME were similar, however a very conspicuous band of approximate 85 $\mathrm{kDa}$ in size was present only in samples incubated with SUMO-2 VMe. This band could represent an isopeptidase that is specific for SUMO-2. To enrich proteins reacting specifically with SUMO-2-VME HeLa, cell extract was first incubated with SUMO-1 Vme, and subjected to immunoprecipitation with an anti-HA antibodies. Proteins specifically bound to anti-HA antibodies were eluted with HA-peptide (fraction S1). The supernatant that was partially depleted from SUMO-1 reacting proteins was then incubated with SUMO-2-VME. Labeled proteins were immunoprecipitated and eluted from the beads as for SUMO-1VME (fraction S2). Eluates were resolved by SDS-PAGE and analyzed by immunobloting with an anti-HA antibody. Also here a strong band was present at $85 \mathrm{kDa}$ only in case of SUMO-2-VME labeled proteins, indicating the presence of a SUMO-2 specific protease (Figure 11). 


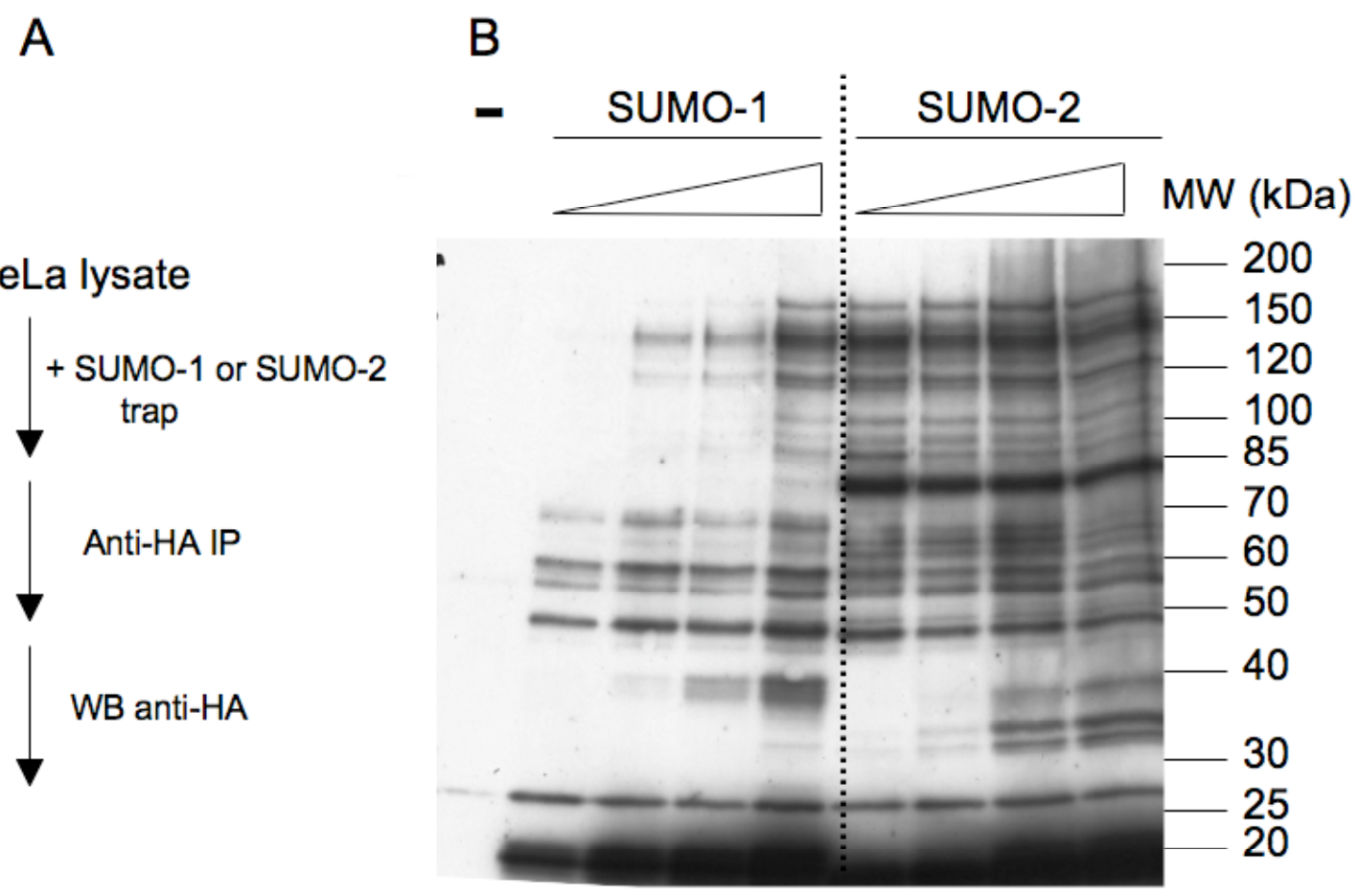

Figure 10. Enrichment of SUMO-1-VME and SUMO-2-VME modified proteins.

A.The scheme of the purification. B. $1.5 \mathrm{mls}$ of HeLa cell lysate $(10 \mathrm{mg} / \mathrm{ml})$ was incubated for 30 minutes at $37^{\circ} \mathrm{C}$ with increasing amounts of either SUMO-1-VME (75-600 ng), SUMO-2VME (250ng - $2 \mu \mathrm{g})$ or buffer (-). Lysates were centrifuged at $100.000 \mathrm{~g}$ and subjected to an anti-HA IP followed by HA-peptide elution. Eluates were analysed by SDS-PAGE followed by anit-HA Western Blotting.

Having established a protocol allowing biochemical purification of SUMOVME modified proteins I upscaled the procedure to identify these proteins by mass spectrometry.

$25 \mathrm{ml}$ HeLa cell lysate was incubated with $10 \mu \mathrm{g}$ of SUMO-1-VME followed by anti-HA immunoprecipitation and HA-peptide elution. Supernatant was incubated with $10 \mu \mathrm{g}$ of SUMO-2-VME, and the same procedure as for SUMO-1-VME was followed. Protein identification was performed in collaboration with Dr. Henning Urlaub (Max-Planck Insitute for Biophysical Chemistry, Göttingen). Eluates were resolved by SDS-PAGE, gel lanes containing proteins were cut into slices from which protein was extracted. 


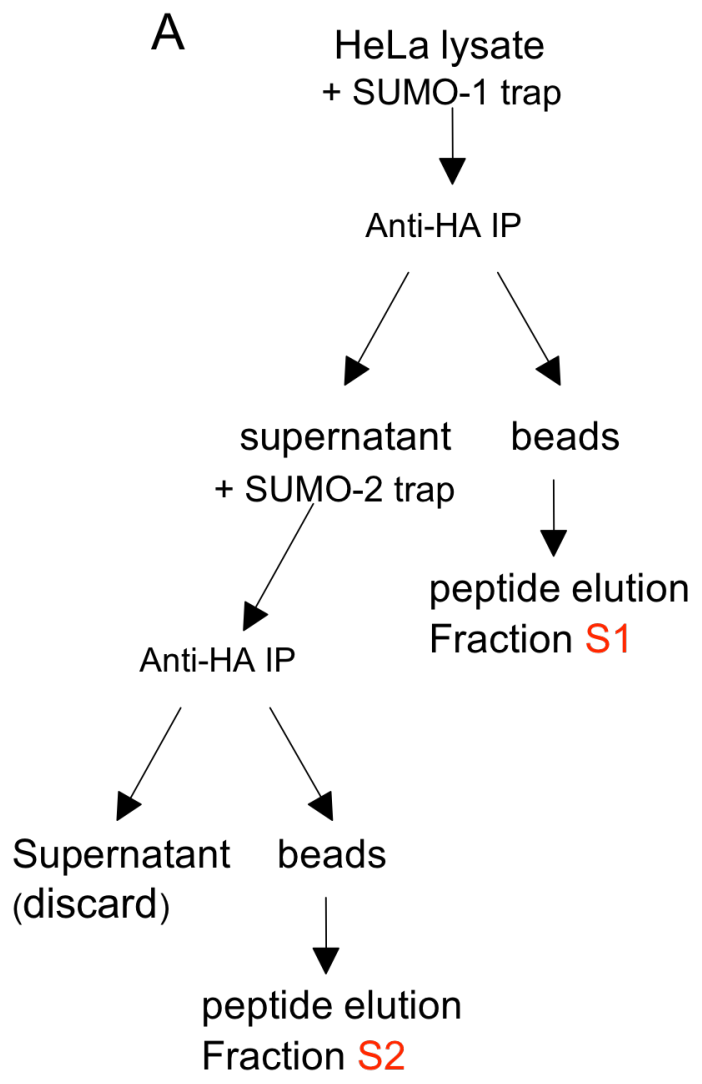

B

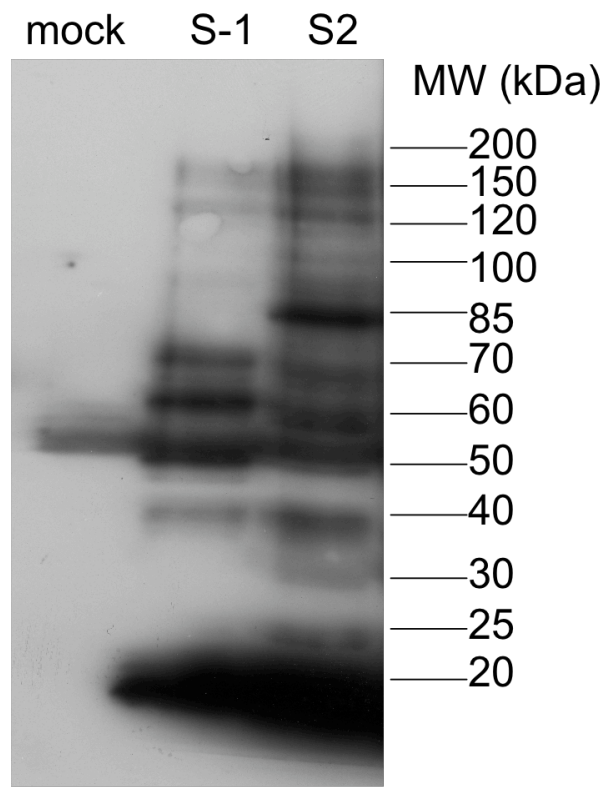

Fig 11. Sequential application of SUMO-VMEs can be used to enrich for paralogue specific isopeptidases.

A. Scheme of purification. B. $1.5 \mathrm{ml}(10 \mathrm{mg} / \mathrm{ml})$ of HeLa cell lysate was incubated with $1 \mu \mathrm{g}$ of SUMO-1-VME for 30 minutes at $37^{\circ} \mathrm{C}$. Afterwards lysates were subjected to centrifugation (100.00 g 30 minutes at $4^{\circ} \mathrm{C}$ ) and anti-HA IP followed by HA-peptide elution (eluted fraction S1). The supernatant was incubated with $1 \mu \mathrm{g}$ of SUMO-2-VME, centrifuged and subjected to anti-HA IP followed by peptide elution. Lysate without trap was used as a control. Eluates were analyzed by SDS-PAGE followed by anti-HA Western Blotting.

After trypsine digestion samples were analysed by mass spectrometry (Figure 12). Identified proteins are shown in Tables 2 and 3 for SUMO-1-VME and SUMO-2-VME respectively. 


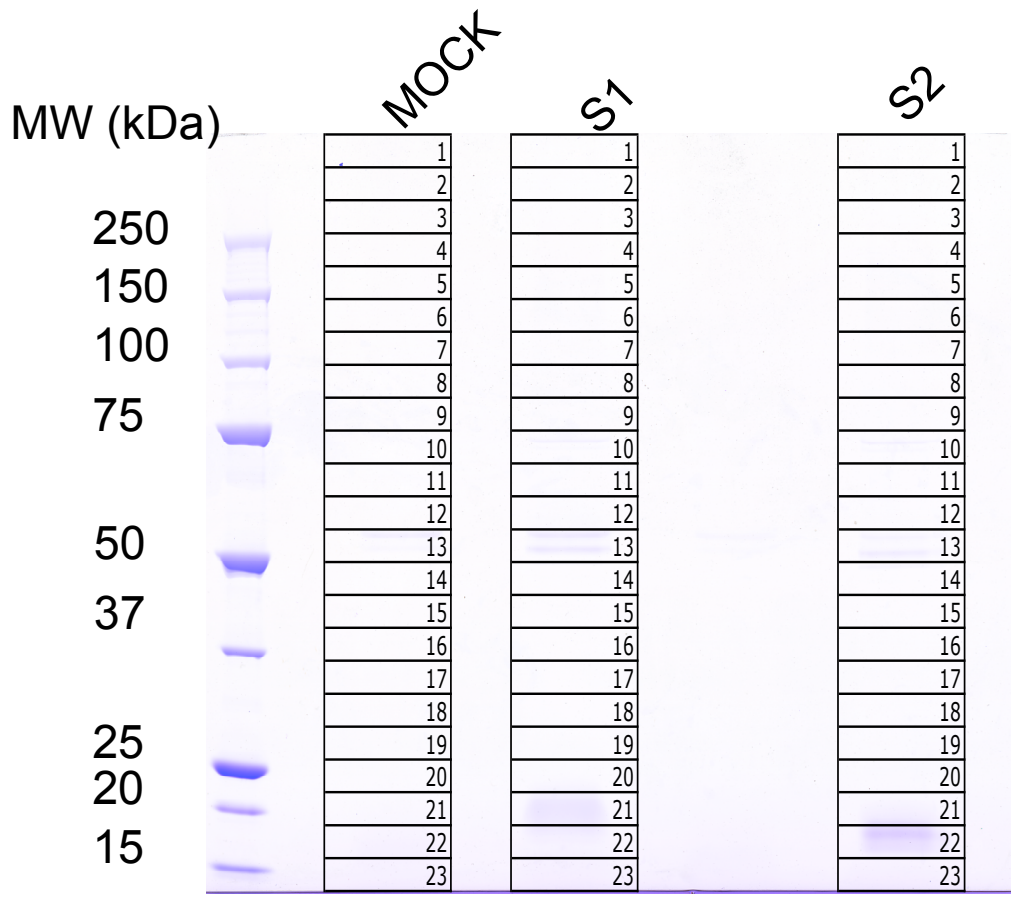

Figure 12. Gel with immunoprecipitated proteins. Gel picture provided by Monika Raabe, (Department of Mass Spectrometry, Max-Planck Institute for biophysical chemistry, Göttingen).

The majority of identified proteins were known SUMO isopeptidases. Four out of six members of the SENP family were identified. One of them, SENP5, was identified only upon SUMO-2-VME labeling. Presence of SENP proteins in many gel slices, including those corresponding to lower than predicted molecular weight of the full length protein suggested presence of splice variants or limited proteolysis products.

Interestingly four proteins of which no link to the SUMO pathway was known were also identified. In case of SUMO-1-VME USPL1 and F-boxWD40.5 were identified. In case of SUMO-2-VME USPL1, F-boxWD40.5, HCF-1 and OGT-1 were found. 


\begin{tabular}{|c|c|c|c|c|}
\hline Slice & Protein & $\begin{array}{c}\text { accesion } \\
\text { number }\end{array}$ & $\begin{array}{c}\text { \# of } \\
\text { peptides }\end{array}$ & score \\
\hline 1 & SENP6 & gi|7662312 & 8 & 256 \\
\hline 2 & SENP6 & gi|7662312 & 9 & 206 \\
\hline 3 & SENP6 & gi|7662312 & 1 & 45 \\
\hline 4 & SENP6 & gi|7662312 & 18 & 464 \\
\hline & USPL1 & gi|55639683 & 3 & 98 \\
\hline 5 & SENP6 & gi|7662312 & 24 & 577 \\
\hline & USPL1 & gi|55639683 & 3 & 149 \\
\hline 6 & SENP6 & gi|7662312 & 26 & 566 \\
\hline & USPL1 & gi|55639683 & 2 & 99 \\
\hline & USPL1 & gi|55639683 & 3 & 63 \\
\hline 7 & SENP6 & gi|7662312 & 13 & 407 \\
\hline & SENP1 & gi|7657550 & 1 & 41 \\
\hline 8 & SENP6 & gi|7662312 & 2 & 103 \\
\hline 9 & SENP6 & gi|7662312 & 4 & 94 \\
\hline 10 & SENP1 & gi|7657550 & 4 & 153 \\
\hline 11 & F-box and WD-40 domain protein 5 & gi|24308129 & 9 & 373 \\
\hline & SENP1 & gi|7657550 & 5 & 167 \\
\hline 12 & SENP1 & gi|7657550 & 3 & 120 \\
\hline & SENP6 & gi|7662312 & 1 & 29 \\
\hline 14 & SENP1 & gi|7657550 & 4 & 192 \\
\hline
\end{tabular}

Table 5. Proteins identified upon SUMO-1-VME treatment. Known SUMOispopeptidases are shown in red, other proteins are shown in blue.

\section{HCF-1}

Host Cell factor- 1 is a conserved and very abundant (100.000 per cell) chromatin associated protein (Wysocka et al., 2001). It is synthesized as a precursor and migrates to the nucleus where it undergoes cleavage near the middle of the protein (Wilson et al., 1993). Generated subunits remain associated noncovalently (Wilson et al., 1995). HCF-1 is involved in the regulation of cell proliferation and functions as a transcriptional regulator (Goto et al., 1997, Wysocka and Herr 2003). It interacts with a number of transcription factors like Sp1 or members of the E2F family and chromatin modifying enzymes like histone deacetylase or methylase (Vogel et al. 2000, Tyagi et al., 2007, Wysocka et al., 2003). HCF-1 also interacts with OGT-1 and is a target for O-glycosylation. 


\begin{tabular}{|r|l|l|r|r|}
\hline slice & Protein & $\begin{array}{l}\text { accesion } \\
\text { number }\end{array}$ & $\begin{array}{l}\text { \# of } \\
\text { peptides }\end{array}$ & score \\
\hline 3 & HCF-1 & gi|558349 & 2 & 42 \\
\hline 4 & HCF-1 & gi|98986457 & 4 & 115 \\
\hline & SENP6 & gi|55626950 & 2 & 108 \\
\hline 5 & SRNP6 & gi|7662312 & 11 & 286 \\
\hline & HCF-1 & gi|98986457 & 8 & 235 \\
\hline & USPL1 & gi|55639683 & 3 & 96 \\
\hline 6 & HCF-1 & gi|98986457 & 10 & 410 \\
\hline & SENP6 & gi|7662312 & 11 & 198 \\
\hline & OGT-1 O-linked GlcNAc transferase & & & \\
& isoform 1 & gi|32307150 & 2 & 93 \\
\hline & USPL1 & gi|55639683 & 1 & 81 \\
\hline 7 & O-linked GlcNAc transferase isoform 1 & gi|32307150 & 9 & 307 \\
\hline & SENP6 & gi|7662312 & 3 & 100 \\
\hline & HCF-1 & gi|55664732 & 6 & 99 \\
\hline 8 & SENP5 & gi|14250319 & 4 & 202 \\
\hline & SENP6 & gi|9963808 & 2 & 78 \\
\hline & HCF-1 & gi|558349 & 3 & 63 \\
\hline & F-box and WD-40 domain protein 5 & gi|10438817 & 2 & 25 \\
\hline & HS-CUL-1 & gi|1381142 & 1 & 24 \\
\hline 9 & SENP6 & gi|7662312 & 2 & 38 \\
\hline & SENP5 & gi|14250319 & 1 & 33 \\
\hline & HCF-1 & gi|558349 & 2 & 23 \\
\hline & FBXW5 protein [Homo sapiens] & gi|10438817 & 1 & 21 \\
\hline 10 & SENP5 & gi|14250319 & 9 & 384 \\
\hline 11 & F-box and WD-40 domain protein 5 & gi|10438817 & 6 & 217 \\
\hline & SENP5 & gi|14250319 & 3 & 130 \\
\hline 12 & SENP1 & gi|7657550 & 2 & 43 \\
\hline & SENP6 & gi|7662312 & 1 & 36 \\
\hline
\end{tabular}

Table 6. Proteins identified upon treatment with SUMO-2-VME. Known SUMOispopeptidases are shown in red, other proteins are shown in blue.

The role of this modification is unclear (Wysocka et al., 2003). Many of the HCF1 interactors bind to it via a tetrapeptide termed the HCF-1 binding motif (HBM) $[D / E] H x Y$ (Wysocka and Herr 2003). Recently it was shown that via the coupling of E2F proteins to chromatin modifying complexes, HCF-1 regulates posttranslational modifications of histones associated with E2F responsive genes. By doing so it affects the transcription of these genes, many of which are in cell proliferation. (Tyagi et al. 2007). We identified HCF-1 only upon SUMO-2- 
Vme labeling, and hypothesized that either it associates with very stably SUMO-2 or a desumoylating enzyme that was purified specifically with SUMO-2. SENP5 was the only SENP that was purified exclusively with SUMO-2. SENP5 has two HBMs (127-130 DHEYand 459-462 DHPY) and is the only human SENP protein that posses such motif. HCF-1 therefore most probably copurified with SENP5. Cells lacking functional HCF-1 arrest in the cell cycle, which is reminiscent of the phenotype of cells depleted from SENP5 (Di Bacco et al. 2006). Sumoylation of transcription factors is known to inhibit transcription, probably by recruiting transcriptional repressors (Hay 2005, Stielov et al. 2008). Sumoylation of histones also represses transcription. An attractive hypothesis that will be followed in the future is that HCF-1 attracts the desumoylating enzyme SENP5 to desumoylate a transcription factor or histone or both.

\section{OGT-1}

OGT-1 (O-linked GlcNAc transferase) is an enzyme involved in O-glycosylation of serine resiudes. It is known to interact with HCF-1, which itself is a target for O-glycosylation.

\section{FboxWD40\#5}

Proteins containing Fbox and WD40 domains are substrate recognition subunits of cullin1-based E3-ubiquitin ligases. These ligases are composed of several subunits: the scaffold subunit is cullin 1 that on one terminus binds both Roc1 and Skp1. Roc1 is a RING finger protein that recruits E2 enzymes, and Skp1 binds receptor recognition subunits. The Fbox module of FboxWD40 proteins binds to Skp1, and the WD40 domain binds substrates (Petroski and Deshaies 2005). We hypothesized that FboxWD40 5 is a receptor subunit responsible for SUMO ubiquitination. This idea is now investigated by other in our laboratory.

Suprisingly none of those three proteins had a domain that could be a protease domain. Therefore the most reasonable explanation for their coimunopufrification is that they interact very stably but noncovalently either with SUMO or enzymes of SENP family. 


\subsection{USPL1 is a SUMO isopeptidase}

The last protein identified from the immunopurification with SUMO-VME is USPL1. Ubiquitin Specific Protease like protein 1 is a member of the Ubiquitin Specific Peptidases Family, the largest family of the known Ubiquitin peptidases (Nijman et al 2005). A generic member of this family has a C19 cysteine protease domain (catalytic domain), in which the catalytic triad consists of cystein, apartate and histidine. USPL1 was suggested to be an inactive ubiquitin protease due to the absence of a non-catalytic histidine residue, conserved among other members of the USP family (swiss-prot/Q5W0Q7)..

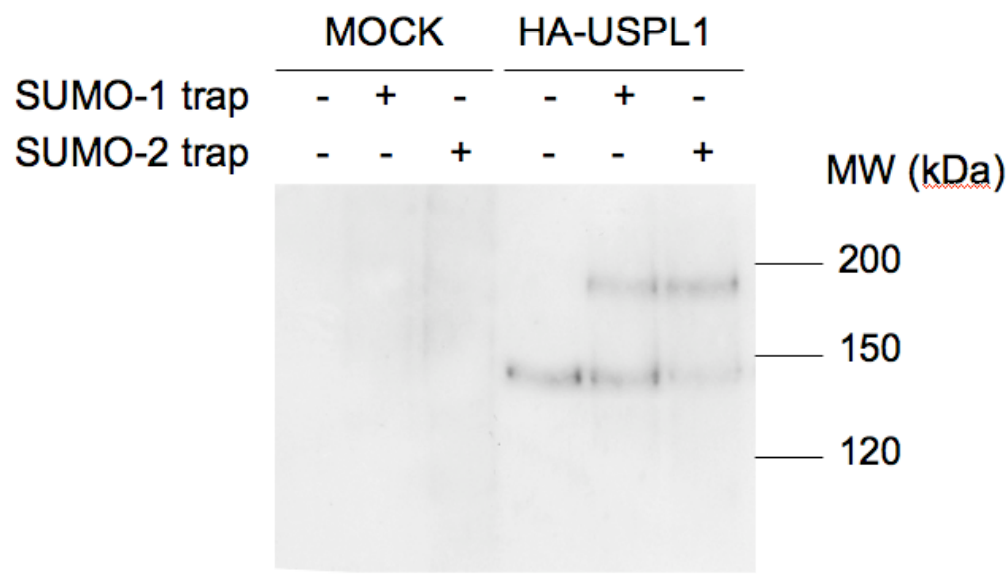

Fig 13. USPL1 reacts with SUMO-VMEs.

HEK 293T cells were transfected with HA-USPL1 using calcium phosphate precipitation method

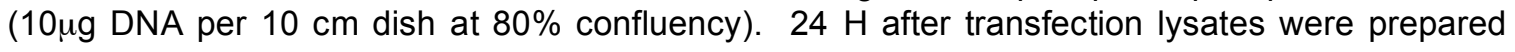
and subjected to anti-HA IP, followed by HA-peptide elution (60 $\mathrm{\mu l}$ of final eluate). Eluates were divided in 3 parts and incubated with either SUMO-1-VME, SUMO-2-VME or buffer. Samples were analyzed by SDS-PAGE followed by anti-HA Western Blotting. 
The alignment of the USPL1 C19 domain with C19 domains of ubiquitin specific proteases revealed the presence of a conserved catalytic triad in USPL1 (Figure 20). Therefore I decided to test whether USPL1 is a SUMO isopeptidase. First, I tested if USPL1 purified from mammalian cells can be labeled with SUMO-VME. In order to do so, HEK293 cells were transfected with HA-USPL1. One day after transfection cells were lysed, HA-USPL1 was immunopurified, eluted from the beads with an HA-peptide and incubated with either SUMO-1-VME, SUMO-2VME or buffer. Samples were analyzes by immunoblotting with anti-HA antibodies. HA-USPL1 could be labeled both by SUMO-1 and SUMO-2-VME (Figure 13). This fact strongly suggested that USPL1 is a SUMO protease.

To further confirm that USPL1 is a SUMO isopeptidase I cloned and expressed its catalytic domain (USPL1cat). The region chosen for a recombinant expression was picked up based on sequence aligment of USPL1 from different species and its secondary structure prediction. Three different fragments were chosen for expression trials, residues $212-489,212-502$ and 212-514. To determine optimal expression conditions I tested different E.coli strains, temperatures, IPTG concentrations and expression times (summarized in Figure 14). A soluble protein was obtained by expressing the residues 212-514 of USPL1 N-terminally tagged with His-GST in E.coli Rosetta2 strain at $15^{\circ} \mathrm{C}$ for 16 hours after induction with $0.5 \mathrm{mM}$ IPTG. The protein was purified by glutathione affinity chromatography, followed by TEV cleavage, removal of the HIS-GST tag as well as uncleaved fusion protein by Nickel affinity chromatography. The final step involved the size-exclusion chromatography. With this protocol I obtained protein of very high purity with a yield of $1 \mathrm{mg}$ per 1 liter of bacterial culture (Figure 14). 
A

\section{E.coli Rosetta}

\begin{tabular}{|l|l|c|l|l|l|l|}
\hline tag & residues & temperature & IPTG concentration & induction time & solubility & yield \\
\hline $\mathrm{N}$-term HIS-GST & $212-489$ & 37 & $1 \mathrm{mM}$ & $3 \mathrm{H}$ & - & $\mathrm{n} / \mathrm{d}$ \\
\hline $\mathrm{N}$-term HIS-GST & $212-489$ & $250.1 \mathrm{mM}$ & $6 \mathrm{H}$ & - & $\mathrm{n} / \mathrm{d}$ \\
\hline $\mathrm{N}$-term HIS-GST & $212-489$ & $160.1 \mathrm{mM}$ & $12-16 \mathrm{H}$ & - & $\mathrm{n} / \mathrm{d}$ \\
\hline $\mathrm{N}$-term HIS-GST & $212-502$ & $371 \mathrm{mM}$ & $3 \mathrm{H}$ & - & $\mathrm{n} / \mathrm{d}$ \\
\hline $\mathrm{N}$-term HIS-GST & $212-502$ & $250.1 \mathrm{mM}$ & $6 \mathrm{H}$ & - & $\mathrm{n} / \mathrm{d}$ \\
\hline $\mathrm{N}$-term HIS-GST & $212-502$ & $160.1 \mathrm{mM}$ & $12-16 \mathrm{H}$ & - & $\mathrm{n} / \mathrm{d}$ \\
\hline $\mathrm{N}$-term HIS-GST & $212-514$ & $371 \mathrm{mM}$ & $3 \mathrm{H}$ & - & $\mathrm{n} / \mathrm{d}$ \\
\hline $\mathrm{N}$-term HIS-GST & $212-514$ & $250.1 \mathrm{mM}$ & $6 \mathrm{H}$ & - & $\mathrm{n} / \mathrm{d}$ \\
\hline $\mathrm{N}$-term HIS-GST & $212-514$ & 16 & $0.1 \mathrm{mM}$ & $12-16 \mathrm{H}$ & - & $\mathrm{n} / \mathrm{d}$ \\
\hline
\end{tabular}

\section{E.coli pLysS}

\begin{tabular}{|l|l|r|l|l|l|l|}
\hline tag & residues & temperature & IPTG concentration & induction time & solubility & yield \\
\hline $\mathrm{N}$-term HIS-GST & $212-489$ & 37 & $1 \mathrm{mM}$ & $3 \mathrm{H}$ & - & $\mathrm{n} / \mathrm{d}$ \\
\hline $\mathrm{N}$-term HIS-GST & $212-489$ & 25 & $0.1 \mathrm{mM}$ & $6 \mathrm{H}$ & - & $\mathrm{n} / \mathrm{d}$ \\
\hline $\mathrm{N}$-term HIS-GST & $212-489$ & 16 & $0.1 \mathrm{mM}$ & $12-16 \mathrm{H}$ & - & $\mathrm{n} / \mathrm{d}$ \\
\hline $\mathrm{N}$-term HIS-GST & $212-502$ & 37 & $1 \mathrm{mM}$ & $3 \mathrm{H}$ & - & $\mathrm{n} / \mathrm{d}$ \\
\hline $\mathrm{N}$-term HIS-GST & $212-502$ & 25 & $0.1 \mathrm{mM}$ & $6 \mathrm{H}$ & - & $\mathrm{n} / \mathrm{d}$ \\
\hline $\mathrm{N}$-term HIS-GST & $212-502$ & 16 & $0.1 \mathrm{mM}$ & $12-16 \mathrm{H}$ & - & $\mathrm{n} / \mathrm{d}$ \\
\hline $\mathrm{N}$-term HIS-GST & $212-514$ & 37 & $1 \mathrm{mM}$ & $3 \mathrm{H}$ & + & $\mathrm{n} / \mathrm{d}$ \\
\hline $\mathrm{N}$-term HIS-GST & $212-514$ & 25 & $0.1 \mathrm{mM}$ & $6 \mathrm{H}$ & + & $\mathrm{n} / \mathrm{d}$ \\
\hline $\mathrm{N}$-term HIS-GST & $212-514$ & 16 & $0.1 \mathrm{mM}$ & $12-16 \mathrm{H}$ & + & $100 \mathrm{ug} / 10 \mathrm{l}$ culture \\
\hline
\end{tabular}

\section{E.coli Rosetta2}

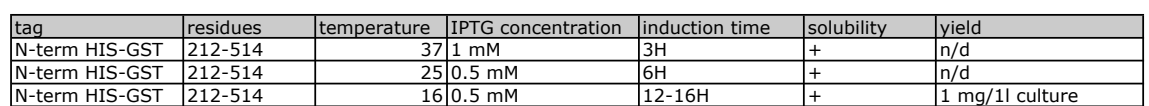

B

Bacterial expression

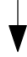

lysis

$\checkmark$

100.000 g centrifugation

$\checkmark$

Capture on glutathionebeads

Glutathione elution

TEV cleaVage

Removal of His-GST and uncleaved over $\mathrm{Ni}$ beads$$
\nabla
$$

Size exclusion

chromatography (S-75)
C

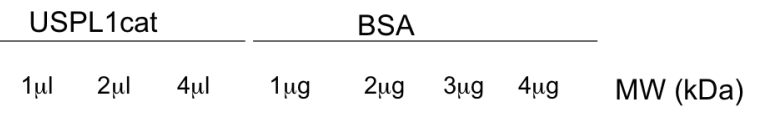

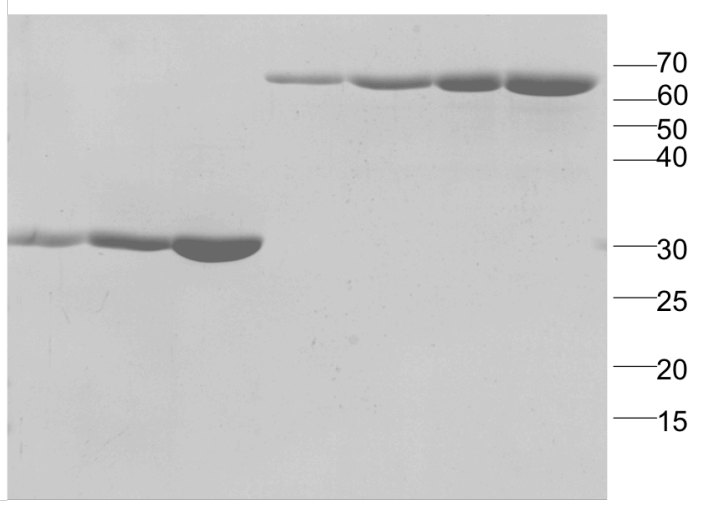

Figure 14. Expression and purification of USPL1 catalytic domain

A. Summary of expression trials. B Scheme of purification. C SDS-PAGE followed by Coomassie staining was used to determine the purity and the concentration of recombinant USPL1cat . 


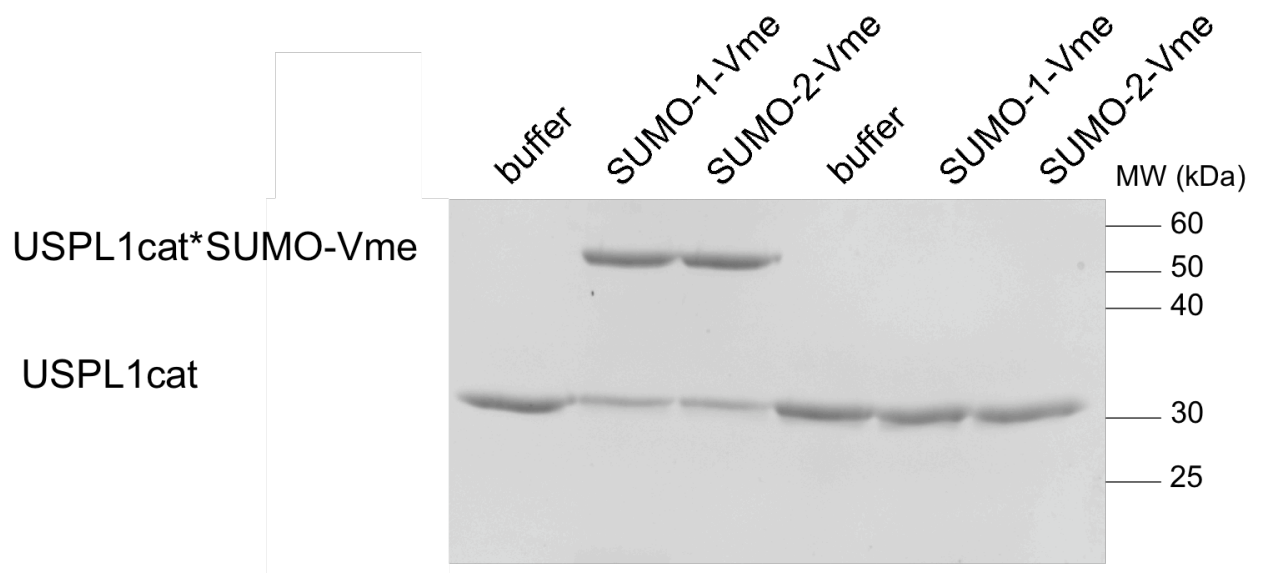

Figue 15. The reaction of USPL1 with SUMO traps depends on the catalytic cysteine C236.

$1 \mu \mathrm{g}$ of recombinant USPL1cat wild type (wt) or catalytic mutant (C236S) was incubated at $37^{\circ}$ for 30 minutes with $1 \mu \mathrm{g}$ of either SUMO-1-VME, SUMO-2-VME or buffer (total volume 20 $\mu \mathrm{l}$ ).

Samples were analyzed by SDS-PAGE followed by Coomassie staining.

To examine whether USPL1 is modified by SUMO-VME at the active site I generated also a mutant version of USPL1cat, in which the predicted catalytic cysteine was replaced by serine. Both proteins were next subjected to SUMOVME labeling. Wild type USPL1 catalytic domain was indeed labeled upon treatment with SUMO-1-VME or SUMO-2-VME, while the mutant showed no reactivity (Figure 15). This result indicated that SUMO-VME indeed labels the catalytic cysteine of USPL1, and that this reaction does not require any additional factors, therefore strongly suggesting that USPL1 is a SUMO protease.

To demonstrate actual isopeptidase activity it was necessary to show that USPL1 can remove SUMO from a target. To do this, RanGAP in vitro sumoylated with either SUMO-1 or SUMO-2 was incubated with catalytic amount of USPL1cat for different times. Samples were analyzed by SDS-PAGE and Coomassie staining. USPL1 was able to remove both SUMO-1 and SUMO-2 from RanGAP, however the reaction was more efficient for RanGAP modified with SUMO-2 (Figure 16). 
This experiment shows that USPL1 is indeed a SUMO isopeptidase that exhibits strong preference towards SUMO-2.

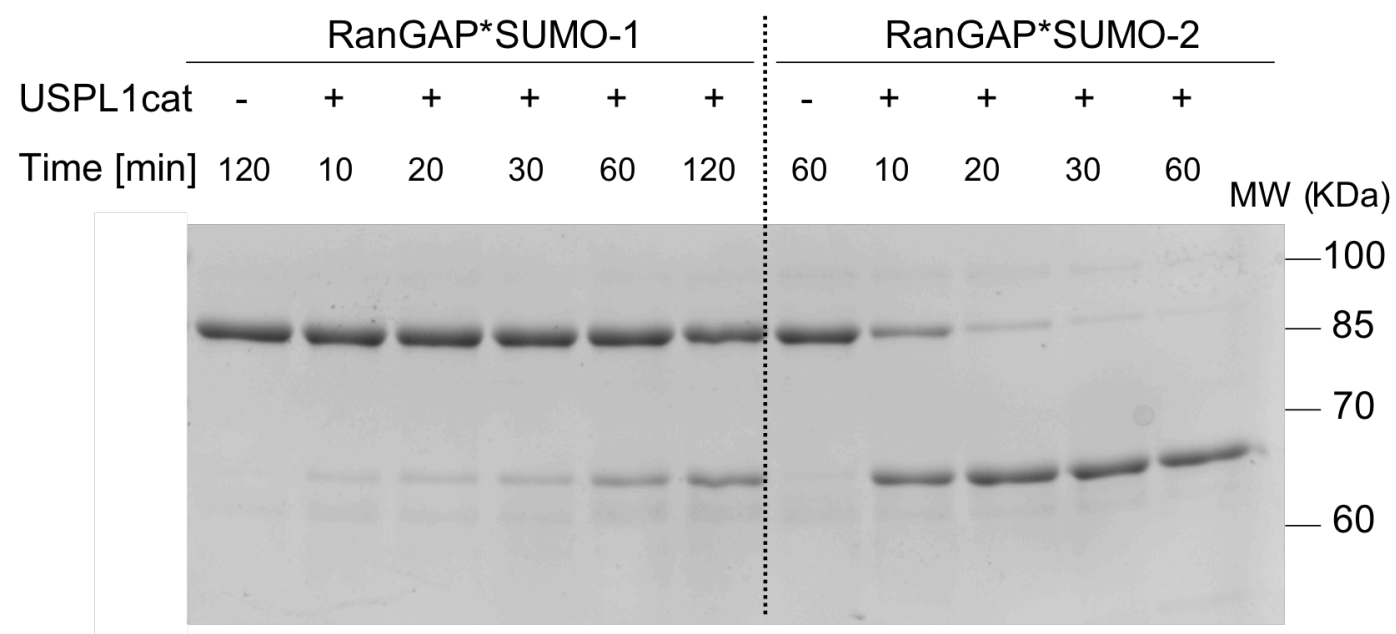

Figure 16. USPL1cat is a SUMO isopeptidase with preference towards SUMO-2.

RanGAP sumoylated in vitro with either SUMO-1 or SUMO-2 $(2 \mu \mathrm{M})$, was incubated at $37^{\circ} \mathrm{C}$ with USPL1cat $(4 \mathrm{nM})$ or buffer (-) in total volume of $20 \mu \mathrm{l}$ for indicated times. The reaction was terminated by adding SDS sample buffer and boiling. Samples were analyzed by SDS-PAGE followed by Coomassie staining. (RanGAP1-SUMO-1 provided kindly by Dr. Andreas Werner).

Similar to Ubiquitin, SUMO-2 can form polymeric chains in vivo. Members of the USP family differ in their specificity towards the type of Ubiquitin chain and at least in some cases this specificity is a feature of the catalytic domain. We were interested whether USPL1cat can cleave SUMO-2 chains. To address this matter, in vitro prepared SUMO-2 chains were incubated with USPL1cat for different time periods and the samples were analyzed by SDS-PAGE. For positive control the catalytic domain of SENP1 was used, for negative control the Ubiquitin specific isopeptidase of the USP family, USP5, was used. USPL1cat was able to cleave SUMO-2 chains (Figure 17). 


\section{- USPL1cat SENP1cat USP5}

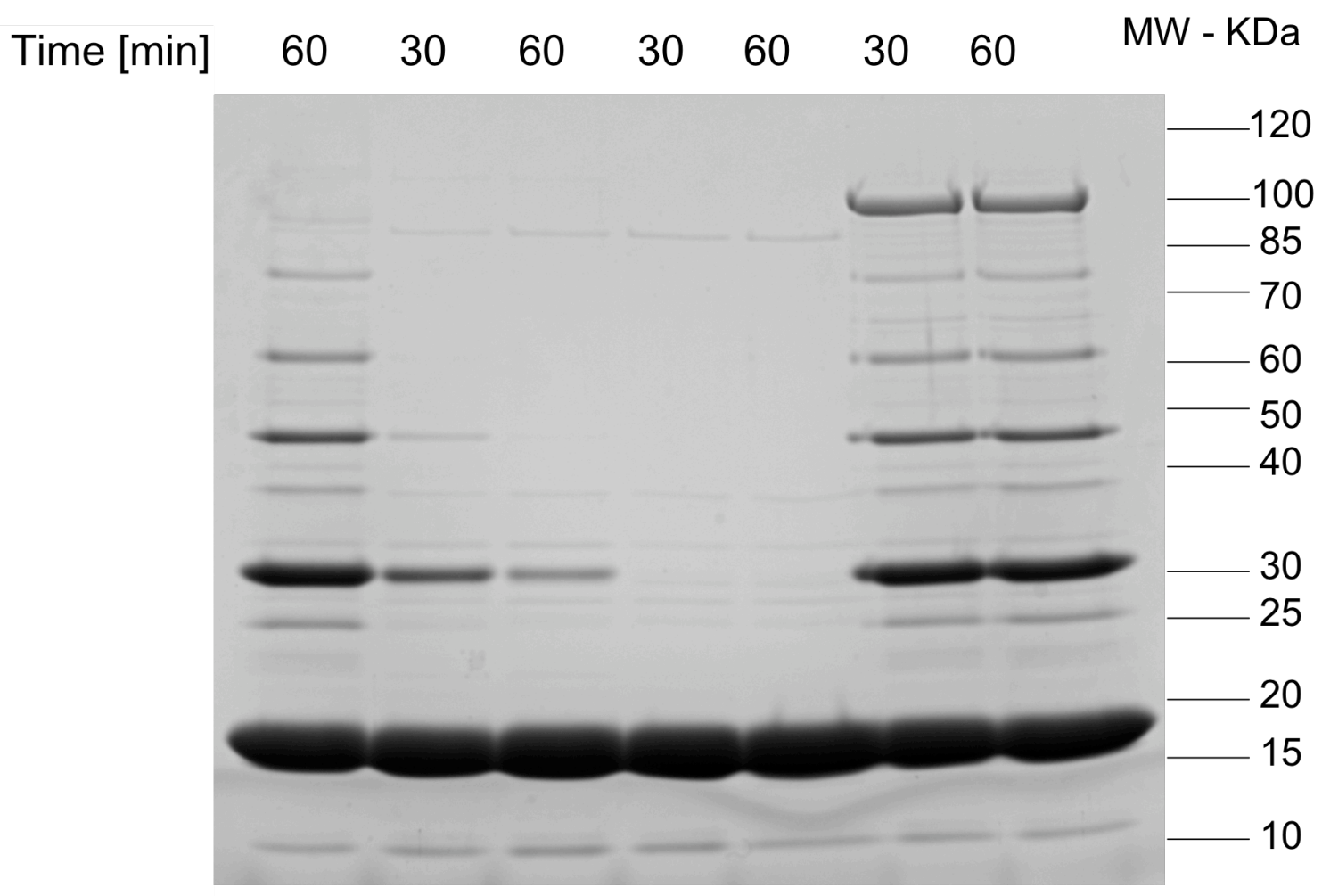

Figure 17. USPL1cat can cleave SUMO-2 chains.

5nM USPL1 or SENP1cat or $150 \mathrm{nM}$ USP5 were incubated with $5 \mu$ in vitro prepared SUMO-2 chains in total a reaction volume of $40 \mu \mathrm{l}$ for indicated times at $37^{\circ} \mathrm{C}$. Reaction was stopped by adding sample buffer. Samples were analyzed by SDS-PAGE followed by Coomassie staining. (SUMO-2 chains and USP5 kindly provided by Sarah Schulz).

Based on sequence homology, USPL1 is classified as a ubiquitin isopeptidase. Several of the USP family members exhibit specificity toward Ubls, whereas other members can act both on Ubiquitin and other Ubls (see introduction). Therefore it was necessary to test USPL1 specificity towards Ubiquitin. Binding of ubiquitin by the catalytic domain is necessary for the ability of ubiquitin proteases to cleave it, therefore USPL1cat ability to bind SUMO and Ubiquitin was examined. USPL1 catalytic domain was incubated with either SUMO1,SUMO-2 or Ubiquitin immobilized on sepharose beads. USP5 (a known 
interactor of ubiquitin) was used as a positive control for Ubiquitin beads. After extensive washing bound protein was eluted by the addition of SDS sample buffer and boiling. The eluates were analyzed by SDS-PAGE. USPL1 bound both SUMO-1 and SUMO-2 but not Ubiquitin (Figure 18). This suggested that USPL1 can not cleave ubiquitin.

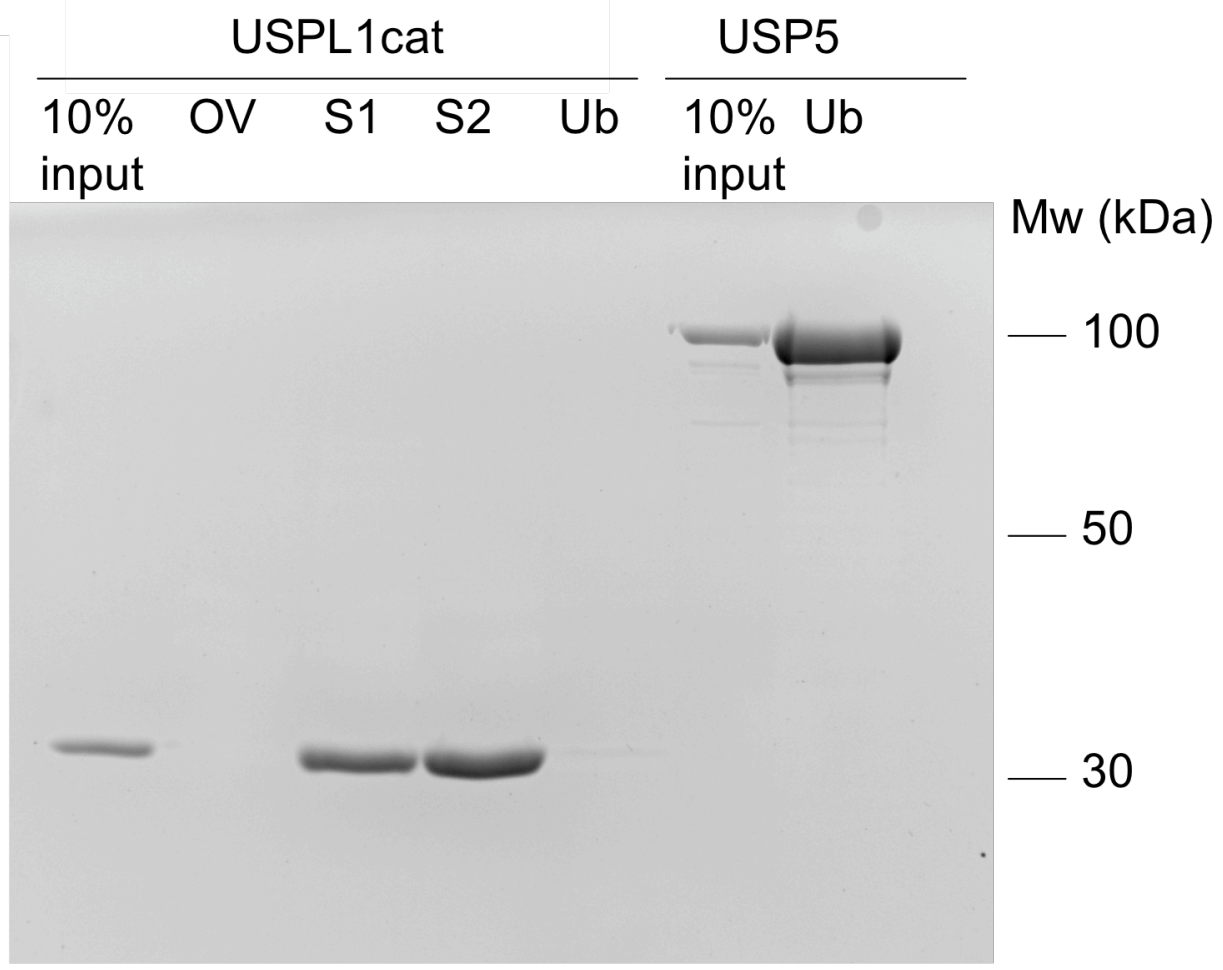

Fig. 18 USPL1 binds non-covalently to SUMO but not to Ubiquitin

$10 \mu \mathrm{g}$ of recombinant USPL1cat was incubated with $20 \mu \mathrm{g}$ of either SUMO-1 (S1), SUMO-2(S-2), Ubiquitin (Ub) or ovalbumin (OV) immobilized on sepharose beads. After extensive washing of beads, the bound proteins were eluted with SDS sample buffer. The eluates were analyzed by SDS-PAGE and visualized by Coomassie staining. (sepharose beads with immobilized proteins and USP5 were kindly provided by Sarah Shulz) 
Finally, USPL1's ability to cleave Ubiquitin was directly analyzed using Ubiquitin$A M C$ as a substrate. Ubiquitin-AMC is a fluorogenic substrate that releases fluorescent $A M C$ upon treatment with Ubiquitin protease. The fluorescence is proportional to the amount of the released AMC and can be used to monitor

Ub-AMC

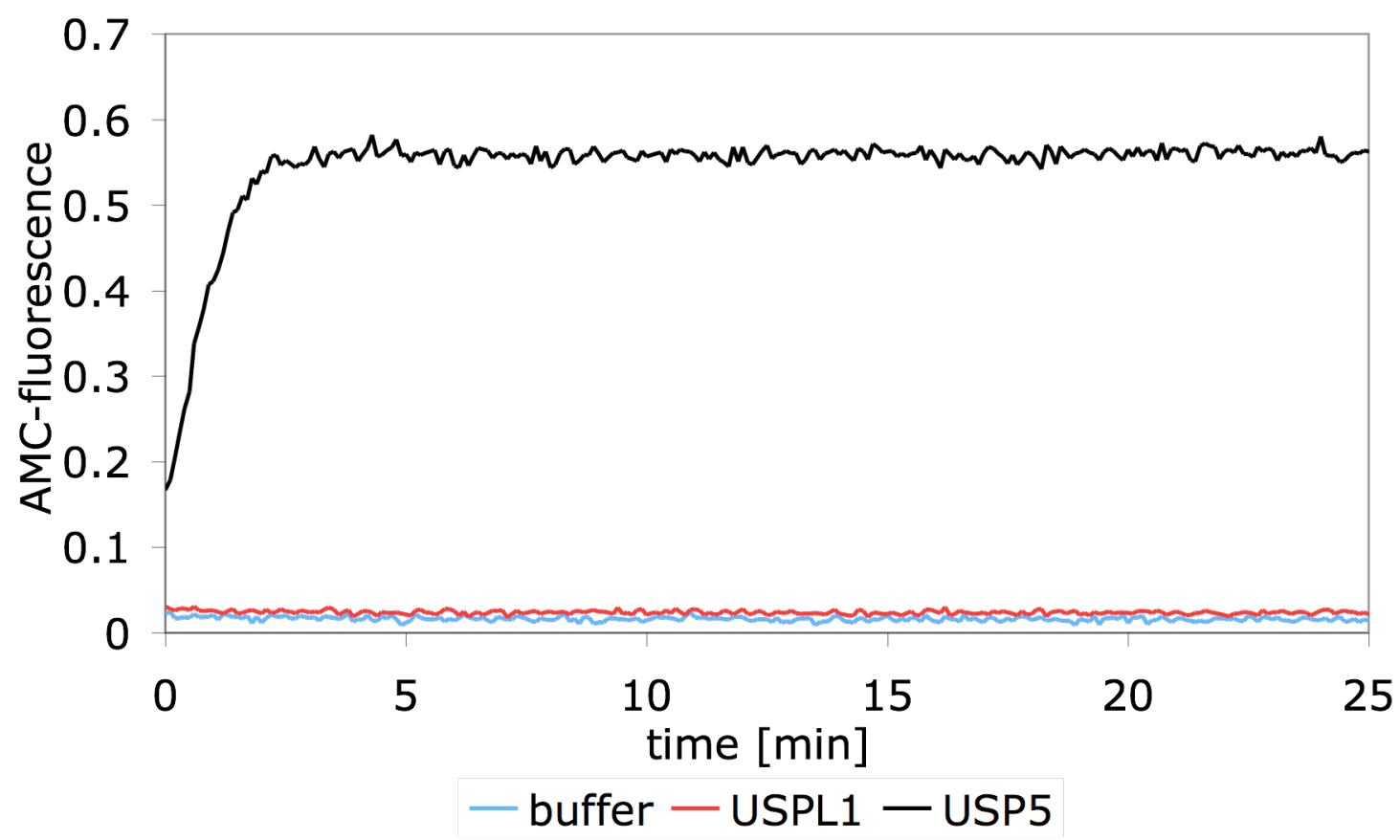

Figure 19. USPL1 does not exhibit specificity towards Ubiquitin-AMC. $5 \mu \mathrm{M}$ Ubiquitin-AMC was incubated with either $5 \mathrm{~nm}$ USP5, $50 \mathrm{nM}$ USPL1cat or buffer. AMC fluorescence was measured and shown as a function of time. (USP5 kindly provided by Sarah Shulz)

enzymatic activity of Ubiquitin proteases. USPL1 showed no activity at all, while the positive control USP5 showed the expected activity. (Figure 19).

The findings presented here demonstrate that USPL1 is a SUMO, but not Ubiquitin, specific isopeptidase. It shows a strong preference for SUMO-2 conjugates and is able to cleave SUMO-2 chains. 


\section{DISCUSSION}

Here, I describe the identification and initial biochemical characterization of a novel SUMO specific isopeptidase, USPL1. This enzyme was previously classified as an inactive Ubiquitin isopeptidase based on sequence homology. We also show that USPL1 prefers SUMO-2 to SUMO-1 and does not exhibit an enzymatic activity towards Ubiquitin.

\subsection{USPL1 is an atypical member of the USP family.}

Alignment of the catalytic domain of USPL1 with those of other USPs shows that the similarity between them is predominantly restricted to two sequence motifs, the Cys-box and the His-box (Figure 20). These motifs, which are present in all members of the USP family, contain residues that are responsible for catalysis and residues participating in binding of the Ubiquitin C-terminus (Hu et al., 2002, Renatus et al., 2004, Nijman et al 2005, ) (Figure 21). In USPL1 the residues of the catalytic triad are conserved $(\mathrm{C} 236, \mathrm{H} 456, \mathrm{D} 473)$ but the residues binding the $\mathrm{C}$-terminus of ubiquitin are not. The most striking example is the absence of the non-catalytic histidine important for binding of the C-terminus of Ubiquitin within the His-box. This residue is present in almost all other USPs (Quesada et al., 2004). Lack of this residue was a reason for suggestion that USPL1 is an inactive Ubiqutin protease (swiss-prot/Q5W0Q7).

A prominent difference between USPL1 and other members of the USP family is the lack of the QQD-box in USPL1. Residues of this box form a loop that participates in binding of the Ubiquitin C-terminus (Hu et al., 2002, Renatus et al., 2004). Instead, USPL1 has a stretch of residues that are highly conserved in USPL1 from different species but absent from other USPs (Figure 20). The conservation of this region and its putative positioning close to the QQD-box in other USPs makes it a good candidate for a binding site for the C-terminus of SUMO. 
Cys-box

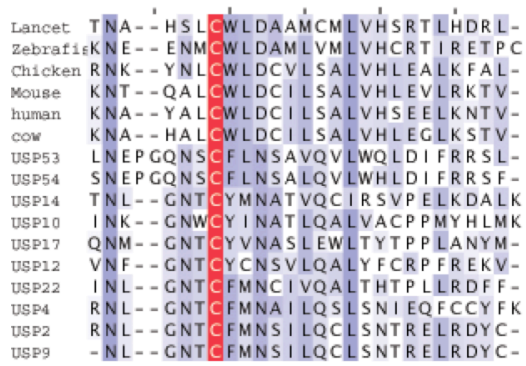

QQD-motif

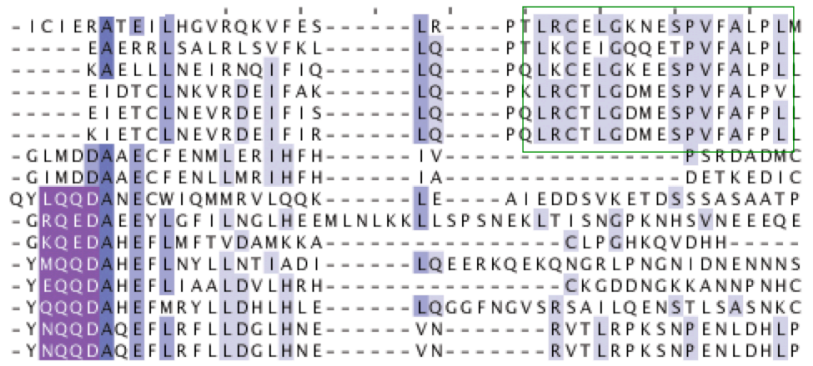

His-box

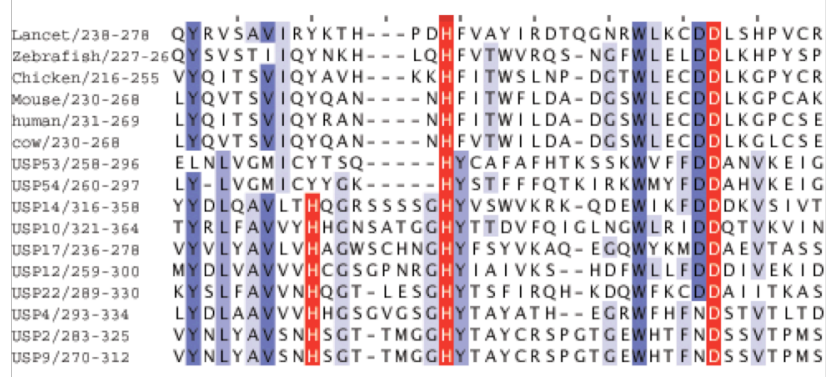

Figure 20. Catalytic domain of USPL1 has conserved Cys-box and His-box but the QQD-motif is absent from it. Catalytic domains of USPL1 from several species were aligned with catalytic domains of several members of the USP family. Conserved residues are shaded, the residues of catalytic triad are shown in red, the residues within QQD-motif in violet and the conserved region of USPL1 that may participate in SUMO binding is marked with a green box. (the aligment was prepared using MUSCLE online application at www.ebi.ac.uk, and visualized with Jalview online editor at www.jalview.org)

The afore mentioned differences between USPL1 and other USPs are easy to explain, since the C-termini of SUMO and Ubiquitin differ significantly. Consequently, it is reasonable to suspect that they are recognized by the proteases in a different way.

USPs bind to the ß-grasp domain of Ubiquitin and the recognition is based on the complementary shapes of Ubiquitin and USP and is mediated by numerous weak interactions (Hu et al., 2002, Renatus et al., 2004). Most probably USPL1 binds to the ß-grasp domain of SUMO, however it is not possible to predict the amino 
acid residues in USPL1 or SUMO that are essential for binding. Structural analysis of a USPL1/SUMO complex and mutagenesis studies will be needed to elucidate the specificity of USPL1 for SUMO.
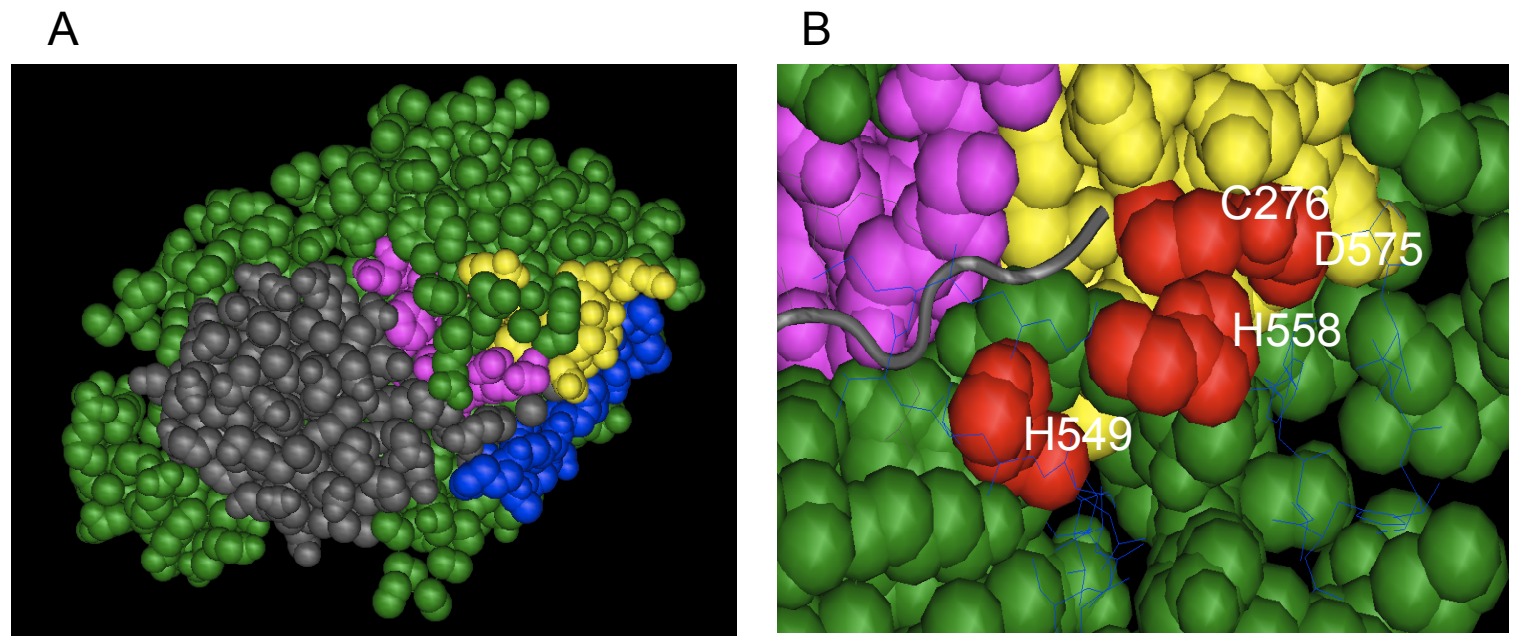

Figure 21. Structural elements of USP2 participating in Ubiquitin recognition.

A) Overall arrangement of the USP2/Ubiquitin complex. Ubiquitin is shown in grey, QQD motif of USP2 in magenta, Cys-box in yellow and His-box in blue. Remaining residues of USP2 are shown in green. B) Catalytic residues of USP2 as well as the non catalytic histidine of the His-box are shown in red. (Prepared using Cn3D application and PBD file 1TDZ)

USPL1 is not the only member of the USP family that exhibits specificity towards a Ubl other than Ubiquitin. However, other Ubls are much more similar to Ubiquitin than SUMO is, especially at their C-termini. Therefore it is not surprising that the QQD motif is present in these USPs. A recent screen for ISG15 crossreactive isopeptidases revealed that $U S P 2,5,13,14$ and18 are able to react with ISG15-VS, an ISG-15 derivative functioning in analogic way to SUMO-VME (Catic et al .,2007). ISG15 is a close homologue of Ubiquitin and contains two ßgrasp domains arranged in a tandem manner. The last six C-terminal residues are identical between ISG15 and Ubiquitin. Some of the ISG-15 proteases have dual specificity (USP2,14), whereas others like USP18 cannot cleave ubiquitin 
containing conjugates. Another closely related Ubl protein Nedd8 is cleaved by USP21, a protease that can also work on Ubiquitin (Gong et al., 2002).

Similar to USPL1 another Ubl protease's specificity was previously misattributed. SENP8/DEN1/NEDP1, which belongs to the UIp/SENP family, was predicted to be a SUMO specific protease based on its sequence. However, biochemical assays revealed that it works on Nedd8 instead (Gan-Erdene et al., 2003, Mendoza et al., 2003). DEN1 is the least related to the other members of the UIp/SENP family and together with its homologues forms a separate branch of the UIp/SENP family. Recently obtained structural data provided insight into the mode that DEN1 uses to recognize Nedd8. The motifs utilized by DEN1 for Nedd8 recognition are found in similar places as motifs through which SENPs recognize SUMO, however the identity of this residues participating in binding is different (Reverter et al., 2005).

\subsection{Conservation of USPL1}

USPL1 homologues can be found in all vertebrates and in lower invertebrates like sea anemone, however it is absent from higher invertebrates like $D$. melanogaster or C.elegans, which suggests that USPL1 is an old gene that was lost during evolution of invertebrates. 


\section{USPL1}

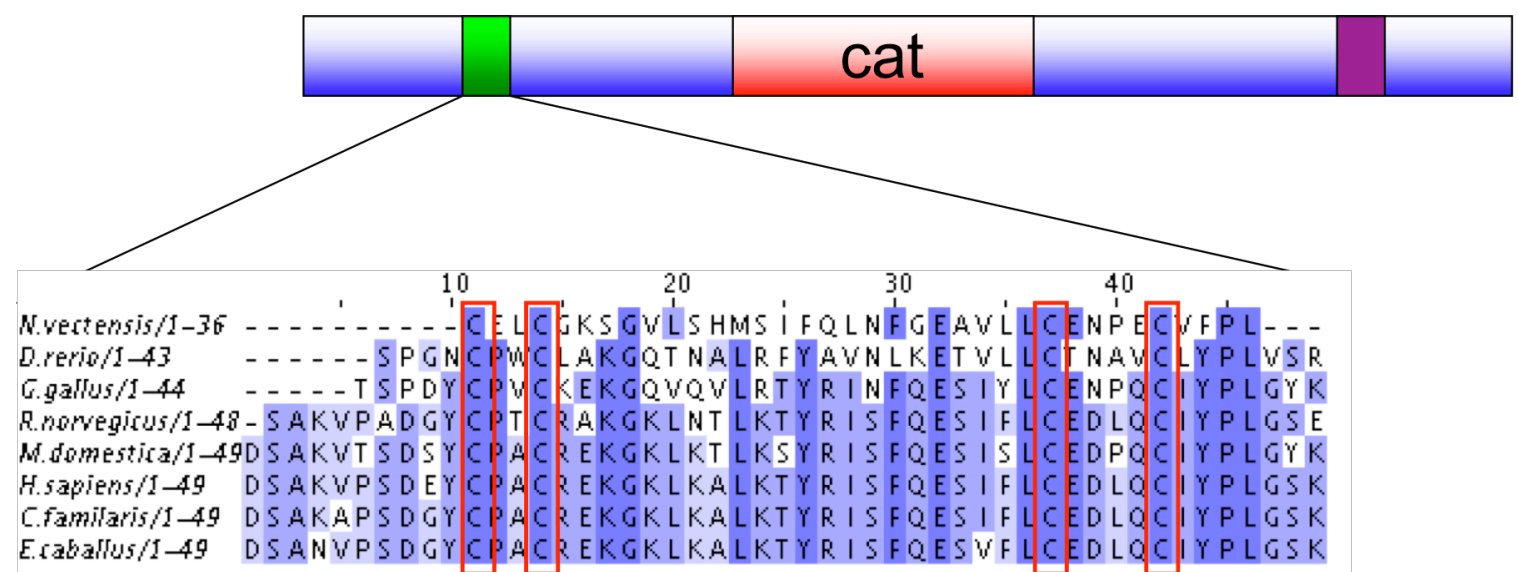

Figure 22. Domain organization of USPL1. The catalytic domain is shown in red, The putative N-terminal Zinc Finger domain is shown in green and the stretch of positive residues within C-terminus is shown in violet. Aligment of the putative Zinc finger is shown with conserved residues shaded and cysteins marked with red boxes. (the aligment was prepared using MUSCLE online application at www.ebi.ac.uk, and visualized with Jalview online editor at www.jalview.org)

A sequence alignment of USPL1 from different species performed by Dr. Kay Hoffman (Miltenyi Biotec, Köln) suggests the presence of three domains: an Nterminal domain, a catalytic domain localized in the middle and the C-terminal domain (Figure 22). Conservation is most prominent within the catalytic domain, especially for the catalytic residues and the region described previously that may mediate interaction with the $\mathrm{C}$ terminus of SUMO. Within the $\mathrm{N}$-terminal domain a forty amino acid region containing four completely conserved cysteines is present. Presence of these cysteines suggests that this may be a Zinc Finger domain. Within the C-terminal part short conserved stretches can be found, including a region rich in positively charged residues. 


\subsection{Functions of USPL1}

Our current knowledge on USPL1 is still insufficient to allow prediction of its physiological function, however information found in databases provides some interesting clues. The Zebra fish homologue of USPL1 was identified in a screen designed to find genes necessary for embryonic development (Amsterdam et al., 2004). The phenotype of the mutant strain is characterized by strong necrosis in the central nervous system and head, leading to death.

The chicken homolog of USPL1 is called retinovin as it is selectively expressed in early stages of retina development (Itami et al., 2002). Both of these studies suggest that USPL1 has a role in development.

One interesting observation comes from the GEO profiles database (www.ncbi.nlm.nih.gov/sites/entrez?db=geo). In HeLa cells, levels of USPL1 mRNA are upregulated in response to heat shock. It is well known that SUMO$2 / 3$ is predominantly present in the unconjugated form, but after heat shock a rapid increase of SUMO-2/3 conjugates is observed. After the temperature comes back to normal, a recovery phase takes place during which highmolecular weight SUMO-2/3 conjugates disappear (Saitoh and Hinchey 2000). Upregulated level of USPL1 after heat shock could be a mechanism that cells use to remove SUMO-2/3 conjugates. The putative Zinc finger present in the $\mathrm{N}$ terminus gives another hint about possible USPL1 function. Many members of the USP family have Ubiquitin binding domains, some of which are Zinc fingers, localized $\mathrm{N}$-terminally from their catalytic domains. The exact role of these domains is still unclear, but in some cases they are important for binding and the effective processing of Ubiquitin chains. By analogy, the putative Zinc finger of USPL1 may be important for SUMO-2/3 chain cleavage. USPL1 is related to the Ubiquitin proteases, which are known to play a role in protein degradation. Recently SUMO-2/3 chains were also implicated in this process (Tatham et al., 2008, Lallemand-Breitenbach $V$ et al., 2008). A very attractive hypothesis is therefore the involvement of USPL1 in SUMO-2/3 mediated protein degradation. 
Another intriguing possibility is an interaction between USPL1 and HCF-1. Similar to SENP5, USPL1 posses HCF-1 binding motif (1023-1026 DHNY). Although it is more probable that in our experiment HCF-1 was copurified with SENP5, due to SENP5's abundance and specific reaction with SUMO-2-VME, it is still possible that HCF-1 attracts USPL1 to desumoylate transcription factors or/and histones. HCF-1 is a target for SUMO-2 modification and SENP5 or USPL1 can be responsible for its desumoylation. The levels of sumoylated HCF1 increase after inhibition of proteasome, which suggests that it may be a target for SUMO-2 mediated protein degradation (Schimmel et al., 2008).

\subsection{Open questions and further work}

The USPL1 studies described in this work can go in at least two directions: structural and functional. First it would be very interesting to obtain a crystal structure of USPL1 in complex with SUMO. This would address the question of how USPL1 structurally differs from other USPs and how it recognizes SUMO. Towards this goal we have established a collaboration with Prof. Titia Sixma (NKI, Amstardam). Characterization of the putative Zinc finger would allow us to address whether it is a new SUMO binding domain and if so, whether it has a role in USPL1 catalytic activity. My attempts to investigate the role of the putative Zinc Finger were unsuccessful as I could not obtain soluble recombinant protein containing this region (data not shown). Functional studies should allow understanding the role of USPL1 and its possible involvement in the heat shock response. Initial data obtained by overexpression of YFP-USPL1 fusion protein suggest that USPL1 is a nuclear protein (data not shown), however this still needs to be confirmed for the endogenous protein. Knocking down USPL1 using siRNA could be used to address its role during heat shock in cell culture, whereas a knock out mouse model would be a good option to study its possible role during development. The most interesting question that arises is that for USPL1 specific substrates. Their identification should significantly contribute to 
understanding its role. To do this, several approaches can be used. Immunoprecipitation of USPL1 or a yeast-two-hybrid approach could identify binding partners, some of which may be USPL1 targets. Another possibility is a proteomic approach in which proteins that show increased sumoylation in the absence of USPL1 can be identified. These would also be putative targets of USPL1.

\subsection{Are there more SUMO specific proteases among the USP family?}

USPL1 was described in the database as an inactive Ubiquitin protease which was attributed to the absence of the non-catalytic histidine within its Hisbox. A similar study reports the inactivity of USP53 and USP54. A number of human USPs were expressed in bacteria together with Ub-ß-galactosidase fusion protein. The activity was judged by the cleavage of the fusion protein. In this kind of assay USP53 and closely related USP54 had no activity (Quesada et al., 2004). Both these proteins lack the non-catalytic histidine residue, but a closer look reveals that all the catalytic residues are present in these proteins. Their QQD box is different from that of other USPs (Figure 20). Although those two proteases are believed to be inactive it is worthwhile to check whether they could be specific for SUMO or Ubls other than ubiquitin.

\subsection{Further approaches to identify novel SUMO specific isopeptidases}

It is possible that more SUMO specific proteases exist. To further investigate this the following approaches can be used.

1) Educated guess - USP53 and 54 were reported to be inactive due to the lack of the conserved noncatalytic histidine within the His-box. However, all the 
residues important for catalysis are conserved in both proteins, therefore it is possible that they can work on SUMO or another Ubl.

2) Biochemical purification from biological material using SUMO-VME. The approach described here is based on lysates from HeLa cells as the source of proteins, which might not be optimal. Sumoylation is involved in meiosis, which does not normally take place in somatic cells. Therefore using lysates prepared from testes as a material may provide more relevant candidates. Also lysates prepared from brain tissue as a source would be a good idea as that is where many proteins are expressed. Also the cellular fraction that we focused on might be not the optimal one. Many SUMO targets are chromatin associated proteins, therefore it would make sense to also test the chromatin associated fraction.

3) Biochemical purification using SUMO derivates other than SUMO-VME. Chemical probes used to study the Ubiquitin system were developed several years ago (Borodovsky et al., 2001 and 2002). They were successfully used to identify new ubiquitin and other Ubl like proteases. They can also be used to study the enzymatic activity of proteases. The specificity of the probe towards the enzyme depends on the chemical moiety attached to the C-terminus. It was observed that a given Ubl derivative can differ significantly in specificity towards proteases of the same family (Borodovsky at el., 2002). Therefore using chemical probes other than SUMO-VME could also be considered.

4) SUMO-4 is a very enigmatic protein and so far it is not know whether it is processed and therefore whether it can be conjugated to targets. This is believed to be caused by a proline residue in the C-terminus of SUMO-4 (Owerbach et al., 2005). Preparing a SUMO-4VMe could help to answer the question whether there are proteases that can recognize the SUMO-4.

5) Screening bacterial expression libraries using the FRET based assay. Although the screen that we performed here did not result in identification of a SUMO protease, we have shown that a FRET based assay can be applied to a high-throughput screen. It would be worth to screen a library covering much 
larger number of ORFs than the library that we used (only 4000). Introducing some modifications should also be considered. We used RanGAP1 modified with SUMO-1, however most of the known SUMO proteases exhibit specificity towards SUMO-2 (Dasso 2007). Therefore using RanGAP modified with SUMO2 seems to be a good idea. Full length SUMO proteases exhibit specificity not only towards different SUMO isoforms but also towards substrate, therefore using a substrate different than RanGAP should also be considered. 


\section{References}

Amerik, A.Y., Hochstrasser, M.

Mechanism and function of deubiquitinating enzymes.

Biochim Biophys Acta. 2004, 1695, 189-207.

Amsterdam, A., Nissen, R.M, Sun, Z., Swindell, E.C., Farrington, S., Hopkins, N. Identification of 315 genes essential for early zebrafish development.

Proc Natl Acad Sci U S A. 2004, 101:12792-7.

Baba, D., Maita, N., Jee, J.G., Uchimura, Y., Saitoh, H., Sugasawa, K., Hanaoka, F., Tochio, H., Hiroaki, H., Shirakawa, M.

Crystal structure of thymine DNA glycosylase conjugated to SUMO-1.

Nature. 2005, 435:979-82.

Bailey, D., O'Hare, P.

Characterization of the localization and proteolytic activity of the

SUMO-specific protease, SENP1.

J Biol Chem. 2004, 279:692-703.

Best, J.L., Ganiatsas, S., Agarwal, S., Changou, A., Salomoni, P., Shirihai, O., Meluh, P.B.,

Pandolfi, P.P., Zon, L.I.

SUMO-1 protease-1 regulates gene transcription through PML.

Mol Cell. 2002, 10:843-55.

Balakirev, M.Y., Jaquinod, M., Haas, A.L., Chroboczek, J.

Deubiquitinating function of adenovirus proteinase.

J Virol. 2002, 76 :6323-31.

Bernier-Villamor, V., Sampson, D.A., Matunis, M.J., Lima, C.D.

Structural basis for E2-mediated SUMO conjugation revealed by a complex between

ubiquitin-conjugating enzyme Ubc9 and RanGAP1.

Cell. 2002, 108:345-56.

Birnboim, H.C., Doly, J.

A rapid alkaline extraction procedure for screening recombinant plasmid DNA.

Nucleic Acids Res. 1979, 7:1513-23.

Bochtler, M., Ditzel, L., Groll, M., Hartmann, C., Huber, R.

The proteasome.

Annu Rev Biophys Biomol Struct. 1999, 28:295-317. 
Borodovsky, A., Ovaa, H., Kolli, N., Gan-Erdene, T., Wilkinson, K.D., Ploegh, H.L., Kessler, B.M.

Chemistry-based functional proteomics reveals novel members of the deubiquitinating enzyme family.

Chem Biol. 2002, 9:1149-59.

Bossis, G., Chmielarska, K., Gärtner, U., Pichler, A., Stieger, E., Melchior, F. A fluorescence resonance energy transfer-based assay to study SUMO modification

in solution.

Methods Enzymol. 2005, 398:20-32.

Bylebyl, G.R., Belichenko, I., Johnson, E.S.

The SUMO isopeptidase Ulp2 prevents accumulation of SUMO chains in yeast. J Biol Chem. 2003, 278:44113-20.

Catic, A., Fiebiger, E., Korbel, G.A, Blom, D., Galardy P,J., Ploegh, H.

Screen for ISG15-crossreactive deubiquitinases.

PLoS ONE. 2007, 2:e679

Cheng, C.H., Lo, Y.H., Liang, S.S., Ti, S.C., Lin, F.M., Yeh, C.H., Huang, H.Y., Wang, T.F.

SUMO modifications control assembly of synaptonemal complex and polycomplex in

meiosis of Saccharomyces cerevisiae.

Genes Dev. 2006,20:2067-81.

Cheng, J., Bawa, T., Lee, P., Gong, L., Yeh, E.T.

Role of desumoylation in the development of prostate cancer.

Neoplasia. 2006, 8:667-76.

Cheng, J., Kang, X., Zhang, S., Yeh, E.T.

SUMO-specific protease 1 is essential for stabilization of HIF1alpha during hypoxia.

Cell. 2007, 131:584-95

Chiu, Y.H., Sun, Q., Chen, Z.J.

E1-L2 activates both ubiquitin and FAT10.

Mol Cell. 2007, 27:1014-23.

Chong, S., Mersha, F.B., Comb, D.G., Scott, M.E, Landry, D., Vence, L.M., Perler, F.B., Benner, J., Kucera, R.B, Hirvonen, C.A., Pelletier, J.J., Paulus, H., Xu, M.Q. Single-column purification of free recombinant proteins using a self-cleavable affinity tag derived from a protein splicing element.

Gene. 1997, 192:271-81. 
Ciechanover, A., Elias, S., Heller, H., Ferber, S., Hershko. A,.

Characterization of the heat-stable polypeptide of the ATP-dependent proteolytic system from reticulocytes.

J Biol Chem. 1980,255:7525-8.

Cotton, G.J., Muir, T.W.

Peptide ligation and its application to protein engineering.

Chem Biol. 1999, 6:R247-5

Dasso, M.

Modification in reverse: the SUMO proteases.

Trends Biochem Sci. 2007, 32:286-95.

Dawlaty, M.M., Malureanu, L., Jeganathan, K.B., Kao, E., Sustmann, C., Tahk, S., Shuai, K., Grosschedl, R., van Deursen, J.M.

Resolution of sister centromeres requires RanBP2-mediated SUMOylation of topoisomerase Ilalpha.

Cell. 2008, 133:103-15

Desterro, J.M., Rodriguez, M.S., Hay, R.T.

SUMO-1 modification of IkappaBalpha inhibits NF-kappaB activation.

Mol Cell. 1998, 2:233-9.

Desterro, J.M., Rodriguez, M.S., Kemp, G.D., Hay, R.T.

Identification of the enzyme required for activation of the small ubiquitin-like protein SUMO-1.

J Biol Chem. 1999,274:10618-24.

Di Bacco, A., Gill, G.

SUMO-specific proteases and the cell cycle. An essential role for SENP5 in cell proliferation.

Cell Cycle. 2006, 5:2310-3.

Di Bacco, A., Ouyang, J., Lee, H.Y., Catic, A., Ploegh, H., Gill, G.

The SUMO-specific protease SENP5 is required for cell division.

Mol Cell Biol. 2006, 26:4489-98.

Deyrieux, A.F., Rosas-Acosta, G., Ozbun, M.A., Wilson V.G.

Sumoylation dynamics during keratinocyte differentiation.

J Cell Sci. 2007, 120:125-36. 
Fraser, A.G., Kamath, R.S., Zipperlen, P., Martinez-Campos, M., Sohrmann, M., Ahringer, J.

Functional genomic analysis of $\mathrm{C}$. elegans chromosome I by systematic RNA interference.

Nature. $2000,408: 325-30$.

Gan-Erdene, T., Nagamalleswari, K., Yin, L., Wu, K., Pan, Z.Q., Wilkinson, K.D. Identification and characterization of DEN1, a deneddylase of the ULP family.

J Biol Chem. 2003, 278:28892-900

Geiss-Friedlander, R., Melchior, F.

Concepts in sumoylation: a decade on.

Nat Rev Mol Cell Biol. 2007, 8:947-56.

Goldknopf, I.L and Busch, H. 1975

Remarkable similarities of peptide fingerprints of histone $2 \mathrm{~A}$ and nonhistone chromosomal protein A24.

Biochem Biophys Res Commun. 1975,65:951-60

Gong, L., Kamitani, T., Millas, S., Yeh, E.T.

Identification of a novel isopeptidase with dual specificity for ubiquitin- and

NEDD8-conjugated proteins.

J Biol Chem. 2000, 275:14212-6.

Gong, L., Yeh, E.T.

Characterization of a family of nucleolar SUMO-specific proteases with preference

for SUMO-2 or SUMO-3.

J Biol Chem. 2006, 281:15869-77

Graham, F.L., Smiley, J., Russell, W.C., Nairn, R.

Characteristics of a human cell line transformed by DNA from human adenovirus type 5.

J Gen Virol. 1977, 36:59-74.

Grelle, G., Kostka, S., Otto, A., Kersten, B., Genser, K.F., Müller, E.C., Wälter, S.,

Böddrich, A., Stelzl, U., Hänig, C., Volkmer-Engert, R., Landgraf, C., Alberti, S., Höhfeld,

J., Strödicke, M., Wanker, E.E.

Identification of VCP/p97, carboxyl terminus of Hsp70-interacting protein (CHIP), and amphiphysin II interaction partners using membrane-based human proteome arrays.

Mol Cell Proteomics. 2006, 5:234-44. 
Hemelaar, J., Borodovsky, A., Kessler, B.M., Reverter, D., Cook, J., Kolli, N., Gan-Erdene,

T., Wilkinson, K.D., Gill, G., Lima, C.D., Ploegh, H.L., Ovaa, H.

Specific and covalent targeting of conjugating and deconjugating enzymes of ubiquitin-like proteins.

Mol Cell Biol. 2004, 24:84-95.

Haindl, M., Harasim, T., Eick, D., Muller, S.

The nucleolar SUMO-specific protease SENP3 reverses SUMO modification of nucleophosmin and is required for rRNA processing

EMBO Rep. 2008, 9:273-9

Hanahan D.

Studies on transformation of Escherichia coli with plasmids.

J Mol Biol. 1983, 166:557-80.

Hang, J., Dasso, M.

Association of the human SUMO-1 protease SENP2 with the nuclear pore.

J Biol Chem. 2002, 277:19961-6.

Hardeland, U., Steinacher, R., Jiricny, J., Schär, P.

Modification of the human thymine-DNA glycosylase by ubiquitin-like proteins

facilitates enzymatic turnover.

EMBO J. 2002, 21:1456-64

Hay, R.T.

SUMO: a history of modification.

Mol Cell. 2005, 18:1-12

Hecker, C.M., Rabiller, M., Haglund, K., Bayer, P., Dikic, I.

Specification of SUMO1- and SUMO2-interacting motifs.

J Biol Chem. 2006, 281:16117-27

Hershko, A., Ciechanover, A., Heller, H., Haas, A.L., Rose, I.A.

Proposed role of ATP in protein breakdown: conjugation of protein with multiple chains of the polypeptide of ATP-dependent proteolysis.

Proc Natl Acad Sci 1980,77:1783-6.

Hershko, A., Ciechanover, A.

The ubiquitin system.

Annu Rev Biochem. 1998, 67:425-79

Hicke, L., Schubert, H.L., Hill, C.P.

Ubiquitin-binding domains.

Nat Rev Mol Cell Biol. 2005, 6:610-21 
Hochstrasser, M.

Protein degradation or regulation: Ub the judge.

Cell. 1996, 84(6):813-5.

Hochstrasser, M.

SP-RING for SUMO: new functions bloom for a ubiquitin-like protein.

Cell. 2001, 107:5-8.

Hu, M., Li, P., Li, M., Li, W., Yao, T., Wu, J.W., Gu, W., Cohen, R.E., Shi, Y.

Crystal structure of a UBP-family deubiquitinating enzyme in isolation and in complex with ubiquitin aldehyde.

Cell. 2002, 111:1041-54

Itami, M., Matsuo, T., Ohtsuki, H.

A novel gene (retinovin) expressed selectively in the early stage of chick

retinal development.

Biochem Biophys Res Commun. 2000, 276:12-5.

Johnson, E.S., Schwienhorst, I., Dohmen, R.J., Blobel, G.

The ubiquitin-like protein Smt3p is activated for conjugation to other proteins by an Aos1p/Uba2p heterodimer.

EMBO J. 1997, 16:5509-19.

Johnson, E.S., Blobel, G.

Ubc9p is the conjugating enzyme for the ubiquitin-like protein Smt3p.

J Biol Chem. 1997, 272:26799-802.

Johnson, E.S., Gupta, A.A.

An E3-like factor that promotes SUMO conjugation to the yeast septins.

Cell. 2001, 106:735-44.

Johnson, E.S.

Protein modification by SUMO.

Annu Rev Biochem. 2004, 73:355-82.

Kagey, M.H., Melhuish, T.A., Wotton, D.

The polycomb protein Pc2 is a SUMO E3.

Cell. 2003,113:127-37.

Kamitani, T., Kito, K., Nguyen, H.P., Fukuda-Kamitani T., Yeh, E.T.

Characterization of a second member of the sentrin family of ubiquitin-like proteins.

J Biol Chem. 1998, 273:11349-53. 
Kang, J.S., Saunier, E.F., Akhurst, R.J., Derynck, R.

The type I TGF-beta receptor is covalently modified and regulated by sumoylation.

Nat Cell Biol. 2008, 10:654-64

Kerscher, O., Felberbaum, R., Hochstrasser, M.

Modification of proteins by ubiquitin and ubiquitin-like proteins.

Annu Rev Cell Dev Biol. 2006,22:159-80

Klein, U.R., Haindl, M., Nigg, E.A., Muller, S.

RanBP2 and SENP3 function in a mitotic SUMO2/3 conjugation-deconjugation cycle on

Borealin.

Mol Biol Cell. 2009, 20:410-8.

Kleppe, K., Ohtsuka, E., Kleppe, R., Molineux, I., Khorana, H.G.

Studies on polynucleotides. XCVI. Repair replications of short synthetic DNA's as catalyzed by DNA polymerases.

J Mol Biol. 1971, 56:341-61.

Knipscheer, P., van Dijk, W.J., Olsen, J.V., Mann, M., Sixma, T.K.

Noncovalent interaction between Ubc9 and SUMO promotes SUMO chain formation.

EMBO J. 2007, 26:2797-807.

Kuo, M.L., den Besten, W., Thomas, M.C., Sherr, C.J.

Arf-induced turnover of the nucleolar nucleophosmin-associated SUMO-2/3 protease

Senp3.

Cell Cycle. 2008, 7:3378-87

Laemmli, U.K.

Cleavage of structural proteins during the assembly of the head of bacteriophage T4.

Nature. 1970, 227:680-5.

Lallemand-Breitenbach, V., Jeanne, M., Benhenda, S., Nasr, R., Lei, M., Peres, L., Zhou, J, Zhu, J., Raught, B., de Thé, H.

Arsenic degrades PML or PML-RARalpha through a SUMO-triggered

RNF4/ubiquitin-mediated pathway.

Nat Cell Biol. 2008, 10:547-55. 
Lapenta, V., Chiurazzi, P., van der Spek, P., Pizzuti, A., Hanaoka, F., Brahe, C. SMT3A, a human homologue of the $\mathrm{S}$. cerevisiae SMT3 gene, maps to chromosome

21 qter and defines a novel gene family.

Genomics. 1997, 40:362-6.

Lebkowski, J.S., Clancy, S., Calos, M.P.

Simian virus 40 replication in adenovirus-transformed human cells antagonizes gene expression.

Nature. 1985, 317:169-71.

Li, S.J., Hochstrasser, M.

A new protease required for cell-cycle progression in yeast.

Nature. 1999, 398:246-51.

Li, S.J., Hochstrasser, M.

The yeast ULP2 (SMT4) gene encodes a novel protease specific for the ubiquitin-like Smt3 protein.

Mol Cell Biol. 2000, 20:2367-77

Li, S.J., Hochstrasser, M.

The UIp1 SUMO isopeptidase: distinct domains required for viability, nuclear envelope localization, and substrate specificity.

J Cell Biol. 2003, 160:1069-81

Lima, C.D., Reverter, D.

Structure of the human SENP7 catalytic domain and poly-SUMO deconjugation activities for SENP6 and SENP7.

J Biol Chem. 2008, 283:32045-55

Love, K.R., Catic, A., Schlieker, C., Ploegh, H.L.

Mechanisms, biology and inhibitors of deubiquitinating enzymes.

Nat Chem Biol. 2007, 3:697-705

López-Otín, C., Simón-Mateo, C., Martínez, L., Viñuela E,.

Gly-Gly-X, a novel consensus sequence for the proteolytic processing of viral and

cellular proteins.

J Biol Chem. 1989, 264:9107-10.

Mahajan, R., Delphin, C., Guan, T., Gerace, L., Melchior, F.

A small ubiquitin-related polypeptide involved in targeting RanGAP1 to nuclear pore complex protein RanBP2.

Cell. 1997, 88:97-107. 
Mahajan, R., Gerace, L., Melchior, F.

Molecular characterization of the SUMO-1 modification of RanGAP1 and its role in

nuclear envelope association.

J Cell Biol. 1998, 140:259-70.

Mangel WF, McGrath WJ, Toledo DL, Anderson CW.

Viral DNA and a viral peptide can act as cofactors of adenovirus virion

proteinase activity.

Nature. 1993,361

Matunis, MJ., Coutavas, E., Blobel, G.

A novel ubiquitin-like modification modulates the partitioning of the

Ran-GTPase-activating protein RanGAP1 between the cytosol and the nuclear pore

complex.

J Cell Biol. 1996, 135:1457-70.

Matunis, M.J., Wu, J., Blobel, G.

SUMO-1 modification and its role in targeting the Ran GTPase-activating protein, RanGAP1, to the nuclear pore complex.

J Cell Biol. 1998, 140:499-509.

Melchior, $\mathrm{F}$.

SUMO--nonclassical ubiquitin.

Annu Rev Cell Dev Biol. 2000, 16:591-626

Melchior, F., Schergaut, M., Pichler, A.

SUMO: ligases, isopeptidases and nuclear pores.

Trends Biochem Sci. 2003, 28:612-8

Mendoza, H.M., Shen, L.N., Botting, C., Lewis, A., Chen, J., Ink, B., Hay, R.T. NEDP1, a highly conserved cysteine protease that deNEDDylates Cullins.

J Biol Chem. 2003, 278:25637-43.

Meulmeester, E., Kunze, M., Hsiao, H.H., Urlaub, H., Melchior, F.

Mechanism and consequences for paralog-specific sumoylation of ubiquitinspecific

protease 25 .

Mol Cell. 2008, 30:610-9.

Mukhopadhyay, D., Ayaydin, F., Kolli, N., Tan, S.H., Anan, T., Kametaka, A., Azuma, Y., Wilkinson, K.D., Dasso, M.

SUSP1 antagonizes formation of highly SUMO2/3-conjugated species.

J Cell Biol. 2006, 174:939-49 
Mullis, K., Faloona, F., Scharf, S., Saiki, R., Horn, G., Erlich, H.

Specific enzymatic amplification of DNA in vitro: the polymerase chain reaction.

Cold Spring Harb Symp Quant Biol. 1986;51 Pt 1:263-73.

Nijman, S.M., Luna-Vargas, M.P., Velds, A., Brummelkamp, T.R., Dirac, A.M., Sixma, T.K.,

Bernards, $R$.

A genomic and functional inventory of deubiquitinating enzymes.

Cell. 2005, 123:773-86

Owerbach, D., McKay, E.M., Yeh, E.T., Gabbay, K.H., Bohren, K.M.

A proline-90 residue unique to SUMO-4 prevents maturation and sumoylation.

Biochem Biophys Res Commun. 2005, 337:517-20.

Palvimo, J.J.

PIAS proteins as regulators of small ubiquitin-related modifier (SUMO)

modifications and transcription.

Biochem Soc Trans. 2007, 35:1405-8.

Panse, V.G., Küster, B., Gerstberger, T., Hurt, E.

Unconventional tethering of Ulp1 to the transport channel of the nuclear pore complex by karyopherins.

Nat Cell Biol. 2003, 5:21-7

Petroski, M.D., Deshaies, R.J.

Function and regulation of cullin-RING ubiquitin ligases.

Nat Rev Mol Cell Biol. 2005, 6:9-20

Pfander, B., Moldovan, G.L., Sacher, M., Hoege, C., Jentsch, S.

SUMO-modified PCNA recruits Srs2 to prevent recombination during $S$ phase.

Nature. 2005, 436:428-33

Pichler, A., Gast, A., Seeler, J.S, Dejean, A., Melchior, F.

The nucleoporin RanBP2 has SUMO1 E3 ligase activity.

Cell. 2002, 108:109-20.

Pichler, A., Knipscheer, P., Saitoh, H., Sixma, T.K, Melchior, F.

The RanBP2 SUMO E3 ligase is neither HECT- nor RING-type.

Nat Struct Mol Biol. 2004, 11:984-91.

Prudden, J., Pebernard, S., Raffa, G., Slavin, D.A., Perry, J.J., Tainer, J.A., McGowan, C.H.,

Boddy, M.N.

SUMO-targeted ubiquitin ligases in genome stability.

EMBO J. 2007, 26:4089-101. 
Quesada, V., Díaz-Perales, A., Gutiérrez-Fernández, A., Garabaya, C., Cal, S., López-Otín, C.

Cloning and enzymatic analysis of 22 novel human ubiquitin-specific proteases.

Biochem Biophys Res Commun. 2004, 314:54-62

Renatus, M., Parrado, S.G., D'Arcy, A., Eidhoff, U., Gerhartz, B., Hassiepen, U., Pierrat, B.,

Riedl, R., Vinzenz, D., Worpenberg, S., Kroemer, M.

Structural basis of ubiquitin recognition by the deubiquitinating protease USP2.

Structure. 2006, 14:1293-302.

Reverter, D., Lima, C.D.

A basis for SUMO protease specificity provided by analysis of human Senp2 and a

Senp2-SUMO complex.

Structure. 2004, 12:1519-31

Reverter, D., Wu, K., Erdene, T.G., Pan, Z.Q., Wilkinson, K.D., Lima, C.D.

Structure of a complex between Nedd8 and the Ulp/Senp protease family member

Den1.

J Mol Biol. 2005, 345:141-51.

Reverter, D., Lima, C.D.

Insights into E3 ligase activity revealed by a SUMO-RanGAP1-Ubc9-Nup358 complex.

Nature. 2005,435:687-92.

Reverter, D., Lima, C.D.

Structural basis for SENP2 protease interactions with SUMO precursors and conjugated substrates.

Nat Struct Mol Biol. 2006, 13:1060-8.

Rubinsztein, D.C.

The roles of intracellular protein-degradation pathways in neurodegeneration.

Nature. 2006, 443:780-6.

Saitoh, H., Hinchey, J.

Functional heterogeneity of small ubiquitin-related protein modifiers SUMO-1 versus SUMO-2/3.

J Biol Chem. 2000, 275:6252-8. 
Saracco, S.A., Miller, M.J., Kurepa, J., Vierstra, R.D.

Genetic analysis of SUMOylation in Arabidopsis: conjugation of SUMO1 and SUMO2 to

nuclear proteins is essential.

Plant Physiol. 2007, 145:119-34.

Schimmel, J., Larsen, K.M., Matic, I., van Hagen, M., Cox, J., Mann, M., Andersen, J.S., Vertegaal, A.C.

The ubiquitin-proteasome system is a key component of the SUMO-2/3 cycle.

Mol Cell Proteomics. 2008, 7:2107-22

Shen, L., Tatham, M.H., Dong, C., Zagórska, A., Naismith, J.H., Hay, R.T.

SUMO protease SENP1 induces isomerization of the scissile peptide bond.

Nat Struct Mol Biol. 2006, 13:1069-77

Shen, T.H., Lin, H.K., Scaglioni, P.P, Yung, T.M., Pandolfi, P.P.

The mechanisms of PML-nuclear body formation.

Mol Cell. 2006, 24:331-9

Song, J., Durrin, L.K., Wilkinson, T.A., Krontiris, T.G., Chen, Y. Identification of a SUMO-binding motif that recognizes SUMO-modified proteins. Proc Natl Acad Sci U S A. 2004,101:14373-8.

Song, J., Zhang, Z., Hu, W., Chen, Y.

Small ubiquitin-like modifier (SUMO) recognition of a SUMO binding motif: a reversal of the bound orientation.

J Biol Chem. 2005,280:40122-9.

Stankovic-Valentin, N., Kozaczkiewicz, L., Curth, K., Melchior, F. An in vitro FRET-based assay for the analysis of SUMO conjugation and isopeptidase cleavage.

Methods Mol Biol. 2009, 497:241-51.

Stielow, B., Sapetschnig, A., Krüger, I., Kunert, N., Brehm, A., Boutros, M., Suske, G.

Identification of SUMO-dependent chromatin-associated transcriptional repression components by a genome-wide RNAi screen.

Mol Cell. 2008, 29:742-54.

Sun, H., Leverson, J.D., Hunter, T.

Conserved function of RNF4 family proteins in eukaryotes: targeting a ubiquitin ligase to SUMOylated proteins.

EMBO J. 2007, 26(18):4102-12. 
Suzuki, T., Ichiyama, A., Saitoh, H., Kawakami, T., Omata, M., Chung, C.H., Kimura, M., Shimbara, N., Tanaka, K.

A new 30-kDa ubiquitin-related SUMO-1 hydrolase from bovine brain. J Biol Chem. 1999, 274:31131-4.

Tatham, M.H., Jaffray, E., Vaughan, O.A., Desterro, J.M., Botting, C.H., Naismith, J.H., Hay, R.T.

Polymeric chains of SUMO-2 and SUMO-3 are conjugated to protein substrates by

SAE1/SAE2 and Ubc9.

J Biol Chem. 2001, 276:35368-74.

Tatham, M.H., Geoffroy, M.C., Shen, L., Plechanovova, A., Hattersley, N., Jaffray, E.G., Palvimo,

J.J, Hay, R.T.

RNF4 is a poly-SUMO-specific E3 ubiquitin ligase required for arsenic-induced

PML

degradation.

Nat Cell Biol. 2008, 10:538-46.

Tyagi, S., Chabes, A.L., Wysocka, J., Herr, W.

E2F activation of $S$ phase promoters via association with HCF-1 and the MLL family of histone H3K4 methyltransferases.

Mol Cell. 2007, 27:107-19.

Uzunova, K., Göttsche, K., Miteva, M., Weisshaar, S.R., Glanemann, C., Schnellhardt, M.,

Niessen, M., Scheel, H., Hofmann, K., Johnson, E.S., Praefcke, G.J., Dohmen, R.J.

Ubiquitin-dependent proteolytic control of SUMO conjugates.

J Biol Chem. 2007, 282:34167-75

Vogel, J.L., Kristie, T.M.

The novel coactivator $\mathrm{C} 1$ (HCF) coordinates multiprotein enhancer formation and mediates transcription activation by GABP.

EMBO J. 2000, 19:683-90

Wada, H., Kito, K., Caskey, L.S., Yeh, E.T., Kamitani, T.

Cleavage of the C-terminus of NEDD8 by UCH-L3.

Biochem Biophys Res Commun. 1998, 251:688-92.

Weger, S., Hammer, E., Heilbronn, R.

Topors acts as a SUMO-1 E3 ligase for p53 in vitro and in vivo.

FEBS Lett. 2005, 579:5007-12. 
Weiss, B., Jacquemin-Sablon, A., Live, T.R., Fareed, G.C., Richardson, C.C. Enzymatic breakage and joining of deoxyribonucleic acid. VI. Further purification and properties of polynucleotide ligase from Escherichia coli infected with bacteriophage $\mathrm{T} 4$.

J Biol Chem. 1968, 243:4543-55.

Welchman, R.L., Gordon, C., Mayer, R.J.

Ubiquitin and ubiquitin-like proteins as multifunctional signals.

Nat Rev Mol Cell Biol. 2005, 6:599-609.

Werner, A., Moutty, M.C., Möller, U., Melchior, F.

Performing in vitro sumoylation reactions using recombinant enzymes.

Methods Mol Biol. 2009, 497:187-99

Wilkinson, K.D., Urban, M.K., Haas, A.L.

Ubiquitin is the ATP-dependent proteolysis factor I of rabbit reticulocytes.

J Biol Chem. 1980, 255:7529-32.

Wilson, A.C., LaMarco, K., Peterson, M.G., Herr, W.

The VP16 accessory protein HCF is a family of polypeptides processed from a large

precursor protein.

Cell. 1993, 74:115-25

Wilson, A.C., Peterson, M.G., Herr, W.

The HCF repeat is an unusual proteolytic cleavage signal.

Genes Dev. 1995, 9:2445-58.

Wu K, Yamoah K, Dolios G, Gan-Erdene T, Tan P, Chen A, Lee CG, Wei N, Wilkinson KD, Wang R, Pan ZQ.

DEN1 is a dual function protease capable of processing the $C$ terminus of Nedd8 and deconjugating hyper-neddylated CUL1.

J Biol Chem. 2003, 278:28882-91.

Wysocka, J., Reilly, P.T., Herr, W.

Loss of HCF-1-chromatin association precedes temperature-induced growth arrest of

tsBN67 cells.

Mol Cell Biol. 2001, 21:3820-9.

Wysocka, J., Myers, M.P., Laherty, C.D., Eisenman, R.N., Herr, W.

Human Sin3 deacetylase and trithorax-related Set1/Ash2 histone H3-K4

methyltransferase are tethered together selectively by the cell-proliferation factor HCF-1.

Genes Dev. 2003, 17:896-911. 
Wysocka, J., Herr, W.

The herpes simplex virus VP16-induced complex: the makings of a regulatory switch.

Trends Biochem Sci. 2003, 28:294-304.

Xie, Y., Kerscher, O., Kroetz, M.B., McConchie, H.F., Sung, P., Hochstrasser, M. The yeast Hex3.SIx8 heterodimer is a ubiquitin ligase stimulated by substrate sumoylation.

J Biol Chem. 2007, 282:34176-84.

Yeh, E.T, Gong, L., Kamitani, T. Ubiquitin-like proteins: new wines in new bottles.

Gene. 2000, 248:1-14

Yeh, ET.

SUMOylation and de-SUMOylation: Wrestling with life's processes.

J Biol Chem. 2008 Nov 13. [Epub ahead of print]

Zhu, J., Zhu, S., Guzzo, C.M., Ellis, N.A., Sung, K.S., Choi, C.Y., Matunis, M.J. Small ubiquitin-related modifier (SUMO) binding determines substrate recognition and paralog-selective SUMO modification.

J Biol Chem. 2008, 283:29405-15.

Zunino, R., Schauss, A., Rippstein, P., Andrade-Navarro, M. McBride, H.M. The SUMO protease SENP5 is required to maintain mitochondrial morphology and function.

J Cell Sci. 2007, 120:1178-88. 


\section{Curriculum Vitae}

Lukasz Czeslaw Kozaczkiewicz

Personal data

Date of birth

Gender

Nationality

Address

E-mail

\section{Education}

December 2005-

July 2005

November 2004 - April 2005

September 2003 - July 2005

October 2000 - June 2003

September 1996 - June 2000

Known languages

Laboratory experience
20 August 1981

Male

Polish

Goethealle 7B, 37073 Göttingen, Germany

lkozacz@gwdg.de

International Max-Planck Research School

Georg-August Universität Göttingen, Göttingen, Germany

PhD program - molecular biology

PhD project - "Characterization of SUMO-specific isopeptidases" Supervision Prof. Frauke Melchior

December 2005-November 2008 Georg-Christoph Lichtenberg

scholarship

Master of Science degree total grade C

Master's project: Identification of cellular targets of

HIV-1 Vpr and SIV Vpr and Vpx Proteins

Supervision Prof Jacek Skowronski

International Max-Planck Research School

Georg-August Universität Göttingen, Göttingen, Germany

Msc/PhD program - molecular biology

Master's exam 08.2004 total grade A (1.35)

2003-2004 Max-Planck International Research School

scholarship

Jagiellonian University, Cracow, Poland

biotechnology

equivalence of bachelor degree

2002-2003 scholarship of Jagiellonian University

Liceum ogolnoksztalcace im. Eugeniusza Romera

General High school

1998-2000 schoolarship of polish prime minister

Polish (mother tounge)

English (fluent)

German (good)

French (basic)

doctoral project

December 2005-November 2008

Characterization of SUMO specific isopeptidases

Supervision Prof Frauke Melchior

Department of Biochemistry, University of Göttingen

Göttingen, Germany

May 2005-October 2005

Characterization of Vpr/VprBP/DDB1 complex

Supervision Prof Jacek Skowronski

Cold Spring Harbor Laboratory, Cold Spring Harbor, USA

Master`s project November 2004-Aprli 2005

Identification of cellular targets of

HIV-1 Vpr and SIV Vpr and Vpx Proteins,

Supervision Prof Jacek Skowronski

Cold Spring Harbor Laboratory, Cold Spring Harbor, USA 
Laboratory experience - cont.

Rotations May 2004 - June 2004 - Cloning and expression of genes representing the flagellar apparatus of Chlamydia pneumoniae. Supervision Dr Raimond Lugert

Department of Bacteriology, University of

Göttingen

Göttingen, Germany

March 2004 - April 2004 - Cloning of

TAPn:csn 4 construct and its introduction

into csn 4-deleted A.nidulans strain.

Supervision Dr Silke Busch

Department of Molecular Microbiology and Genetics

University of Göttingen

Göttingen, Germany

January 2004 - February 2004

Characterization of structure and dynamics of the C2A domain of synaptotagmin I and its interfacial interactions with membranes.

Supervision Dr Markus Zweckstetter

Department of NMR- Based Structural Biology. Max

Planck Institute for Biophysical Chemistry,

Göttingen, Germany

2003 - Determination of intracellular

localization of TACE (TNF- alpha Converting

Enzyme) and its maturation.

Supervision Dr Joanna Bereta.

Department of cellular biochemistry, Jagiellonian

University,

Cracow Poland 